\title{
Etablierung und Anwendung der \\ Chromatin-Immunopräzipitation für in vivo-Bindungsstudien der bZIP-Transkriptionsfaktoren TGA2.1 und TGA2.2 an Promotoren der Pathogenabwehr in Tabak
}

\author{
Dissertation \\ zur Erlangung des Doktorgrades \\ der Mathematisch-Naturwissenschaftlichen Fakultäten \\ der Georg-August-Universität zu Göttingen
}

vorgelegt von

Thomas Butterbrodt

aus Itzehoe / Kreis Steinburg

Göttingen 2005 
D7

Referent: Prof. Dr. C. Gatz

Korreferent: PD Dr. G. Lohaus

Tag der mündlichen Prüfung: 3. November 2005 
„Wir liebten die Weisheit wie eine Braut, wir haben in all und jedem erschaut -

Sein großes und hehres Angesicht.

Und lösten den letzten Schleier doch nicht."

König Kaspar aus „Das Kronsberger Krippenspiel“ 


\section{Inhaltsverzeichnis}

1 Zusammenfassung 1

2 Einleitung 2

2.1 Abwehr von Pathogenen . . . . . . . . . . . . . . . . . . 2

2.2 Salizylsäure-das zentrale Molekül der pflanzlichen Pathogenabwehr . . . . 3

2.3 Das as-1-Element als salizylsäureinduzierbares cis-Element in Promotoren pflanzlicher Abwehrgene . . . . . . . . . . . . . . . . . . . . 4

2.4 Die TGA-Faktoren als as-1-Element bindende Proteine . . . . . . . . . . 6

2.4.1 Der ASF-1 und SARP-Komplex . . . . . . . . . . . . . 8

2.4.2 Beteiligung der TGA-Faktoren an der Regulation der Genexpression 8

2.5 NPR1 als zentrales Regulatorprotein der PR-Genexpression . . . . . . . . . 10

2.6 Fragestellung und Zielsetzung der Arbeit . . . . . . . . . . . . . . . . . . . 12

3 Material $\quad 13$

3.1 Geräte . . . . . . . . . . . . . . . . . . . 13

3.2 Verbrauchsmaterialien . . . . . . . . . . . . . . . 14

3.3 Chemikalien . . . . . . . . . . . . . . . . . . . . . . 15

3.4 Proteine . . . . . . . . . . . . . . . . . . . 16

3.4 .1 Verwendete Enzyme . . . . . . . . . . . . . . 16

3.4 .2 Proteinstandard . . . . . . . . . . . . . . . . . 16

3.4.3 Antikörper . . . . . . . . . . . . . . . . 16

3.5 Nukleinsäuren . . . . . . . . . . . . . . . . . . . . . . . . . . . . 17

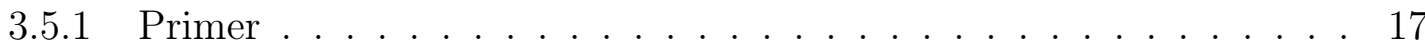

3.6 Organismen . . . . . . . . . . . . . . . . 17

3.6.1 Pflanzen . . . . . . . . . . . . . . . . . 17

3.7 Nährmedien und Zusätze . . . . . . . . . . . . . . . . . . . . 17

3.7 .1 Nährmedien für Bakterien . . . . . . . . . . . . . . . . . . 17

3.7.2 Nährmedien für Pflanzen . . . . . . . . . . . . . . . . . . 18

3.8 Puffer und Lösungen . . . . . . . . . . . . . . . . . . . . . . . . . 18

4 Methoden $\quad 18$

4.1 Anzucht von Organismen . . . . . . . . . . . . . . . . . . . 18

4.1.1 Tabakpflanzen . . . . . . . . . . . . . . . . . . 18 
4.1.2 Anzucht von E.coli . . . . . . . . . . . . . . . . . . . . . 19

4.2 Salizylsäure Behandlung von Tabakpflanzen . . . . . . . . . . . . . . . . 19

4.3 Formaldehyd-vermittelte Quervernetzung von Proteinen und DNA . . . . . 19

4.4 Isolierung von Zellkernen aus Tabak-Blattmaterial . . . . . . . . . . . . . . 20

4.5 Äquilibrierung von Phenol . . . . . . . . . . . . . . . . . . . . 21

4.6 Moleklulargenetische Standardmethoden - Nukleinsäuren . . . . . . . . . . 21

4.6.1 Ethanolfällung von DNA . . . . . . . . . . . . . . 21

4.6.2 Konzentrationsbestimmung von Nukleinsäuren . . . . . . . . . . . . 21

4.6.3 Auftrennung von DNA in Agarosegelen . . . . . . . . . . . . . . 22

4.6.4 Auftrennung von DNA in Polyacrylamidgelen . . . . . . . . . . . . 22

4.6.5 Extraktion genomischer DNA aus Tabak . . . . . . . . . . . 23

4.7 Chromatin-Immunopräzipitation . . . . . . . . . . . . . . . 23

4.7.1 Isolierung des Chromatins . . . . . . . . . . . . . . . . 23

4.7.2 Bestimmung des DNA-Gehalts der Chromatin-Proben . . . . . . . . 24

4.7.3 Protein A-Sepharose . . . . . . . . . . . . . . . . . . . . 24

4.7.4 Chromatin-Imunopräzipitation . . . . . . . . . . . 25

4.7.5 Elution der Antikörper-Protein-DNA-Komplexe (Immunokomplexe) 26

4.7.6 Aufreinigung und Fällung der präzipitierten ChIP-DNA . . . . . . . 26

4.8 Polymerasekettenreaktion PCR . . . . . . . . . . . . . . 27

4.9 Molekulargenetische Standardmethoden - Proteine . . . . . . . . . . . . . 27

4.9.1 Aufreinigung von rekombinanten Proteinen aus E.coli . . . . . . . . 27

4.9.2 Herstellung von spezifischen Antiseren aus Kaninchen . . . . . . . . 28

4.9.3 Aufreinigung von Antikörpern aus Antiserum . . . . . . . . . . . . 28

4.10 Proteinextraktionsmethoden . . . . . . . . . . . . . . . . . . . . . . 29

4.10 .1 Kernproteinextrakte, denaturierend . . . . . . . . . . . . . . . . 29

4.10 .2 Kernproteinextrakte, nativ . . . . . . . . . . . . . . . . . . 29

4.10.3 Denaturierende Gesamtzellextrakte aus Tabakblättern . . . . . . . 30

4.10 .4 Proteinextrakte für MUG-Assay . . . . . . . . . . . . . . . . . . . . 30

4.10.5 Konzentrationsbestimmung von Proteinextrakten . . . . . . . . . . 30

4.10.6 Diskontinuierliche SDS-Polyacrylamid-Gelelektrophorese . . . . . . 31

4.10.7 Kolloidal-Coomassie-Färbung von Proteinen . . . . . . . . . . . . . 31

4.10.8 Silberfärbung von Proteinen im SDS-Gel . . . . . . . . . . . . . . . 31

4.11 Western-Blot-Analyse . . . . . . . . . . . . . . . . . . . . 32

4.11.1 Semi-Dry Blotting von Proteinen . . . . . . . . . . . . . 32 
4.11.2 Antikörper-Detektion von geblotteten Proteinen . . . . . . . . . . . 32

4.12 Messung der \&s-Glucuronidase (GUS)-Aktivität . . . . . . . . . . . . 33

4.13 2D-Gelelektrophorese $(2 \mathrm{D}-\mathrm{GE}) \ldots \ldots \ldots \ldots$

4.13 .1 Probenaufbereitung . . . . . . . . . . . . . . . 34

4.13.2 Isoelektrische Fokussierung (1. Dimension) . . . . . . . . . . . 34

4.13.3 Auftrennung nach Molekulargewicht (2. Dimension) . . . . . . . . 35

4.13.4 Detektionsmöglichkeiten von Proteinen in 2D-Gelen . . . . . . . . . 35

5 Ergebnisse $\quad 36$

5.1 Herstellung eines Antiserums gegen die C-termini von TGA2.1 und TGA2.2 36

5.2 Herstellung eines Antiserums gegen die Aktivierungsdomäne VP16 aus Herpes simplex . . . . . . . . . . . . . . . . . . . . . 38

5.3 Die Chromatin-Immunopräzipitation . . . . . . . . . . . . . . 41

5.3 .1 Grundlagen . . . . . . . . . . . . . . . . . . . 41

5.3.2 Formaldehyd-Quervernetzung . . . . . . . . . . . . . . . 43

5.4 Etablierung der ChIP . . . . . . . . . . . . . . . 45

5.4.1 Anwendung der ChIP am Tetrazyklin-induzierbaren Expressionssystem . . . . . . . . . . . . . . . . . . . . . 45

5.4 .2 Unterschiede der verwendeten Protokolle . . . . . . . . . . . . . 49

5.4.3 Anwendung der ChIP am Tetrazyklin-reprimierbaren Expressionssystem $\mathrm{pTAX} \ldots \ldots \ldots$. . . . . . . . . . . . . . . 49

5.5 Anwendung der ChIP zum Bindungsverhalten der TGA-Faktoren . . . . . 55

5.5.1 ChIP mit affinitätsaufgereinigten $\alpha$ TGA2.2C . . . . . . . . . . 55

5.6 ChIP mit Antiserum TGA2-C . . . . . . . . . . . . . . . 58

5.6.1 Das Bindeverhalten der TGA-K2 am isolierten as-1-Element . . . . 58

5.6.2 Das Bindeverhalten des TGA-K2 am as-1-ähnlichen Element $\operatorname{im}$ parA-Promotor . . . . . . . . . . . . . . 63

5.6.3 Das Bindeverhalten der TGA-K2 am as-1-ähnlichen Element im PR-1a-Promotor . . . . . . . . . . . . . . . . . 64

5.6.4 Die Besetzung des as-1-Elements sowie as-1-ähnlicher Promotoren in TGA2.2RNAi-Linien . . . . . . . . . . . . . . . . 66

5.6.5 Funktionsanalyse des VP16-TGA2.2 . . . . . . . . . . . 67

5.7 Histon-Acetylierungen an Promotoren der frühen und späten Genantwort . 70 
5.8 Anwendung der 2D-Gelelektrophorese zur Identifizierung möglicher Proteinmodifikation nach Induktion mit Salizylsäure . . . . . . . . . . . . . 74

6 Diskussion

6.1 Die Chromatin-Immunopräzipitation als Technik zur Detektion von DNAProtein-Interaktionen ． . . . . . . . . . . . . . . . . . . . . 77

6.2 TGA-Faktoren der Klasse 2 binden konstitutiv und SA-unabhängig am as-1-Element sowie am as-1-ähnlichen Element des frühen Gens parA . . . 79

6.3 Die Besetzung des as-1-ähnlichen Element im PR-1a-Promotor durch TGAFaktoren der Klasse 2 ist durch Salizylsäure induzierbar . . . . . . . . . . . 84

6.4 Einfluß von Strukturveränderungen des Chromatins . . . . . . . . . . . . 85

6.5 Anwendung proteinbiochmischer Methoden zur Analyse des TGA2.2 . . . . 89

6.6 Ausblick . . . . . . . . . . . . . . . . . . . . . . 91

$\begin{array}{lll}7 & \text { Literaturverzeichnis } & 92\end{array}$

8 Anhang 107

8.1 Abkürzungen . . . . . . . . . . . . . . . . . . . . 107 


\section{Zusammenfassung}

Bei Pflanzen kommt es im Rahmen der Pathogenantwort zu einem Anstieg von Salizylsäure (SA). Die Transkription einer Reihe von Abwehrgenen erfolgt als Antwort auf dieses Signal über eine weitgehend unbekannte Signaltransduktionskette. Dabei kann zwischen „frühen“ und „,späten“ Abwehrgenen unterschieden werden. Die „frühen“ Gene werden bereits ein bis zwei Stunden nach dem Salizylsäuresignal aktiviert, die „späten“ erst nach sieben bis 24 Stunden. Eine gemeinsame Charakteristik der Promotoren einiger „früher" und „später" Abwehrgene ist ein konserviertes cis-Element, das as-1-Element. Ein künstlich hergestellter Promotor mit einer oder mehreren Kopien des as-1-Elements, weist dieselbe Expressionskinetik wie die ,frühen“" Abwehrgene auf.

Im Rahmen der Arbeit wurde mithilfe der Chromatin-Immunopräzipitation (ChIP) das Bindeverhalten der bZIP-Transkriptionsfaktoren TGA2.1 und TGA2.2 aus Nicotiana tabacum an Promotoren der ,frühen“ und ,späten“ Genantwort sowie am as-1-Element nach Induktion mit SA untersucht. Dazu wurde zunächst die Methode für Nicotiana tabacum etabliert. Die Bindung am isolierten as-1-Element wurde mittels transgener Pflanzen untersucht, die ein as-1-Element im Reportergenkonstrukt tragen. Als „frühes“ Abwehrgen wurde parA untersucht, $P R-1 a$ als ,spätes“ Gen. Für $P R-1 a$ wurde eine induzierbare, salizylsäure-abhängige Besetzung festgestellt, was bereits veröffentlichter Daten aus Arabidopsis thaliana entspricht.

Die Daten für parA und dem as1-Element sprechen für eine konstitutive, SA-unabhängige Bindung der TGA-Faktoren am Promotor der „frühen“ Gene. Pflanzen, die ein Fusionprotein aus TGA2.2 und der Aktivierungsdomäne VP16 exprimieren, zeigen dieselbe Besetzung. Northern-Blot-Analysen der Pflanzen zeigen, dass das Fusionsprotein nicht in der Lage ist, eine konstitutive Expression des nachgeschalteten Reportergens zu vermitteln. Die Ergebnisse deuten auf einen Transkriptionsrepressors hin, der im uninduzierten Zustand mit einem Komplex aus TGA2.2 und TGA2.1 und weiteren unbekannten Komponenten verbunden an as-1-Elemente bindet. Nach Behandlung mit SA könnte die Dissoziation des Repressors erfolgen, verbunden mit der Aktvierung der Expression. Weitere Experimente beschäftigten sich mit Veränderungen der Chromatin-Struktur. Hierbei spielt die Acetylierung von Histonen, dem zentralen Baustein des Chromatins, eine wichtige Rolle. Durch gezielte Acetylierung von Histonen kann die Struktur des Chromatins aufgelöst, und Promotoren für Transkriptionsfaktoren zugänglich gemacht werden. Es zeigte sich, dass Promotoren der „frühen“ Abwehrgene eine offene Chromatinstruktur besitzen. Im Gegensatz dazu wird der Promotor von PR1a erst nach SA-Behandlung über Acetylierungen der Histone für TGA-Faktoren zugänglich gemacht. 


\section{Einleitung}

\subsection{Abwehr von Pathogenen}

Pflanzen sind in ihrer Umwelt einer Vielzahl von pathogenen Organismen ausgesetzt, die ernsthafte Schäden verursachen oder sogar zum Tod führen können. Neben Fraßfeinden zählen vor allem Viren, Bakterien und Pilze dazu. Um einem solchen Angriff Widerstand zu leisten, haben Pflanzen im Laufe der Evolution eine Vielzahl physikalischer und chemischer Barrieren sowie induzierbare Abwehrstrategien entwickelt.

Man unterscheidet zwischen virulenten und avirulenten Pathogenen. Virulente Pathogene werden von der Pflanze nur sehr ineffizient erkannt. Da die pflanzliche Abwehr in diesem Fall sehr schwach ausgeprägt ist, breitet sich das Pathogen weiter aus. Pflanze und Pathogen sind kompatibel. Avirulente Pathogene werden dagegen vom pflanzlichen System effektiv über spezifische Resistenzproteine erkannt. Eine indirekte oder direkte Interaktion des pflanzlichen Resistenzproteins mit dem Avirulenzprotein des Pathogens erzeugt ein Signal (FLOR, 1955; VAN DER BIEZEN und JONES, 1998). Das postulierte „Gen-für-Gen-Modell " besagt, dass Pflanzen eine hohe Anzahl spezifischer Resitenzgene besitzen müssen, da für jedes Pathogen ein entsprechendes Erkennungsprotein vorliegen muss. Durch die Proteininteraktion werden pflanzliche Abwehrmechanismen aktiviert, die den Pathogenbefall weitestgehend stoppen bzw. lokal eingrenzen. Die Interaktion zwischen der Pflanze und dem Pathogen wird als inkompatibel bezeichnet. Ein Beispiel ist die inkompatible Interaktion ist die Infektion von Tabak mit dem Tabakmosaikvirus (TMV). Das Genprodukt des N-Gens aus Tabak (BAKER et al., 1996; DINESH-KUMAR und BAKER, 2000) interagiert direkt mit der Replikase von TMV. Als Folge werden lokale Resistenzreaktionen hervorgerufen, welche als hypersensitive Antwort oder Reaktion ( $h y$ persensitive response, HR; LOR, 1971; HAMMOND-KOSACK und JONES, 1996; KEEN, 1992; LAMB, 1994; LAMB et al., 1989, STASKAWICZ et al., 1995) bezeichnet werden. Reaktionen der HR sind neben dem lokal begrenzten Zelltod an der Infektionsstelle die Bildung reaktiver Sauerstoffspezies (ROS; LAMB und DIXON, 1997; SUTHERLAND, 1991; BAKER und ORLANDI, 1995; ROSETTI und BONATTI, 2001), die Expression von Proteinen mit Schutzfunktion (z.B. Glutathion-S-Transferasen und PR-Proteine) sowie die Synthese von Substanzen mit antimikrobieller Wirkung (Phytoalexine). Im Zuge der HR kommt es zudem zur Ausbildung der von Salizylsäure (SA) abhängigen systemisch

erworbenen Resistenz (systemic required resistance; ROSS und BOSSARTH, 1960; ROSS, 1961; KUC 1982; RYALS et al., 1996). 


\subsection{Salizylsäure-das zentrale Molekül der pflanzlichen Pathogen- abwehr}

ROSS (1961) zeigte, dass resistente Tabakpflanzen, die mit TMV infiziert wurden, eine erhöhte Resistenz gegenüber einer Zweitinfektion mit demselben Virus oder mit anderen Viren aufwiesen. Dieses Phänomen der sogenannten systemisch erworbenen Resitenz (SAR) war sogar auf weit entfernte Blattbereiche ausgedehnt. MALAMY et al. (1990) und MÉTRAUX et al. (1990) konnten zeigen, dass Salizylsäure das Signal zur Auslösung der SAR ist. Durch exgogen applizierte Salizylsäure oder Acetylsalizylsäure (Aspirin) lässt sich dieser Effekt experimentell nachstellen (WHITE, 1979; KLESSIG und MALAMY, 1994; VERBENE et al., 2000; MAUCH et al., 2001).

Im Zuge der SAR werden PR-Gene (pathogenesis-related proteins) in lokalem, aber auch in systemischem Gewebe exprimiert. PR-Proteine, wie zum Beispiel PR-1 aus Arabidopsis thaliana oder das verwandte Protein PR-1a aus Nicotiana tabacum, besitzen antimikrobielle Eigenschaften (VAN LOON und VAN STRIEN, 1999) oder hemmen das Pilzwachstum (ALEXANDER et al., 1993; RAUSCHER et al., 1999). Die Expression der $P R$-Gene korreliert mit dem Anstieg der endogenen Salizylsäure-Konzentration in lokalen und systemischen Blättern nach TMV-Infektion (MALAMY et al., 1990). Experimente mit Tabakpflanzen, die das bakterielle $n a h G$-Gen exprimieren, zeigen, dass das Vorhandensein von endogener Salizylsäure für die Ausbildung der SAR notwendig ist (GAFFNEY et al., 1993). Das nahG-Gen kodiert für eine Salizylsäure-Hydroxylase, die Salizylsäure hydrolytisch zu Catechol abbaut. Dadurch konnte in den transgenen Tabakpflanzen keine SAR mehr nachgewisen werden (DELANEY et al., 1994). Durch die Expression von bakteriellen Enzymen, die Chorismat in Salizylsäure umsetzen können, wurden dagegen Pflanzen generiert, die erhöhte Mengen endogener Salizylsäure besitzen (VERBENE et al., 2000; MAUCH et al., 2001). Hier konnte beobachtet werden, dass diese Konzentrationszunahme mit einer erhöhten Resistenz gegenüber Pathogenen einhergeht, wie sie auch bei Wildtyp-Pflanzen nach Ausbildung der SAR vorhanden ist. Dieser Effekt wirkt sich auf die Expression der PR-Gene aus. Sie werden konstitutiv exprimiert (VERBENE et $a l ., 2000)$.

Neben den $P R$-Genen werden noch weitere Gene durch den Salizylsäurestimulus induziert. Dabei handelt es sich u.a. um die Gene GNT1(Nt103-1) und GNT35 (Nt10335), welche für Glutathion-S-Transferasen kodieren (BOOT et al., 1993). Glutathion-STransferasen spielen eine wichtige Rolle bei der Detoxifikation (DANIEL, 1993; LEVINE et al., 1994). 
Andere Gene kodieren für eine Glycosyltransferase (IEGT; HORVATH und CHUA, 1996) und für das Genprodukt von parA, einem Kern-Protein mit Homologie zu GlutathionS-Transferasen (protoplast auxin regulated; TAKAHASHI et al. 1989). Die transiente Expression dieser Gene wird sehr schnell aktiviert. Erste mRNAs sind bereits 30 Minuten nach Salizylsäure-Applikation nachweisbar. Man spricht von der „frühen“ Genantwort. Eine Proteinneusynthese ist für die Aktivierung der Expression im Gegensatz zu der Expression der späten $P R$-Gene nicht notwendig. Die Expression der $P R$-Gene ist auf mRNA-Ebene erst nach sieben bis zwölf Stunden nachweisbar, was eine Proteinneusynthese zwingend erforderlich macht (UKNES et al., 1993b; QIN et al., 1994). Mit Hilfe von Micorarray-Analysen konnten neben den Genen, die für Glutathion-S-Transferasen und PR-Proteine kodieren, eine Vielzahl weiterer, neuer Abwehrgene identifiziert werden, die ebenfalls durch Salizylsäure induzierbar sind (MALECK et al., 2000; SCHENK et al., 2000).

\subsection{Das as-1-Element als salizylsäureinduzierbares cis-Element in Promotoren pflanzlicher Abwehrgene}

In den Promotoren pflanzlicher Abwehrgene wurden salizylsäure-induzierbare cis-Elemente identifiziert (LAM et al., 1990; BOUCHEZ et al., 1989; FROMM et al., 1989; RUSHTON und SOMMSICH, 1998; YANG et al., 1997). Diese findet man ebenfalls in Promotoren von Genen pflanzlicher Pathogene. Ein besonderes Augenmerk fiel dabei auf das SA-induzierbare cis-Element des CaMV 35S-Promotors (cauliflower mosaic virus; Blumenkohlmosaikvirus; BENFEY et al., 1989; BENFEY und CHUA, 1990; QIN et al. 1994). Die Fusion des CaMV 35S-Promotors mit einem GUS-Reportergen vermittelt eine konstitutive Expression des GUS-Gens in allen pflanzlichen Geweben (ODELL et al., 1985). Deletiert man den Bereich des CaMV 35S-Promotors ab -90 bp stromaufwärts (relativ vom Transkriptionsstartpunkt +1 ), konnte die Expression des Reportergens nur noch nach Auxin- oder SA-Stimulus in Blättern beobachtet werden, während die Expression in den Wurzelspitzen, Kalluszellen, Protoplasten konstitutiv verläuft (BENFEY et al., 1989; FROMM et al., 1989; LIU und LAM, 1994; QIN et al., 1994). In diesem Promotorbereich ist das SA-sensitive as-1-Element (activating sequence-1) lokalisiert. Das as-1-Element besteht aus zwei TGACG-Motiven, welche sich als Teilsequenz von zwei nicht perfekten Palindromen mit der Sequenz TGAC|GTCA ableiten (LAM et al., 1989; KRAWCZYK et al., 2002). Sie sind durch 12 bp getrennt, wobei als Bezugspunkt die Symmetrieachse gilt (Querstriche). 
Das as-1-Element des CaMV 35S-Promotors hat die Sequenz

$$
\text { 5'- TGAC | GTAA ggga TGAC | GACAC -3' }
$$

Die erwähnten frühen Gene GNT1 und GNT35 (XIANG et al., 1996) ebenso wie IEGT (HORVATH und CHUA,1996), parA (TAKAHASHI et al. 1989) oder AtGST6 (CHEN und SINGH, 1999) aus Arabidopsis thaliana enthalten ein cis-Element, welches ähnlich aufgebaut ist wie das as-1-Element des CaMV 35S-Promotors. Deshalb spricht man hier von as-1-ähnlichen Elementen (DROOG et al., 1995; VAN DER ZAAL et al., 1996; HORVATH et al., 1998). As-1-ähnliche Elemente wurden auch in den Promotoren der späten $P R$-Gene $P R$-1a aus Nicotiana tabacum und PR-1 aus Arabidopsis thaliana identifiziert (STROMPEN et al., 1998; LEBEL et al., 1998). Eine Zusammenstellung wichtiger as-1Elemente findet sich in Tabelle 1.

\begin{tabular}{|l||l|}
\hline Nt103-1 $($ N. tabacum $)$ & TTAG | CTAA gtgc TTAC | GTAT \\
Nt103-35 $($ N. tabacum $)$ & TTAG | CTAA gtgc TTAC | GTAT \\
GST6 $($ A. thaliana $)$ & TTAT | GTCA ttga TGAC | GACC \\
as-1 $($ CaMV $35 S)$ & TGAC | GTAA ggga TGAC | GCAC \\
ocs $($ A. tumefaciens $)$ & AAAC | GTAA gcgc TTAC | GTAC \\
nos $($ A. tumefaciens $)$ & TGAG | CTAA gcac ATAC | GTCA \\
\hline consensus & TGAC | GTCA gnnn TGAC | GTCA \\
\hline PR-1a $($. tabacum $)$ & TAAC | GTCA tcgaga TGAC | GGCC \\
PR- 1 (A. thaliana $)$ & CTAC | GTCA ctattttac TTAC | GTAC \\
\hline
\end{tabular}

Tabelle 1: Sequenz as-1-ähnlicher cis-Elemente in verschiedenen Pflanzen- und Pathogenpromotoren

Fusionskonstrukte aus isolierten as-1-ähnlichen Elementen (Pflanze oder Pathogen), Minimalpromotor (TATA-Box) und einem Reportergen vermitteln die Expression des Reportergens in pflanzlichen Zellen durch Induktion mit Salizylsäure, Auxin und Methyljasmonat (KIM et al., 1994; LIU und MAL, 1994; QIN et al., 1994; ULMASOV et al., 1994; VAN DER ZAAL et al., 1996; XIANG et al., 1996; ZHANG und SINGH, 1994). Allerdings erfolgt die Induktion der Genexpression nur, wenn unphysiologisch hohe Konzentrationen der Phytohormone eingesetzt werden. Somit kann die Responsivität der as-1-ähnlichen Elemente als Antwort auf xenobiotischen Stress nicht ausgeschlossen werden (JOHNSON et al., 2001b; PASUZZI et al., 1998; ULMASOV et al., 1994; XIANG et al., 1996). 


\subsection{Die TGA-Faktoren als as-1-Element bindende Proteine}

KATAGIRI et al. (1989) isolierten aus Nicotiana tabacum den an das as-1-Element bindenen bZIP-Transkriptionsfaktor TGA1a. Sie durchmusterten dazu eine cDNA-Expressionsbank aus Tabak mit dem radioaktiv markierten, as-1-ähnlichen, hex1-Element. Der Transkriptionsfaktor erhielt seinen Namen wegen seiner Bindungsfähigkeit an das TGACG-Motiv.

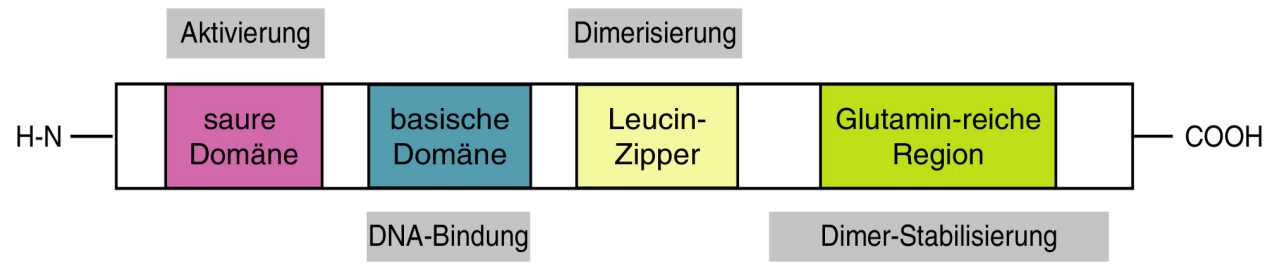

Abbildung 2.1: Aufbau des bZIP-Transkriptionsfaktors TGA1a

TGA1a besitzt eine basische DNA-Bindedomnäne und eine Region mit charakteristischen Wiederholungen von Leucin-Resten (Leucin-Zipper; englisch: Zipper $=$ Reißverschluß; Abb.2.1). Durch die idealerweise heptamere Wiederholung eines Leucin-Restes wird über hydrophobe Wechselwirkungen die Dimerisierung mit anderen TGA-Faktoren vermittelt. Die weiteren charakteristischen Domänen von TGA1a sind der saure Bereich im N-Terminus und die glutaminreichen Domäne im carboxyterminalen Bereich. NEUHAUS et al. (1994) und PASCUZZI et al. (1998) zeigten, dass beide Regionen Aktivierungspotential besitzen. Die carboxyterminale Domäne ist zudem für die Stabilisierung der Dimer-Bildung verantwortlich (KATAGIRI et al., 1992), sowie an der Bindung eines $120 \mathrm{kDa}$ großen Repressorproteins beteiligt (JOHNSON et al., 2001a)

Bis heute konnten zahlreiche TGA-Faktoren aus verschiedenen Pflanzenarten isoliert werden. Dazu zählen Mais (SINGH et al., 1990; FOLEY et al., 1993; WALSH et al., 1997), Weizen (TABATA et al., 1991), Ackerbohne (EHRLICH et al., 1993), Kartoffel (FELTKAMP et al., 1994), Sojabohne (CHEONG et al., 1994), Tomate (ZHANG et al., 1999) und Reis (CHERN et al., 2001). Die Mehrzahl der TGA-Faktoren wurden jedoch in Arabidopsis thaliana identifiziert. Basierend auf ihrer Aminosäurehomologie wurden die verschiedenen TGA-Faktoren in Unterklassen aufgeteilt (XIANG et al., 1997). Eine Zusammenstellung zeigt Tabelle 2 . 


\begin{tabular}{|c|c|c|}
\hline Klasse & Arabidopsis & Tabak \\
\hline Klasse I: & $\begin{array}{l}\text { TGA1 (SCHINDLER et al., 1992) } \\
\text { TGA4 (OBF4; ZHANG et al., 1993) }\end{array}$ & $\begin{array}{l}\text { TGA1a (KATAGIRI et al., 1989) } \\
\text { PG13 (FROMM et al., 1991) }\end{array}$ \\
\hline KLASSE II: & $\begin{array}{l}\text { TGA2 (HBP1b; KAWATA et al., 1992) } \\
\text { TGA5 (OBF5; ZHANG et al., 1993; } \\
\text { FOLEY et al., 2004) } \\
\text { TGA6 (XIANG et al., 1995) }\end{array}$ & $\begin{array}{l}\text { TGA2.1 (NIGGEWEG et al., 1997) } \\
\text { TGA2.2 (NIGGEWEG et al., 2000a) }\end{array}$ \\
\hline KLasse III & $\begin{array}{l}\text { TGA3 (MIAO et al., 1994) } \\
\text { AtbZIP50 (JABCOBY et al., 2002) }\end{array}$ & \\
\hline KLasse IV & $\begin{array}{l}\text { PERIANTHIA } \\
\text { (CHUANG et al., 1999) }\end{array}$ & \\
\hline Klasse V & AtbZIP21 (JACOBY et al., 2002) & \\
\hline Klasse IV & AtbZIP65 (JACOBY et al., 2002) & TGA10 (SCHIERMEYER et al., 2003) \\
\hline
\end{tabular}

Tabelle 2: Übersicht über die TGA-Faktoren aus Arabidopsis und Tabak

Aus Nicotiana tabacum wurden bislang fünf TGA-Faktoren isoliert. TGA1a (KATAGIRI et al., 1989), sowie PG13 (FROMM et al., 1991) wurden wegen der Homologie zu TGA1 aus Arabidopsis thaliana der Unterklasse 1 zugeordnet. TGA2.1 und TGA2.2 wurden mit einer TGA5-Sonde aus einer Tabak-cDNA-Bank isoliert (NIGGEWEG et al., 2000a). Entsprechend ihrer hohen Aminosäurehomologie von $85 \%$ bzw. $91 \%$ gegenüber dem aus Arabidopsis thaliana bekannten TGA2 wurden sie in die Unterklasse 2 eingebunden. Beide Transkriptionsfaktoren unterscheiden sich in ihrem Aufbau. Während der N-Terminus bei TGA2.1 170 Aminosäuren umfasst, ist dieser bei TGA2.2 mit 43 Aminosäuren deutlich kürzer. TGA2.1 und TGA2.2 werden in Blättern und Wurzeln exprimiert (NIGGEWEG et al., 2000a). Der TGA-Faktor TGA10 (SCHIERMEYER et al., 2003) zeigt nur geringe Ähnlichkeiten zu den bekannten Unterklassen 1 bis 3, weist jedoch eine $70 \%$ ige Homologie zu AtbZIP65 aus Arabidopsis thaliana auf. TGA10 wird wie PERIANTHIA aus Arabidopsis thaliana gewebsspezifisch exprimiert. Während sich Transkripte von PERIANTHIA im Apikalmeristem und Blütengewebe der Pflanze nachweisen lassen, wird TGA10 nur in den Wurzeln exprimiert (SCHIERMEYER et al., 2003).

TGA Faktoren sind generell in der Lage, mit verwandten bZIP-Proteinen Heterodimere zu bilden. Für die TGA-Faktoren aus Nicotiana tabacum konnte gezeigt werden, dass diese in vitro als Heterodimere an das as-1-Element binden (NIGGEWEG et al., 2000a; SCHIERMEYER, 2001). 


\subsubsection{Der ASF-1 und SARP-Komplex}

Mithilfe von Gelretardationsanalysen (EMSA; electrophoretic mobility shift assay) kann überprüft werden, ob Proteine oder Proteinkomplexe in vitro an spezifische DNA-Sequenzen binden. LAM et al. (1989) konnten so in Tabak-Zellkernproteinextrakten einen Proteinkomplex nachweisen, der an die TGACG-Motive des as-1-Elements bindet. Das Bindemuster besteht aus zwei Banden, welche die einfache und die doppelte Besetzung der TGACG-Motive widerspiegelt. Der Proteinkomplex, welcher als als ASF-1 (activating sequence factor-1 bezeichnet wurde, bindet auch an as-1-ähnliche Elemente (BOUCHEZ et al., 1989; FROMM et al., 1989; LAM et al., 1990; FELTKAMP et al., 1994; DROOG, et al., 1995).

Die Bindeaktivität eines Proteinkomplexes konnte von JUPIN und CHUA (1996) auch in Gesamtzellextrakten nachgewiesen werden. Da eine Verstärkung der Bindung nach Gabe von Salizylsäure erfolgt, wurde der Komplex als SARP (salicylic acid resonse protein) bezeichnet. Im EMSA-Supershift-Experimenten mit spezifischen Antikörpern zeigen ASF1 und SARP ein identisches Bandenmuster. Deswegen wird angenommen, dass es sich bei ASF-1 und SARP wahrscheinlich um denselben Protein-Komplex handelt (NIGGEWEG et al., 2000b).

Eine Erweiterung der Gelretardationsanalyse stellt die Inkubation des Protein-DNABindeansatzes mit einem spezifischen Antikörper gegen das Protein dar. Mit dieser als „,supershift" bezeichneten Variante konnten NIGGEWEG et al. (2000b) Aussagen über die Zusammensetzung von ASF-1 und SARP treffen. Es zeigte sich in Kombination mit Western-Blot-Analysen, dass TGA2.2 und TGA2.1 Bestandteile von ASF-1 und SARP sind, während TGA1a nicht nachweisbar ist. ASF-1 (SARP) besteht zu $80 \%$ aus TGA2.2 und zu $10 \%$ (20\%) aus TGA2.1. Da über die verwendeten Antikörper nicht nur Homodimere, sondern auch Heterodimere von TGA2.2 und TGA2.1 mit noch nicht identifizierten TGA-Faktoren detektiert werden können, ist die Anwesenheit weiterer verwandter Proteine nicht ausgeschlossen (NIGGEWEG et al., 2000b).

\subsubsection{Beteiligung der TGA-Faktoren an der Regulation der Genexpression}

Die Ergebnisse einer Vielzahl von Experimente sprechen für eine direkte Beteiligung des ASF-1-Komplexes an der transkriptionellen Aktivierung von Genen der Pathogenantwort über das as-1-Element. LAM et al. (1989) konnten zeigen, dass eine Mutation im as-1Element des CaMV $35 S$ (-90)-Promotors die DNA-Bindeaktivität von ASF-1 reduziert. 
Gleichzeitig nimmt die Expressionsstärke des Reportergens ab. Diese Ergebnisse wurden durch weitere Experimente bekräftigt. In transgenen Pflanzen, die eine dominant negative Mutante der Klasse-2-TGA-Faktoren mit veränderter oder deletierter DNA-Bindedomäne exprimieren (RIEPING et al., 1994; MIAO und LAM, 1995; NIGGEWEG et al., 2000b; KEGLER et al., 2004; PONTIER et al., 2001), ist in vitro die Menge an ASF-1 verringert und in vivo die as-1-abhängige Genexpression reduziert (MIAO und LAM, 1995; NIGGEWEG et al., 2000b; KEGLER et al., 2004). Es wird angenommen, dass die Effekte auf die Bildung bindeinaktiver Heterodimere zwischen der TGA-Mutante und den endogenen TGA-Faktoren zurückzuführen sind. PONTIER et al. (2001) zeigten jedoch für transdominant negative TGA2-Mutanten in vivo eine 2fach verstärkte Aktivität des PR-1-Promotors. Zusätzlich ist die Expressionstärke der frühen Gene GNT35 und parA (str246; DROOG et al., 1993; GOUGH et al., 1995) reduziert. Diese Ergebnisse wurden von den Autoren so interpretiert, dass as-1-Element bindende TGA-Faktoren die Genexpression sowohl aktivieren als auch reprimieren.

Eine Überexpression von TGA2.1 und TGA2.2 führt zu einer gesteigerten as-1-Bindeaktivität des ASF-1 bzw. SARP im EMSA. Zudem ist die Induzierbarkeit des frühen Gens GNT35 durch SA, Auxin erhöht (NIGGEWEG et la., 2000b; KEGLER et al., 2004). Die Überexpression hat jedoch keinen Einfluss auf die Expression von PR-1a. Durch NorthernAnalysen von transgenen TGA2.2/2.1RNAi-Pflanzen, in denen TGA2.2 und TGA2.1 auf Proteinebene nicht mehr detektierbar sind (THUROW et al., 2005), konnten für GNT35 und PR1-a im uninduzierten Zustand und nach Induktion mit SA keine oder nur sehr verminderte Transkriptmengen nachgewiesen werden. Aus diesem Ergebnis kann man ableiten, dass ein direkter Zusammenhang zwischen der Expression dieser Gene und der Funktionalität der TGA-Proteine besteht.

JOHNSON et al. (2001a; 2001b) konnten in Tabak-Suspensionskulturen durch die Anwendung der Chromatin-Immunopräzipitation (ChIP) zeigen, dass TGA1a direkt an der Bindung der Auxin induzierbaren Gene GNT1 und GNT35 beteiligt ist. TGA1a interagiert über die C-terminale Domäne mit einem 120 kD großen Proteinkomplex, einem Korepressor. Erst nach Auxin-Gabe löst sich dieser Komplex, TGA1a wird frei, kann nun an das as-1-ähnliche Element binden und die Gen-Expression induzieren. Ein ähnliches Modell ist auch für die frühe Genantwort denkbar. JUPIN und CHUA (1996) und STANGE et al. (1997) konnten zeigen, dass die Bindeaktivität des ASF-1 in Gegenwart von Salizylsäure zunimmt. Diese Erhöhung ist jedoch unabhängig von einer de novo-Proteinsynthese (JUPIN und CHUA, 1996). 
Es wird angenommen, dass die TGA-Faktoren im uninduzierten Zustand an einen SAInhibitor (SAI) gebunden vorliegen und dadurch inaktiv sind. Lenk (2001) fusionierte die Aktivierungsdomäne VP16 mit TGA2.1 und TGA2.2, um die in vivo-Bindungseigenschaft der Proteine auf die Expression potentieller Zielgene zu untersuchen. Die Experimente zeigen, dass die starke Aktivierungsdomäne VP16 (VP16-AD) zwar nach SA-Stimulus in der Lage war, die angesprochenenen Zielgene in der Expression zu verstärken, nicht jedoch eine Steigerung der basalen Expression auszulösen. Dieses Ergebnis lässt zwei Vermutungen zu: Erstens binden die TGA-Faktoren im uninduzierten Zustand nicht am cis-Element, sie sind also mit dem von JUPIN und CHUA postulierten SAI verbunden. Zweitens binden und interagieren sie mit einem Transkriptionsrepressor, der stark genug ist, die VP16-AD zu inhibieren. Phosphorylierungsereignisse wurden ebenfalls im Zusammenhang mit der Regulation des as-1-Elements nachgewiesen: STANGE et al. (1997) konnten eine Abhängigkeit der Bindeaktivität des ASF-1 am as-1-Element durch unterschiedliche Phosphorylierungszustände nachweisen. Dabei steigerte die Behandlung eines SA-induzierten Zellkernextraktes aus Nicotiana tabacum mit ATP die Bindeaktivität des ASF-1. Die Behandlung mit Phosphatase führte hingegen zu einer Aktivitätsabnahme. KANG und KLESSIG (2005) zeigten für Arabidopsis thaliana, dass eine Casein Kinase II (CK2) die Eigenschaft besitzt, TGA2 stark, aber auch TGA5, TGA6 und TGA3 in geringerem Maße, zu phosphorylieren. Für TGA2 konnte eine Phosphorylierung bereits 10 min nach SA-Stimulus nachgewiesen werden, verbunden mit einer verringerten DNABindeaktivität. Ein Vergleich der Klasse 2-TGA-Faktoren aus Nicotiana tabacum und Arabidopsis thaliana zeigte homologe Phosphorylierungsbereiche.

\subsection{NPR1 als zentrales Regulatorprotein der PR-Genexpression}

Um Komponenten der Salizylsäure-abhängigen Signaltransduktion zu identifizieren, wurden durch genetische Screens bis heute mehrere Allele eines Gens gefunden, welches als NPR1 (nonexpressor of PR genes), NIM1 (non immunity) oder SAI1 (salicylic acid insensitivity) bezeichnet wird (CAO et al., 1994; DELANEY et al., 1995; GLAZEBROOK et al., 1996; SHAH et al., 1997). NPR1 zeichnet sich durch zwei Protein-Protein-Interaktionsdomänen aus: eine Ankyrin-Wiederholung und eine BTB/POZ-Domäne (broad-complex, tramtrack, bric-a-brac/poxyvirus, zinc finger). Ferner liegen eine Zellkern-Transitsequenz sowie diverse Phosphorylierungsstellen vor (CAO et al., 1997; RYALS et al., 1997). 
In npr1-Mutanten wird nach Pathogeninfektion oder exogener Gabe von Salizylsäure die Transkription der $P R$-Gene nur in sehr geringem Maße aktiviert. Eine SAR kann ebenso nicht etabliert werden. Die Überexpression von NPR1 hat eine erhöhte Resistenz gegenüber einer Vielzahl von Pathogenen zur Folge (CAO et al., 1998). Diese Erhöhung der Resistenz ist jedoch nicht auf eine konstitutive Expression der $P R$-Gene zurückzuführen. Vielmehr beruht dieser Effekt auf einer schnelleren und verstärkten Aktivierung der $P R$ Genexpression nach Pathogenbefall, bzw. Gabe von Salizylsäure.

KINEKMA et al. (2000) führten zur weiteren Klärung der Funktionsweise von NPR1 Lokalisationsexperimente mit GFP-markierten NPR1 durch. Nach Induktion der SAR konnte NPR1 im Zellkern nachgewiesen werden. Durch einen induzierbaren Kerntransport über die Fusion eines Glykocorticoid-Rezeptors wurde bewiesen, dass die Lokalisierung von NPR1 im Zellkern die entscheidende Voraussetzung zur Aktivierung der PRGenexpression darstellt.

NPR1 besitzt die Eigenschaft zur Interaktion mit anderen Proteinen. So konnten im Hefe-Zwei-Hybrid-System die Interaktion mit TGA-Faktoren nachgewiesen werden (DESPRÉS et al., 2000; NIGGEWEG et al., 2000b; ZHANG et al., 1999; ZHOU et al., 2000). Ein entscheidender Schritt zum Verständnis der Wirkungsweise von NPR1 lieferten MOU et al. (2003). Sie zeigten, dass NPR1 im uninduzierten Zustand als Oligomer, verbunden über Disulfidbrücken-ausbildende Cysteinreste, im Cytoplasma vorliegt. Im Zuge der SAR findet eine Reduzierung der Cystein-Reste statt, das Oligomer zerfällt und NPR1 wandert als Monomer in den Zellkern. Ausgelöst wird dieser Regulationsmechanismus über eine Veränderung des Redox-Zustands der Zelle (MOU et al., 2003; VANACKER et al., 2000). Zusammenfassend kann man festhalten, dass NPR1 ein zentrales Regulatorprotein in der Salizylsäure-vermittelten $P R$-Genexpression sowie der SAR ist. 


\subsection{Fragestellung und Zielsetzung der Arbeit}

TGA-Faktoren regulieren über die Bindung an das as-1-Element die Salizylsäure-aktivierte Expression von Abwehrgenen. Der Mechnismus, über den die Aktivierung reguliert wird, ist noch nicht bekannt. Denkbar sind zwei verschiedene Modelle: Die TGA-Faktoren binden im uniduzierten Zustand konstitutiv an das as-1-Element und ihre Aktivität wird durch einen Inhibitor unterdrückt. Es wäre aber auch denkbar, dass die TGA-Faktoren nach Pathogenbefall SA-induziert an das as-1-Element binden, und dadurch die Expression der Abwehrgene aktivieren. Der SA-Stimulus könnte z.B. die Loslösung der Transkriptionsfaktoren von einem Inhibitor bewirken.

Um Erkenntnisse über die Regulation der SA-induzierten Expression von Abwehrgenen zu erlangen, ist es wichtig, die Ereignisse in vivo direkt am Promotor zu analysieren. Dazu wurde im Rahmen dieser Arbeit zunächst die Chromatin-Immunopräzipitation (ChIP) etabliert. Anschließend wurde mit dieser Methode die SA-regulierte Bindung der Klasse-2TGA-Faktoren TGA2.1 und TGA2.2 aus Nicotiana tabacum an das isolierte as-1-Element und an die Promotoren von parA (frühes Gen) und PR-1a (spätes Gen) analysiert. 


\section{Material}

\subsection{Geräte}

\begin{tabular}{|c|c|c|}
\hline Gerät & Modell & Hersteller/Bezugsquelle \\
\hline Autoklav & $3870 \mathrm{ELV}$ & Tuttnauer \\
\hline Automatische Pipetten & & Gilson \\
\hline Bioimager(Phosphoimager) & BAS-1000 & Fuji \\
\hline Plate Reader & & PerSeptive \\
\hline Gefriertrocknungsanlage & L 05 & WKF \\
\hline Geldokumentationsstation & & MWG Biotech \\
\hline $\begin{array}{l}\text { Gelelektrophoresekammer, } \\
\text { horizontal }\end{array}$ & & Werkstatt der Universität \\
\hline $\begin{array}{l}\text { Gelelektrophoresekammer, } \\
\text { vertikal }\end{array}$ & Joey JGC-4 AGS V 15-17 & $\begin{array}{l}\text { GIBCO BRL } \\
\text { Werkstatt der Universität }\end{array}$ \\
\hline Gelelektrophorese 2D & Protean II XL & Biorad \\
\hline Geltrockner & Phero-Temp & Biotec-Fischer \\
\hline Handmonitor & Contamat & Eberline \\
\hline Heizblock & & Boekel Scientific \\
\hline Heizrührer & $\mathrm{RCT}$ basic & IKA Labortechnik \\
\hline Heizschüttler & Thermomixer 5436 & Eppendorf \\
\hline Hybridisierungsofen & & Bachhofer \\
\hline Hybridisierungswasserbad & Belly Dancer & Stovall \\
\hline IEF-Zelle(2D-PAGE) & Protean IEF & Biorad \\
\hline Inkubationsschränke & & WTC binder;Memmert \\
\hline Kühlschränke & glass line & Liebherr \\
\hline Kühlzentrifuge & Sorvall RC 5B Plus & DuPont \\
\hline Netzgeräte & E 323 & Benedikt Heinemann \\
\hline Netzgeräte & EC 105 EC & Apparatus Corporation \\
\hline PCR-Gerät & MiniCycler PTC-150 & MJ Research \\
\hline pH-Meter & HI 9321 & Hanna Instruments \\
\hline RNA-/DNA-Calculator & GeneQuant II & Pharmacia \\
\hline Scanner & EPSON 3000 & EPSON \\
\hline
\end{tabular}




\begin{tabular}{|l|l|l|}
\hline Gerät & Modell & Hersteller/Bezugsquelle \\
\hline $\begin{array}{l}\text { Spektralphotometer für } \\
\text { Mikrotiterplatten }\end{array}$ & MRX Dynex Plate Reader & Dynex \\
Sterilbank, horizontales Gebläse & Microflow Laminar & Nunc \\
Sterilbank, vertikales Gebläse & Microflow Biohazard & Nunc \\
& raytest & Isotopenmeßgeräte \\
Tischzentrifuge & Biofuge pico & GmbH \\
Tischzentrifuge, kühlbar & 5403 & Heraeus Christ \\
Über-Kopf-Schüttler & RM-2L & Eppendorf \\
Sonifizierer & Soniprep 150 & LTF-Labortechnik \\
UV-Transilluminator & FLX-20 M & Scientific Instruments \\
Vortex & L46 & Vilber Lourmat \\
Wasseraufbereitungsanlage & Option 4, Maxima & Labinco BV, \\
\hline
\end{tabular}

\subsection{Verbrauchsmaterialien}

\begin{tabular}{|l|l|}
\hline Produkt & Hersteller/Bezugsquelle \\
\hline Einmal-Handschuhe & Hartmann \\
Fließpapier & 3MM Whatman \\
Gläser für Pflanzensterilkultur & Weck \\
Insulinspritzen & BD Science \\
Kunststoff-Einwegmaterial & Eppendorf, Greiner \\
& Roth, Sarstedt \\
Mikrotiterplatten & Roth \\
Miracloth & Calbiochem \\
PVDF-Membran Immobilon-P & Millipore \\
Röntgenfilme Cronex 4 & DuPont \\
\hline
\end{tabular}




\subsection{Chemikalien}

\begin{tabular}{|c|c|}
\hline Chemikalie & Hersteller/Lieferant \\
\hline $30 \%$ w/v Acrylamid:N,N'-Methylenbisacrylamid $(37,5: 1)$ & Roth \\
\hline $40 \%$ w/v Acrylamid:N,N'-Methylenbisacrylamid (19:1) & Roth \\
\hline Agarose & SeaKem \\
\hline APS (Ammoniumpersulfat) & Biometra \\
\hline Bradford-Reagenz & Roth \\
\hline Bromphenolblau & Roth \\
\hline BSA (Rinderserum-Albumin) & Serva \\
\hline Coomassie Brilliant Blue G-250 & BioRad \\
\hline$\alpha^{32}$-dATP; $800 \mathrm{Ci} / \mathrm{mmol}$ & Hartmann \\
\hline & Analytic \\
\hline CHAPS & Roth \\
\hline Dithiothreitol (DTT) & Sigma \\
\hline dNTPs & MBI; Roth \\
\hline EDTA & AppliChem \\
\hline Ethidiumbromid & Roth \\
\hline Glutathion-Sepahrose & Pharmacia \\
\hline Hydroxyethylcellulose (HEC) & Fluka \\
\hline Harnstoff (Urea) & Roth \\
\hline IPG-StreifenpH3-10 (2D) & Biorad \\
\hline Isopropylthiogalactosid (IPTG) & BioTech Trade \\
\hline Magermilchpulver & Glücksklee \\
\hline is -Mercaptoethanol & Roth \\
\hline Murashige und Skoog Medium & Duchefa \\
\hline Nickel-NTA-Sephaorse & Qiagen \\
\hline Orange $\mathrm{G}$ & Sigma \\
\hline Phenol & AppliChem \\
\hline Protase-Inhibitor Mix & Sigma \\
\hline Protein A-Sepharose & Sigma \\
\hline Röntgen-Entwickler LX24 & Kodak \\
\hline Röntgen-Fixierer AL4 & Kodak \\
\hline Salicylsäure (SA) & Merck \\
\hline Select Agar & Life Technologies \\
\hline TEMED & Roth \\
\hline Triton X-100 & Roth \\
\hline Tween20 & Roth \\
\hline X-Gal & BioTech \\
\hline Xylencyanol FF & Roth \\
\hline
\end{tabular}

Weitere Standard-Chemikalien wurden von den Firmen Boehringer, Fluka, Merck, Serva, Sigma oder Roth bezogen. 


\subsection{Proteine}

\subsubsection{Verwendete Enzyme}

\begin{tabular}{|l|l|}
\hline Enzym & Hersteller/Bezugsquelle \\
\hline Advantage 2 taq-Polymerase & BD Scince \\
Lysozym & Sigma \\
Proteinase K & Sigma \\
\hline
\end{tabular}

\subsubsection{Proteinstandard}

Zur Größenabschätzung von Proteinen im SDS-PAAG wurde der PAGE-Ruler ${ }^{\complement}$ der Firma Fermentas verwendet.

\subsubsection{Antikörper}

\begin{tabular}{|c|c|c|c|}
\hline Bezeichnung & Spezifität & Eigenschaft & Referenz \\
\hline$\alpha \mathrm{H} 4 \mathrm{ac}$. & 3 - bis 4 fach & polyklonal & Upstate/Biomol \\
\hline & acetylierte Histone & & Kat. \#06-866 H4 \\
\hline$\alpha$ TGA2.1/2.2-C & C-Termini TGA2.1/TGA2.1 & polyklonal & $\begin{array}{l}\text { NICKOLOV } \\
(2002)\end{array}$ \\
\hline$\alpha$ TGA2.2C & C-Terminus TGA2.2 & $\begin{array}{l}\text { polyklonal, } \\
\text { affinitätsaufgereingt }\end{array}$ & $\begin{array}{l}\text { NICKOLOV } \\
(2002)\end{array}$ \\
\hline$\alpha$ TGA2-C & C-Termini TGA2.1/TGA2.1 & polyklonal & diese Arbeit \\
\hline$\alpha \mathrm{VP} 16$ & $\begin{array}{l}\text { VP16-Aktivierungsdomäne aus } \\
\text { Herpes simplex }\end{array}$ & polyklonal & diese Arbeit \\
\hline
\end{tabular}




\subsection{Nukleinsäuren}

\subsubsection{Primer}

Die aufgeführten Primer wurden von den Firmen MWG, Operon und Roth synthetisiert und geliefert.

\begin{tabular}{|l|l|}
\hline Primer & Sequenz $5^{\prime}-3^{\prime}$ \\
\hline 20381N & TCG CGA TCC AGA CTG AAT GCC CAC \\
35SI & ATT GAT GTG ATA TCT CCA CTG AC- \\
near-as1 & AAA TTG ATG ATA TAG CTA GCT TAG CTC ATC GG \\
parA s & CTA GAC AAA ATC TAC CGT TCA CC \\
parA as & CAT GCC AGA CTT CAT CAA TGT AC \\
PR-1a & GTA ACA TCA AGT TGG AAA TTA AGG GAA GG \\
PR-1a as & TCA GAA TGG GAA TGT CCA TTG GAA AAA G \\
uni24 & ACG ACG TGG TAA AAC GAC GGC CAG \\
\hline
\end{tabular}

\subsection{Organismen}

\subsubsection{Pflanzen}

\begin{tabular}{|l|l|}
\hline Linie & Referenz \\
\hline SNN2.2UE $\# 8$ & NIGGEWEG, $(1999)$ \\
SNN as-1::GUS & KEGLER et al. $(2004)$ \\
SNN TGA2.1RNAi & THUROW et al. $(2005)$ \\
SNN TGA2.2RNAi & THUROW et al. $(2005)$ \\
W38 $\Delta 35$ S-GUS & PRAT, unveröffentlicht \\
W38 pTAX \#11 und \#23 & BÖHNER et al., 1999 \\
SNN TGA2.2-VP16 & LENK $(2001)$ \\
\hline
\end{tabular}

\subsection{Nährmedien und Zusätze}

\subsubsection{Nährmedien für Bakterien}

LB-Medium: $\quad 10 \mathrm{~g} / \mathrm{l}$ Trypton, $5 \mathrm{~g} / \mathrm{l}$ Hefeextrakt, $10 \mathrm{~g} / \mathrm{l} \mathrm{NaCl}$

dYT-Medium: $20 \mathrm{~g} / 1$ Trypton, $10 \mathrm{~g} / 1$ Hefeextrakt, $10 \mathrm{~g} / 1 \mathrm{NaCl}$

SOC-Medium: $20 \mathrm{~g} / 1$ Trypton, $5 \mathrm{~g} / 1$ Hefeextrakt, $10 \mathrm{mM} \mathrm{NaCl}$, $2,5 \mathrm{mM} \mathrm{KCl}$

nach dem Autoklavieren sterilfiltriert zugeben: $10 \mathrm{mM} \mathrm{MgCl}_{2}, 10 \mathrm{mM} \mathrm{MgSO}{ }_{2}, 20 \mathrm{mM}$ Glukose 


\title{
3.7.2 Nährmedien für Pflanzen
}

2 MS-Medium: 4,24 g/1 Murashige und Skoog Medium, $20 \mathrm{~g} / 1$ Saccharose, $6,4 \mathrm{~g} / 1$ Select-Agar, $\mathrm{pH}$ mit $\mathrm{KOH}$ auf 5,8

\subsection{Puffer und Lösungen}

\author{
DNA-Ladepuffer \\ $0.25 \%$ Orange G, $30 \%$ Glycerin \\ PBS 20X \\ $1.4 \mathrm{M} \mathrm{NaCl}, 27 \mathrm{mM} \mathrm{KCl}, 15 \mathrm{mM} \mathrm{KH}_{2} \mathrm{PO}_{4}$, \\ $81 \mathrm{mM} \mathrm{Na}_{2} \mathrm{HPO}_{4}$ \\ Protein-Ladepuffer \\ $80 \mathrm{mM}$ Tris $/ \mathrm{HCl} \mathrm{pH} 6.8,10 \%$ Glycerin, \\ $2 \%$ SDS, $0.005 \%$ Bromphenolblau, \\ frisch dazu: $20 \%$ \&-Mercaptoethanol \\ Proteinase $\mathrm{K}$ \\ $20 \mathrm{mg} / \mathrm{ml}$ in $\mathrm{H}_{2} \mathrm{O}$ gelöst \\ Transferpuffer Westernblot \\ $25 \mathrm{mM}$ Tris, $192 \mathrm{mM}$ Glycin, $0.04 \% \mathrm{SDS}$ \\ TAE 20x \\ $0.8 \mathrm{M}$ Tris, $2.3 \% \mathrm{v} / \mathrm{v}$ Essigsäure, $20 \mathrm{mM}$ EDTA
}

\section{Methoden}

\subsection{Anzucht von Organismen}

\subsubsection{Tabakpflanzen}

Tabakpflanzen wurden als Sterilkultur ausschließlich auf 2MS-Medium nach MURASHIGE und SKOOG (1962) kultiviert. Unter sterilen Arbeitsbedingungen wurde hierzu die Spitze der Pflanze mit einem Skalpell abgetrennt und in das Medium überführt. Die Anzucht erfolgte bei $24^{\circ} \mathrm{C} / 22^{\circ} \mathrm{C}$ Umgebungstemperatur in der Klimakammer bei einem Tag/Nacht-Rhythmus von 16/8h. Unsterile Kulturen auf Erde erfolgten bei einem Tag / Nacht-Rhythmus von $12 / 12 \mathrm{~h}$ bei $22^{\circ} \mathrm{C} / 19^{\circ} \mathrm{C}$ Umgebungstemperatur und ca. $85 \%$ Luftfeuchte. Die Bestrahlungsstärke betrug $65 \mu \mathrm{E}$ in der hauptsächlich genutzten Klimakammer. Die Bestrahlungsstäkre von Klimakammer 7 betrug $140 \mu$ E. Hier wurden die Pflanzen für die Versuche aus Kapitel 5.21 und 5.25 angezogen. Hierzu wurden die Pflanzen aus der sterilen 2MS-Kultur für 2 Wochen auf Pikiererde überführt und danach im dreiwöchigen Wechsel in größere Töpfe mit Torf umgesetzt. Die Ernte erfolgte nach dem Aussetzen meist nach 4-6 Wochen. 


\subsubsection{Anzucht von E.coli}

Escherichia coli (E. coli) wurde in LB-Flüssigmedium bei $37{ }^{\circ} \mathrm{C}$ angezogen. Bei plasmidtragenden Stämmen wurde das Medium mit dem Antibiotikum versetzt, für das ein Resistenzgen vorlag. Für Minipräparationen von Plasmid-DNA wurde LB- und dYTMedium verwendet, für Transformationen SOC-Medium. Für die Gewährleistung einer guten Sauerstoffversorgung wurden Kulturvolumina bis zu $5 \mathrm{ml}$ in kontinuierlich drehenden Kulturröhrchen gezogen. Größere Flüssigkulturen wurden bei 250 Upm geschüttelt. Kulturmedien bis $50 \mathrm{ml}$ wurden in $250 \mathrm{ml}$-, Medien bis $200 \mathrm{ml}$ in 1 l-Erlenmeyerkolben gezogen. Die langfristige Lagerung von Bakterienstämmen erfolgte in Form von Glycerinkulturen. Zur Herstellung solcher Kulturen wurden $850 \mu \mathrm{l}$ der stationären $E$. coli-Kultur mit $150 \mu \mathrm{l}$ Glycerin (steril) vermischt und in flüssigem Stickstoff eingefroren (SAMBROOK et al., 1989). Die Lagerung erfolgte bei $-80^{\circ} \mathrm{C}$.

\subsection{Salizylsäure Behandlung von Tabakpflanzen}

Die in Kapitel 4.1.1 beschriebenen Tabakpflanzen wurden nach vier bis sechs Wochen nach Ausbringen auf Erde vor der Entwicklung eines Blütenstandes geerntet. Hierzu wurden 4-6 der mittleren Blätter mit einem Skalpell abgetrennt und die Mittelrippe entfernt. Je nach Experiment muss die Menge an Blattmaterial berechnet werden: Für ChIP-Experimente ist eine Zellkernisolation erforderlich, die $10 \mathrm{~g}$ Blattmaterial pro Ansatz benötigt. Die weiteren Angaben beziehen sich auf die angegebene Menge für die ChIP-Experimente. Das Blattmaterial wurde in $500 \mathrm{ml}$ Weckgläser überführt und mit $500 \mu$ l Induktionspuffer (50 mM Kaliumphosphatpuffer pH 5.8 mit oder ohne $1 \mathrm{mM} \mathrm{SA}$ ) überschichtet. Durch Zusammenpressen der Blätter wurden überschüssige Luftblasen herausgedrückt. Die Induktion wurde zu unterschiedlichen Zeiten abgebrochen und die Blätter entweder direkt in flüssigem Stickstoff schockgefrostet und in Stickstoff gelagert oder sie wurden der weiteren Verarbeitung unterzogen.

\subsection{Formaldehyd-vermittelte Quervernetzung von Proteinen und DNA}

Die Ausbildung der von Formaldeyhd (FA)-vermittelten Vernetzung von Protein und DNA ist Grundvorraussetzung für den späteren Erfolg der ChIP und muss deshalb sehr sorgfältig erfolgen. Das aus Kapitel 4.2 erhaltene Blattmaterial wurde mit dem X-Puffer (50 mM Kaliumphosphatpuffer $\mathrm{pH} 5.8+1 \%$ Formaldehyd) überschichtet $(\mathrm{X}=$ englisch für „,crosslinking“") und beschwert. Wie in Kapitel 4.2 beschrieben, wurden auch hier die Luftblasen herausgerückt, damit der Puffer überall gleichmäßig eindringen konnte. Es erfolgte das Anlegen eines starken Vakuums für 5 min. Eine langsame Belüftung nach Ablauf der Zeit sorgte für die erste Infiltration des Gewebes. Ein weiteres Mal wurde nun für 5 min das Vakuum angelegt. Nach anschließender Belüftung erfolgte eine 10 minütige Ruhepause, wobei das Material ohne Beschwerung frei schwimmen kann. Nach Abgießen 
des X-Puffers folgte die Behandlung mit Q-Puffer, wobei $\mathrm{Q}=$ englisch für „quenching“ bedeutet. Er bestand ebenfalls aus $50 \mathrm{mM}$ Kaliumphosphatpuffer pH 5.8, enthielt aber zusätzlich $300 \mathrm{mM}$ Glycin. Das Blattmaterial wurde ebenfalls überschichtet und im Exsiccator für 5 min per Vakuum infiltriert. Es folgte eine fünf minütige Inkubation ohne Vakuum. Nach dem Q-Puffer wurde das Blattmaterial dreimal mit $\mathrm{H}_{2} \mathrm{O}_{\text {bidest. }}$ gewaschen und anschließend auf mehreren Lagen Küchenpapier getrocknet, bevor es in Alufolie als kleines Päckchen in flüssigem Stickstoff gelagert werden konnte.

\subsection{Isolierung von Zellkernen aus Tabak-Blattmaterial}

KEGLER et al (2004) beschreibt die Isolierung von Zellkernen aus Tabakblättern. Das Protokoll wurde jedoch in leicht abgewandelter Form verwendet und wird somit komplett angegeben. In einem 250ml Becherglas wurden $40 \mathrm{ml}$ NEB 1 (1 M Hexylenglykol, $0.25 \mathrm{M}$ Saccharose, $20 \mathrm{mM}$ TAPES pH $8.5\left(25^{\circ} \mathrm{C}\right), 10 \mathrm{mM} \mathrm{MgCl}_{2}, 0.15 \mathrm{mM}$ Spermin, $0.5 \mathrm{mM}$ Spermidin, $0.6 \% \mathrm{v} / \mathrm{v}$ Nonidet P-40, frisch dazu: $8 \mathrm{mM}$ ßs-Mercaptoethanol) vorgelegt. Die auf Stickstoff gelagerten Proben mit jeweils $10 \mathrm{~g}$ Blattmaterial wurden kurz mit einer Schöpfkelle zerstoßen und die so vorzerkleinerten Blätter in eine mit flüssigem Stickstoff vorgekühlte Kaffeemühle überführt. Die Zerkleinerung zu feinstem Pulver erfolgte für $15 \mathrm{~s}$. Mit einem ebenfalls in Stickstoff vorgekühlten Löffel wurde das Blattpulver in das jeweilige Becherglas überführt und auf dem Magnetrührer gerührt. Mitunter konnten die sich bildende Klumpen auch mit dem Löffel geschmeidig gerührt werden. Im Gegensatz zu nicht quervernetztem Material wird bei Formaldehyd-behandelten Blättern nie ein ganz flüssiger Brei enstehen. Nach 20 min jedoch sollte sich eine sämige Masse gebildet haben, die sich nun über zwei Lagen Miracloth filtern, bzw. auswringen lässt. Das Filtrat wurde nun in $40 \mathrm{ml}$ Zentrifugen-Röhrchen (Sorval RC5B Plus) überführt und bei $4^{\circ} \mathrm{C}$ im Rotor SS34 in der Sorvall RC 5B Plus für 5 min bei $311 \mathrm{x}$ g zentrifugiert. Der Überstand wurde danach zügig abgegossen, was eine gleichzeitige Präparation von höchstens sechs Proben zuließ. Durch Zugabe von $8 \mathrm{ml}$ NEB 2 (0.5 M Hexylenglykol, 0.25 M Sacchyrose, $20 \mathrm{mM}$ TAPES pH $8.5\left(25^{\circ} \mathrm{C}\right), 10 \mathrm{mM} \mathrm{MgCl}_{2}, 0.15 \mathrm{mM}$ Spermin, $0.5 \mathrm{mM}$ Spermidin, $0.6 \% \mathrm{v} / \mathrm{v}$ Nonidet P-40, frisch dazu: $8 \mathrm{mM}$ ß-Mercaptoethanol) und einem anschließendem Vortex-Schritt bei Stufe 3 wurde das sich gebildete Zellkernpellet gelöst und erneut 5 min zentrifugiert. Der Waschschritt wurde insgesamt mindestens 3 Mal wiederholt, bis das Pellet eine hellgrüne bis weiße Farbe angenommen hatte. Für den letzten Zentrifugationsschritt wurde das gelöste Pellet in ein $12 \mathrm{ml}$ Falcon-Röhrchen überführt für $5 \mathrm{~min}$ bei 701 x g zentrifugiert. Mit einem an die Wasserstrahlpumpe angeschlossenen Schlauch mit gelber Spitze konnte danach der Überstand sauber und ohne Rückstände abgezogen und das Röhrchen mit dem Zellkernpellet auf flüssigen Stickstoff schockgefrostet werden. Die Lagerung des Zellkernpellets erfolgte bei $-80^{\circ} \mathrm{C}$ nicht länger als ein halbes Jahr lagern. 


\section{5 Äquilibrierung von Phenol}

Phenol dient in erster Linie der Aufreinigung von Protein-DNA-Gemischen. Hierzu ist es nötig, das Phenol auf einen pH-Wert zu äquilibrieren, der keinerlei Einfluss auf die DNA ausüben kann, vorzugsweise pH 8.0. Da Phenol sehr aggressiv ist, ist das Tragen von Schutzkleidung unablässig. Das Phenol wurde in benötigter Menge abgemessen und mit $100 \mathrm{mM}$ Tris/HCl pH 8.0 in gleicher Menge versetzt. Auf dem Magnetrührer wurde die enstehende Emulsion für eine Stunde gerührt. Danach folgte eine zweistündige Ruhepause zwecks Phasentrennung. Die obere Tris-Phase konnte nun abgezogen werden und durch neues Tris/ $\mathrm{HCl}$ ersetzt werden. Diese Prozedur erfolgte insgesamt dreimal. Mit dem pHTeststreifen kann der pH-Wert kontrolliert werden.

\subsection{Moleklulargenetische Standardmethoden - Nukleinsäuren}

\subsubsection{Ethanolfällung von DNA}

Liegt eine wässrige Lösung von DNA in geringer Konzentration vor, so kann diese mittels Ethanol und Natriumacetat präzipitiert werden. Diese Technik eignet sich auch zur Abreicherung von Nukleotiden, z.B. nach einer PCR. Hierzu wird der DNA-Lösung 1/10 des Volumens an $3 \mathrm{M}$ Natriumacetat pH 3 zugegeben und gemischt. Anschließend wird das 2,5fache Volumen an reinem Ethanol zugefügt und sorgfältig vermischt. Die Fällung kann dann für $3 \mathrm{~h}$ bei $-80^{\circ} \mathrm{C}$ oder über Nacht bei $-20^{\circ} \mathrm{C}$ erfolgen. Anschließend wird die präzipitierte DNA für 30 min bei $4^{\circ} \mathrm{C}$ in der Tischzentrifuge mit $13.000 \mathrm{rpm}$ pelletiert, der Überstand abgezogen und das Pellet mit $70 \%$ Ethanol gewaschen. Nach erneuter Zentrifugation für $20 \mathrm{~min}$ bei RT und $13.000 \mathrm{rpm}$ wurde der Überstand abgezogen und das Pellet für $20 \mathrm{~min}$ bei $37^{\circ} \mathrm{C}$ getrocknet. Es konnte nun in $10 \mathrm{mM}$ Tris $/ \mathrm{HCl} \mathrm{pH} 7.4$ oder $\mathrm{pH} 8.0$ aufgenommen werden. Sollten sehr kleine Fragmente präzipitiert werden, so wurde eine zusätzliche Hilfe benötigt. Dazu kann Glycogen einer Endkonzentration $1 \mu \mathrm{g} / \mu \mathrm{l}$ hinzugegeben werden. Eine weitere hilfreiche Möglichkeit ist die Zugabe von „Pelletpaint“ der Firma Nunc. Die Mengenzugabe erfolgte dabei nach Herstellerngaben.

\subsubsection{Konzentrationsbestimmung von Nukleinsäuren}

Bei der Bestimmung des Nukleinsäure-Gehalts in wässrigen Lösungen wurde die Absorption bei Anregung durch UV-Licht bei $260 \mathrm{~nm}$ gemessen. Eine optische Dichte (OD) von 1,0 entspricht dabei einer Nukleinsäurekonzentration von $50 \mu \mathrm{g} / \mathrm{ml}$ bei doppelsträngiger DNA oder $40 \mu \mathrm{g} / \mathrm{ml}$ bei RNA. Die Messungen erfolgten im GeneQuant II der Firma Pharmacia. Das Gerät verfügt außerdem über die Option, die Absorption bei $280 \mathrm{~nm}$ parallel zu messen. Dies hat den Vorteil, dass der Quotient der beiden Werte $\mathrm{OD}_{260}$ sowie $\mathrm{OD}_{280}$ eine Aussage über mögliche Proteinkontaminationen zulässt. Bei $280 \mathrm{~nm}$ besitzen die aromatischen Seitenketten der Proteine ihr Absorptionsmaximum. Je weniger Proteine in 
der Lösung vorhanden sind, umso höher ist der Wert. Im Idealfall liegt er zwischen 1,8 und 2,0. Die DNA-Lösungen wurden für den Gene Quant II soweit verdünnt, dass die gemessenen Absorptionen zwischen 0,1 und 1,0 liegen.

\subsubsection{Auftrennung von DNA in Agarosegelen}

Zur Auftrennung von DNA wurden von der hauseigenen Werkstatt hergestellte horizontale Agarosegele mit den Maßen 10x7x0,3 cm verwendet. Je nach Bedarf standen verschiedene Kämme mit 12 oder 16 Taschen zur Verfügung. Als Lauf- sowie Agarosepuffer wurde 1xTAE verwendet (s. Kapitel 3.8). Wenn nicht anders angegeben, wurden 1\%ige w/v Agarosegele benutzt. PERLMANN und HALVORSON haben 1987 die Verwendung von 0,7\% $\mathrm{w} / \mathrm{v}$ Hydroxyethylcellulose im 1\% w/v Agaraosegel vorgeschlagen. Diese als HEC-Gele bezeichneten Agaraosegele liefern gerade für kleinere DNA-Fragmente ein deutlich verbessertes Aufösungsvermögen. Da DNA-Proben in wässrigen Lösungen vorliegen, müssen sie mit einem Ladepuffer versehen werden. Dieser besteht aus $67 \%$ Sucrose, $50 \mathrm{mM}$ EDTA $\mathrm{pH} 8.0$ und 0,42\% w/v Orange G. In anderen Puffern findet auch noch Bromphenolblau oder Xylenxyanol in gleicher Konzentration Verwendung. Nach Beladen der einzelnen Geltaschen wurde die DNA-Probe für den Zeitraum von 45-50 min bei 120 V elektrophoretisch aufgetrennt. Bei Verringerung der Volt-Vorgabe verlängerte sich der Lauf des Gels dementsprechend. Der Fortschritt der Auftrennung wurde mit der orangenen Bande beobachtet. Um die DNA im Gel sichtbar zu machen, wurde es für mind. 10 min in ein Ethidiumbromid-Bad $\left(1 \mathrm{mg} / \mathrm{l} \mathrm{H}_{2} \mathrm{O}\right)$ gelegt. Unter dem Transilluminator wird das Ethidiumbromid mit UV-Licht der Welenlänge $320 \mathrm{~nm}$ zur Emission von längerwelligem Licht angeregt, was mit der Geldokumentationsanlage aufgezeichnet werden kann.

\subsubsection{Auftrennung von DNA in Polyacrylamidgelen}

Wird ein feineres Auflösungsvermögen für DNA-Fragmente benötigt oder handelte es sich um radioaktive PCR-Fragmente, so ist die Auftrennung im 5\%igen Polyacrylamidgel (PAAG) nötig. Für die Auftrennung der radioaktiv markierten PCR-Fragmente wurde das gleiche Gelsystem verwendet, welches in Kapitel 4.10.6 bereits für die diskontinuierliche SDS-Polyacrylamid-Gelelekrophorese von Proteinen beschrieben wurde. Für ein natives PAAG wurde eine Lösung aus $5 \% \mathrm{w} / \mathrm{v}$ Acrylamid: N,N'-Methylenbisacrylamid, $10 \% \mathrm{w} / \mathrm{v}$, 1xTBE (0.1 M Tris, 0.1 M Borsäure, 2 mM EDTA) mit $0.04 \% \mathrm{v} / \mathrm{v}$ TEMED und 0,06\% v/v APS versetzt und in die vorbereiteten Glasplatten gegossen. Die Polymerisation des Gels betrug mindestens eine Stunde. Die radioaktiv markierten DNA-Fragmente werden mit Ladepuffer BX versehen und für ca. $6 \mathrm{~h}$ bei $40 \mathrm{~V}$ aufgetrennt. Nach erfolgter Demontage wird das Gel für eine Stunde bei $80^{\circ} \mathrm{C}$ im Geltrockner auf Whatman-Papier getrocknet. Die Detektion erfolgt danach durch Auflegen eines Phosphoimagerscreens. 


\subsubsection{Extraktion genomischer DNA aus Tabak}

Zur Extraktion genomischer DNA wurden 2 Blattscheiben mit dem Korkbohrer aus dem Blatt entnommen (ca.100 mg). Diese wurden mit $150 \mathrm{ml}$ Extraktionspuffer (200 mM Tris, $50 \mathrm{mM}$ EDTA, $2 \mathrm{M}$ Natriumchlorid, $2 \%$ Cetyltriammoniumbromid) in einem EppendorfReaktionsgefäß mit einem rotierenden Pistill zerstoßen. Nach Zugabe weiterer $500 \mathrm{ml}$ Extraktionspuffer wurde der Ansatz für $30 \mathrm{~min}$ bei $65^{\circ} \mathrm{C}$ im Heizschüttler inkubiert. Nach Zugabe von $600 \mathrm{ml}$ Chroroform: Isoamylalkohol (24:1) wurde der Ansatz für 2 min stark gevortext. Nach einem Zentrifugationsschritt bei $13.000 \mathrm{rpm}$ für $5 \mathrm{~min}$ bei RT wurde der Überstand abgezogen und in ein neues Eppendorf-Reaktionsgefäßüberführt. Es erfolgte die Zugabe von $500 \mathrm{ml}$ eiskaltem Isopropanol. Die Mischung des Ansatzes erfolgte über mehrmaliges vorsichtiges invertieren. Anschließend wurde der Ansatz für 5 min bei $13.000 \mathrm{rpm}$ zentrifugiert und der Überstand abgezogen. Das Pellet konnte nun mit $800 \mathrm{ml} 70 \%$ Ethanol gewaschen werden. Die Trockung des Pellets erfolgte entweder für $10 \mathrm{~min}$ im $37^{\circ} \mathrm{C}$ Schrank. Das getrocknete Pellet wurd nun in $100 \mu \mathrm{l} 10 \mathrm{mM}$ Tris/HCl pH 8.0 gelöst. Die Lagerung erfolgte bei $-20^{\circ} \mathrm{C}$.

\subsection{Chromatin-Immunopräzipitation}

\subsubsection{Isolierung des Chromatins}

Nach erfolgter Isolierung der Zellkerne aus $10 \mathrm{~g}$ Blattmaterial wurde das Pellet in $1 \mathrm{ml}$ Sonifizierungspuffer I (10 mM HEPES/NaOH pH 7.4, 1 mM EDTA, 0.5\% SDS, 1 \% ProteaseInhibitormix [Sigma-Aldrich]) aufgenommen und resuspendiert. Anschließend erfolgt eine 20 minütige Inkubation im Roller bei $4^{\circ} \mathrm{C}$. Nach Zugabe von $1 \mathrm{ml}$ Sonifizierungspuffer II (10 mM HEPES/NaOH pH 7.4, 1 mM EDTA, 1 \% Protease-Inhibitormix [Sigma-Aldrich]) und kurzer Durchmischung erfolgte das Scheren der DNA im Ultaschall-Sonifizierer. Die Ultraschall-Behandlung wurde durchgeführt in 4 Schritten mit einer jeweiligen Dauer von 20 s bei 12 ,amplitude microns“ (herstellereigene Bezeichnung). Hierzu wurden die Proben direkt in einem EtOH/Eisbad gekühlt. Die Lagerung der Proben zwischen den einzelnen Ultraschall-Durchgängen erfolgte auf normalen Eis. Bei durchschnittlich vier bis sechs Proben reicht die Pausierung auf Eis zwischen den einzelnen Schritten aus, um die Probe zu kühlen. Ansonsten ist eine Pausierung von mindestens einer Minute zu empfehlen. Der Ultraschall-Behandlung angefügt ist eine Zentrifugation in der Sorvall RC 5B Plus mit dem Rotor SS34 für $20 \mathrm{~min}$ bei $13176 \mathrm{x}$ g und $4{ }^{\circ} \mathrm{C}$. Dem Überstand wurde nun ein $50 \mu \mathrm{l}$ -Aliquot zur späteren DNA-Quantifizierung abgezogen (s. Kapitel 4.7.2). Die ChromatinProben werden in $500 \mu \mathrm{l}$ Aliquots auf Stickstoff schockgefrostet und wurden danach bei $-80^{\circ} \mathrm{C}$ bis zu sechs Wochen gelagert. 


\subsubsection{Bestimmung des DNA-Gehalts der Chromatin-Proben}

Vor der ChIP muss der Gehalt an DNA der einzelnen Chromatin-Proben bestimmt werden. Durch die Formaldehyd-Behandlung des Blattmaterials sind viele Proteine mit der DNA quervernetzt, was zur Folge hat, dass eine reine Quantifizierung nach $\mathrm{OD}_{260}$ nicht möglich ist, bzw. ungenau wäre. Aus diesem Grund wurde ein Reinigungsschritt mitsamt Fällung der DNA vorgenommen, um anschließend den Gehalt an DNA sehr genau am GeneQuant II bestimmen zu können. Hierzu wurden $50 \mu \mathrm{l}$ Aliquots direkt nach der Chromatin-Präparation von jeder Probe entnommen, mit Sonifizierungspuffer III $(10 \mathrm{mM}$ HEPES,NaOH pH 7.4, 1 mM EDTA, 0,25\% SDS) auf ein Gesamtvolumen von $450 \mu \mathrm{l}$ gebracht und mit $2 \mu \mathrm{l}$ Proteinase $\mathrm{K}(20 \mathrm{mg} / \mathrm{ml})$ vermischt bei $37^{\circ} \mathrm{C}$ für $1 \mathrm{~h}$ inkubiert. Eine anschließende Inkubation für $16 \mathrm{~h}$ bei $65^{\circ} \mathrm{C}$ im Wärmeschrank sorgte für eine Auflösung der Formaldehyhd-bedingten Quervernetzungen. Direkt im Anschluß wurde eine Mischung aus Phenol/Chloroform/Isoamylalkohol (25:24:1) im gleichen Probenvolumen hinzugegeben und für $30 \mathrm{~s}$ stark gevortext. Durch die sich anschließende fünfminütige Zentrifugation in der Tischzentrifuge bei $13.000 \mathrm{rpm}$ erfolgte die Phasentrennung. Der Überstand wurde komplett in ein neues Eppendorf-Gefäß überführt und mit gleichem Volumen Choroform/Isoamylalkohol (24:1) aufgefüllt und für 30s stark gevortext. Nach erneuter Zentrifugation unter gleichen Bedingungen wurde der Überstand in ein neues Reaktionsgefäß überführt. Durch den Zusatz von 1/10 Volumen 3 M Natriumacetat und 2,5 Volumen $100 \%$ igem Ethanol erfolgte die Präzipitation bei $-80^{\circ} \mathrm{C}$ für mindestens $3 \mathrm{~h}$. Durch die sich anschließende Zentrifugation für $45 \mathrm{~min}$ bei $4^{\circ} \mathrm{C}$ und $13.000 \mathrm{rpm}$ wurde die präzipitierte DNA pelletiert, sodass durch das Abschütten des $100 \%$ igen Ethanols und einer anschließenden Waschung mit $70 \%$ igen Ethanol sämtliche Salze aus dem Pellet herausgewaschen werden. Eine abschließende Zentrifugation bei $13.000 \mathrm{rpm}$ bei RT für 20 min pelletiert die DNA erneut. Mit einer Pipette kann der größte Teil an Überstand abgenommen und die Probe in der SpeedVac für 10 min oder wahlweise bei $37^{\circ} \mathrm{C}$ für 10 min eingetrocknet werden. Durch diesen Schritt werden alle in späteren Prozessen kontaminierend wirkenden Ethanolrückstände eliminiert. Das getrocknete Pellet konnte nun in $100 \mu \mathrm{l}$ DNA-Puffer $(10 \mathrm{mM}$ Tris $/ \mathrm{HCl} \mathrm{pH}$ 8.0) aufgenommen werden. Eine Inkubation für $10 \mathrm{~min}$ bei $65^{\circ} \mathrm{C}$ beschleunigt den Prozeß des Lösens der DNA. Eine Verdünnung von 1:10 mit $\mathrm{H}_{2} \mathrm{O}$ konnte nun direkt ohne störende Proteine oder RNA am GeneQuant II gemessen werden. Die gemessenen Konzentrationen bewegten sich dabei im Bereich von $0,80-0,250 \mu \mathrm{g} / \mu \mathrm{l}$.

\subsubsection{Protein A-Sepharose}

Für die Präzipitation der Antikörper-Protein-DNA-Komplexe wurde Protein A-Sepharose verwendet. Bei Protein A handelt es sich um ein Oberflächenprotein von Staphylococcus aureus, welches die Eigenschaft besitzt die $\mathrm{F}_{c}$-Domäne von Antikörpern zu binden. Diese Bindung ist reversibel und kann durch Detergenzbehandlung oder sauren pH-Werten aufgelöst werden. Bei der verwendeten Sepharose handelte es sich um Cyanogen-aktivierte 
Sepharose (=kugelförmige Agarose), die mit rekombinantem Protein A gekoppelt ist und lyophilisiert vorliegt. Ein vorheriges Quellen im Reaktionspuffer ist für den Gebrauch notwendig. Die Angaben über die Verwendung der Sepharose beziehen sich immer auf eine Lösung von 50 \% Beads (Kügelchen) im Puffer (engl.: $50 \%$ slurry). Das Volumen von gequollenen, trockenen $100 \%$ igen Beads wurde nach Herstellerangaben als „BettVolumen" bezeichnet. Pro ChIP-Ansatz werden ca. $100 \mu \mathrm{l}$ einer $50 \%$ Lösung an Beads inclusive Voraufreinigung benötigt, für einen Ansatz von 9 ChIP-Reaktionen somit ca. $1 \mathrm{ml} 50 \%$. Da $1 \mathrm{~g}$ Sepharose etwa $4 \mathrm{ml}$ fertiges Bettvolumen ergeben, müssen somit 0,125 g lyophilisierte Sepharose abgewogen werden. Das Quellen erfolgte für $30 \mathrm{~min}$ in $1 \mathrm{ml}$ RIPAPuffer (50 mM HEPES/NaOH, pH 7.4, $140 \mathrm{mM} \mathrm{NaCl,} 1 \mathrm{mM}$ EDTA, $1 \%$ Triton-X100, $0.1 \%$ Deoxycholat, $0.1 \%$ SDS) im Intellimixer bei $4{ }^{\circ} \mathrm{C}$. Die Beads wurden für $3 \mathrm{~min}$ bei $5000 \mathrm{rpm}$ bei RT abzentrifugiert, der Puffer mit einer Insulinspritze abgezogen und die Beads erneut mit $1 \mathrm{ml}$ RIPA für $10 \mathrm{~min}$ gewaschen und in der Zentrifuge pelletiert. Anschließend wurden $500 \mu$ l RIPA hinzugegeben und die Sepharose bis zur weiteren Verwendung auf Eis gelagert.

\subsubsection{Chromatin-Imunopräzipitation}

Die Menge an DNA pro ChIP betrug in der Regel $15 \mu \mathrm{g}$. Das berechnete Volumen an Chromatinprobe wurde mit Sonifizierungspuffer II auf $200 \mu \mathrm{l}$ aufgefüllt und mit $300 \mu \mathrm{l}$ RIPA (-SDS) auf ein Reaktionsvolumen von $500 \mu \mathrm{l}$ gebracht. Eine Voraufreinigung des Reaktionsansatzes erfolgte durch die Zugabe von $5 \mu$ l Prä-Immunserum bei einer Inkubation von $30 \mathrm{~min}$ bis zu einer Stunde bei $4{ }^{\circ} \mathrm{C}$ im Intellimixer. Hierzu wurde nach Möglichkeit jeweils das dem Antikörper-/serum entsprechende Prä-Immunserum verwendet. Lag kein geeignetes Prä-Immunserum vor, so wurde das Prä-Immunserum des $\alpha$ TGA2$\mathrm{C}$ verwendet. Die Zugabe von $50 \mu \mathrm{l}$ Protein A-Gebrauchslösung und eine anschließende Inkubation von 30 min bis zu einer Stunde sorgte für eine Antikörper-Depletierung des ChIP-Ansatzes. Dieser vorangestellte Schritt reduziert die spätere Kontamination mit unspezifisch an Sepharose gebundenen Proteinen und DNA. Eine kurze Zentrifugation mit $13.000 \mathrm{rpm}$ bei RT für $3 \mathrm{~min}$ in der Tischzentrifuge pelletierte die Sepharose und der Überstand wurde in neue Eppendorf-Gefäße überführt. Während der Voraufreinigung des ChIP-Ansatzes werden die Reaktionsgefäße für die eigentliche ChIP sowie das Quellen der Protein A-Sepharose vorbereitet. Pro ChIP-Ansatz wurden 4-5 $\mu$ l Antiserum oder affinitätsaufgereinigter Antikörper vorgelegt. Für Kompetitionsexperimente, bei welchen die spezifischen Antikörper des Serums durch rekombinantes Protein (Antigen) abgereichert werden und somit der Erkennung von endogenem Antigen nicht mehr zur Verfügung stehen, wurden dem Ansatz noch 30-40 $\mu \mathrm{g}$ rekominantes Protein hinzugefügt. Ein weiterer Ansatz mit 4-5 $\mu$ l Prä-Immunserum diente der Kontrolle mit unspezifischen Antikörpern. Während der Voraufreinung des Reaktionsansatzes konnten somit Antikörper und Antigen Kompetitionsansatzes miteinander reagieren. Nach Zugabe des Überstandes aus der Voraufreinung zum ChIP-Reaktionsansatz erfolgte eine vierstündige Inkubation bei $4{ }^{\circ} \mathrm{C}$ im Intellimixer mit dem Programm F1 Stufe 15. Nach Zugabe von $50 \mu$ l fertiger Protein 
A-Sepharose/Ansatz erfolgte eine erneute Inkubation für mindestens $1 \mathrm{~h}$. Nach der Inkubation werden die Ansätze für 3 min bei $5000 \mathrm{rpm}$ in der Tischzentrifuge pelletiert und der Überstand mit einer Insulinspritze abgezogen. Dabei wurde gleichfalls ein $50 \mu \mathrm{l}$-Aliquot des Immunserum-Ansatzes als spätere Input-DNA-Kontrolle abgenommen. Sie wurden bis zur weiteren Verwendung auf Eis gelagert. Das Sephaarose-Pellet wurde in $1 \mathrm{ml}$ RIPA resuspendiert und für 5 min bei RT im Intellimixer mit Programm F1 Stufe 15 inkubiert, danach wieder für $3 \mathrm{~min}$ bei $5000 \mathrm{rpm}$ pelletiert und der Überstand abgenommen. Dieser Waschschritt erfolgte insgesamt drei Mal. Beim abschließenden Waschschritt erfolgte die Resuspendierung des Pellets in $800 \mu \mathrm{l}$ RIPA samt gleichzeitiger Überführung in ein neues Eppendorf-Reaktionsgefäß. Nach erfolgteer Inkubation und Abnahme des Überstandes war das Sepharose-Pellet bereit für die Elution der Immunkomplexe.

\subsubsection{Elution der Antikörper-Protein-DNA-Komplexe (Immunokomplexe)}

Die Elution der Immunokomplexe erfolgte unter Verwendung eines sehr niedrigen pHWertes, wobei die Bindung von Protein $\mathrm{A}$ an die $\mathrm{F}_{c}$-Domäne des Antikörpers aufgelöst wurde. Es wurden pro ChIP-Ansatz ein Reaktionsgefäß mit jeweils $150 \mu \mathrm{l} 1 \mathrm{M}$ Tris pH 8.0 vorgelegt. Empfehlenswert ist eine maximale Elution von 4 Proben gleichzeitig. Pro Ansatz wurden $150 \mu$ l Elutionspuffer (100 mM Glycin pH 2.5, $500 \mathrm{mM}$ NaCL, 0.05\% Tween20) auf das Pellet gegeben, 30s stark gevortext und in der Tischzentrifuge bei $13000 \mathrm{rpm}$ für 1 min zentrifugiert. Der Überstand wurde mithilfe einer Insulinspritze direkt in den TrisPuffer überführt. Dieser Schritt erfolgte insgesamt zwei Mal, d.h. ein Gesamtvolumen von $450 \mu \mathrm{l}$ liegt nach erfolgteer Elution vor.

\subsubsection{Aufreinigung und Fällung der präzipitierten ChIP-DNA}

Die aus Kapitel 4.7.4 auf Eis gelagerten Input-Kontrollen wurden mit Sonifizierungspuffer III (10 mM HEPES/NaOH pH 7.4, 1 mM EDTA, 0,25\% SDS) auf ein Gesamtvolumen von ebenfalls $450 \mu \mathrm{l}$ gebracht. Alle Ansätze wurden mit $2 \mu$ l Proteinase K $(20 \mathrm{mg} / \mathrm{ml})$ vesehen. Den eluierten Immunokomplexe wurden zusätzlich $10 \mu$ l SDS (10\%) sowie $1 \mu$ l Glykogen $(10 \mathrm{mg} / \mathrm{ml})$ als Fällungshilfe zugegeben. Eine hilfreiche Alternative zu Glykogen ist die Zugabe von $1 \mu \mathrm{l}$ „Pelletpaint“ der Firma Nunc, da es das sehr kleine DNA-Pellet blau anfärbt und in späteren Reaktionen nicht stört. Es erfolgte eine Inkubation bei $37^{\circ} \mathrm{C}$ für $1 \mathrm{~h}$. Eine Aufösung der Formaldehyd-bedingten Quervernetzung fand statt durch eine Inkubation von etwa $16 \mathrm{~h}$ bei $65^{\circ} \mathrm{C}$ im Wärmeschrank. Die anschließende Aufreinigung der DNA erfolgte wie bereits in Kapitel 4.7.2 beschrieben. Die Aufnahme des getrockneten DNA-Pellets erfolgte in $40 \mu \mathrm{l}$ Lösungspuffer $(10 \mathrm{mM}$ Tris/HCl pH 8.0). Das Pellet der Input-Kontrolle wurde in $100 \mu \mathrm{l}$ Lösungspuffer gelöst. Für die sich anschließende PCR wurden $5 \mu \mathrm{l}$ ChIP-DNA bzw. $1 \mu \mathrm{l}$ Input-DNA eingesetzt. 


\subsection{Polymerasekettenreaktion PCR}

Das Vorgehen basierte auf den Protokollen von MULLIS und FALOONA (1987) und SAIKI et al. (1988). Die Reaktionen fanden zumeist in $25 \mu \mathrm{l}$ Gesamtvolumen statt und enthielten für die meisten Anwendungen folgende Komponenten: 1-10 ng Matrizen-DNA oder $5 \mu \mathrm{l}$ aus der ChIP, $0.4 \mu \mathrm{M}$ von jedem Primer, Taq-Puffer (Standard), $200 \mu \mathrm{M}$ eines jeden dNTPs und 2.5 U Advantage II-Polymerase Mix (Fa. BD-Science). Bei der Planung der PCR-Reaktion wurde den Empfehlungen von McPHERSON et al. (1995) gefolgt. Die Länge und Temperatur der einzelnen Schritte eines Zyklus sowie die Anzahl der Zyklen wurden durch die Wahl der Matrize, die Basenzusammensetzung und Länge der Primer sowie durch die Länge der zu amplifizierenden Sequenz bestimmt. Die Zyklen starteten nach einmaliger 2-minütiger Denaturierung bei $94^{\circ} \mathrm{C}$. Die anschließende Denaturierung erfolgtee in der Regel für $30 \mathrm{~s}$ bei $94^{\circ} \mathrm{C}$, das Primer-Annealing für $30 \mathrm{~s}$ (bei der für das jeweilige Primerpaar charakteristischen Temperatur; siehe unten) und die Elongation für $1 \mathrm{~min} / \mathrm{kb}$ bei $68^{\circ} \mathrm{C}$. Die Schmelztemperatur TM eines Oligonukleotides berechnete sich nach einer empirischen Formel, die sowohl den relativen molaren GC-Gehalt (\%GC), als auch die Länge der Oligonukleotide (n) berücksichtigt (BOLTON und McCARTHY, 1962): $\mathrm{TM}\left({ }^{\circ} \mathrm{C}\right)=69.3+0.41 \times(\% \mathrm{GC})-\left(\frac{650}{n}\right)$ Bei Differenzen zwischen den AnnealingTemperaturen der beiden Primer von mehr als $2{ }^{\circ} \mathrm{C}$ wurde die optimale Annealing-Temperatur TA für eine Polymerasekettenreaktion nach $\mathrm{TA}\left({ }^{\circ} \mathrm{C}\right)=\frac{\left(T M_{1}+T M_{2}\right)}{2}-3$

berechnet $\left(\mathrm{TM}_{1}\right.$ und $\mathrm{TM}_{2}=$ Schmelztemperaturen der beiden Primer $)$. Es wurden die Herstellerempfehlungen für die Polymerase übernommen. Bei der in Kapitel 5.5.1 vorgestellten PCR mit radioaktiv markiertem Nukleotid wurde dem Gesamtansatz der PCR $1 \mu \mathrm{l}$ $\alpha$-P ${ }^{3} 2$-dATP (Stammlösung $800 \mu \mathrm{Ci}$ ) zugefügt. Die Auftrennung der radioaktiven PCR erfolgtee im nativen $5 \%$ PAAG.

\subsection{Molekulargenetische Standardmethoden - Proteine}

\subsubsection{Aufreinigung von rekombinanten Proteinen aus E.coli}

Grundsätzlich wurden zwei unterschiedliche käufliche Protein-Expressionssysteme verwendet: Zum einen eine Variante, bei der das Protein durch einen 6fach HIS-tag ergänzt wurde (Fa. Qiagen), also einer hexameren Histidin-Wiederholfrequenz und zum anderen durch eine GST-markierte Version. Hierzu wurden die kodierenden Bereiche (C-terminus oder Volllängen-Bereich) in die jeweiligen Expressionsvektoren kloniert und in E.coli Expressionsstämme W3110 oder BL21 transformiert. Die Aufreinigung der Proteine erfolgtee nach den Herstellerangaben über eine Gelmatrix. 


\subsubsection{Herstellung von spezifischen Antiseren aus Kaninchen}

Vor der eigentlichen Immunisierung von Kaninchen durch die Firma Eurogentec (Belgien) wurden fünf Prä-Immunseren auf Kreuzreaktivität mittels Western-Blot-Analyse getestet. Es wurden daraufhin zwei Kaninchen ausgewählt, die weder mit denturiereten Harnstoffextrakten, noch mit nativen Chromatin-Proteinextrakten sowie dem Fusionsprotein eine Kreuzreaktivität im Detektionsbreich aufwiesen. Die Prä-Immunseren wurden dafür in einer Verdünnung von 1:1000 eingesetzt. Von den aufgereinigten Proteinen GST-2.1C, GST-2.2C (später als Antikörper „, $\alpha$ TGA2-C“ bezeichnet) bzw. GST-VP16 („, VP16“) wurden jeweils $125 \mu \mathrm{g}$ pro Injektion $(250 \mu \mathrm{g}$ als Mischung von GST-TGA2.1 und GSTTGA2.2) zur Auslösung der Immunantwort verabreicht. Nach 14, 28 und 56 Tagen wurden weitere Injektionen verabreicht. Nach 38 Tagen erfolgtee eine als „PP"bezeichnete kleine Blutentnahme, mit deren Serum ein erster Test der Immunantwort erfolgen konnte. Nach 60 Tagen erfolgtee die letzte Blutung. Der Test der Seren erfolgtee unter den gleichen Bedingungen wie die Tests der Präimmunseren. Es zeigte sich, dass die Immunantwort von Kaninchen SA 3958 am besten für den $\alpha$ TGA2-C ausfiel, für den $\alpha \mathrm{VP}$ zeigte das Serum des Kaninchens SA4134 die beste Detektion des angebotenen Antigens.

\subsubsection{Aufreinigung von Antikörpern aus Antiserum}

Zur Aufreinigung von Antikörpern aus einem Antiserum wurde eine Methode gewählt, bei der das Antigen, also das rekombinante Protein, gegen welches der Antikörper gerichtet ist, auf eine Matrix gekoppelt wurde und somit das Antiserum an spezifischen Antikörpern abgereichert wurde. Hierzu wurde eine Cyanogen-aktivierte Gelmatrix (Cn-Br activated Sepharose 4B der Firma Pharmacia) mit 2-5 mg rekombinanten Protein nach Herstellerangaben beladen, gewaschen und in eine Plastiksäule gegeben. Anschließend wurden die Beads mit 10fach (Beads)Volumen $10 \mathrm{mM}$ Tris $\mathrm{pH} 7.5$ gewaschen. Die nachfolgenden Waschschritte erfolgen durch Zugabe des Puffers mit anschließender Passage des Puffers ohne Hilfsmittel. Die Säule wurde nun nacheinander mit jeweils 10fach Volumen gewaschen: 100 mM Glycin pH 2.5, 10 mM Tris pH 8.8. Den pH-Wert der Säule kann man dabei immer per pH-Teststäbchen kontrollieren. Danach wurden mit $100 \mathrm{mM}$ Triethylamine $\mathrm{pH}$ 11.5 gewaschen gefolgt von einer Waschung mit $10 \mathrm{mM}$ Tris $\mathrm{pH}$ 7.5. Im Anschluß an die Waschungen ist die Säule bereit zur Aufnahme von Antikörpern. Hierzu wurde das für $10 \mathrm{~min}$ bei $13.000 \mathrm{rpm}$ abzentrifugierte Antiserum in einer 1:10 Verdünnung in $10 \mathrm{mM}$ Tris pH 7.5 eingesetzt. Die Inkubation kann für mindestens $4 \mathrm{~h}$ bei RT oder über Nacht im Intellimixer erfolgen. Das Serum, welches aus der Säule läuft konnte nun verworfen wurden, da sich keine spezifischen Antikörper mehr darin befinden sollten. Die Säule wurde nun mit 20fach Volumen $10 \mathrm{mM}$ Tris pH 7.5 und anschließend mit 20fach Volumen $500 \mathrm{mM}$ Natriumchlordid in $10 \mathrm{mM}$ Tris pH 7.5 gewaschen. Die Elution der Antikörper erfolgte mit der Zugabe von 10fach Volumen $100 \mathrm{mM}$ Glycin pH 2.5, wobei das Eluat in 1fach Volumen 1 M Tris pH 8.0 aufgefangen wurde. Die Regeneration der Säule erfolgte durch Waschung mit $10 \mathrm{mM}$ Tris pH 7.5. Die Lagerung der Säule konnte durch Zugabe 
von 0.02 Natriumazid in $10 \mathrm{mM}$ Tris $\mathrm{pH} 7.5$ erfolgen. Das Eluat wurde nun über Centricon 50-Säulen durch Zentrifugation bei $5000 \mathrm{x}$ g aufkonzentriert, bis ein Volumen von ca. $300 \mu \mathrm{l}$ entstanden ist. Dies kann mehrere Stunden dauern, weshalb die Verwendung von 2 Säulen zu empfehlen ist. Es erfolgte die Aufteilung des Antikörpers in $50 \mu$ l-Aliquots, welche in flüssigem Stickstoff schockgefrostet wurden. Anschließend erfolgte die Gefriertrocknung über Nacht. Das verwendete Protokoll findet sich bei HARLOW und LANE, (1999).

\subsection{Proteinextraktionsmethoden}

\subsubsection{Kernproteinextrakte, denaturierend}

Um denaturierende Kernproteinextrakte zu erhalten, wurde das aus Kapitel 4.4 erhaltene Zellkernpellet in $600 \mu \mathrm{l}$ Extraktionspuffer (4 M Harnstoff, 16,6\% v/v Glycerin, $5 \% \mathrm{w} / \mathrm{v}$ SDS, $5 \% \mathrm{v} / \mathrm{v}$ ß-Mercaptoethanol) resuspendiert und für $10 \mathrm{~min}$ bei $65{ }^{\circ} \mathrm{C}$ im Wasserbad inkubiert. Eine anschließende einminütige Ultraschallbehandlung scherte das Chromatin in kleine Fragmente und setzt so die Viskosität herab. Eine 20 minütige Zentrifugation bei $13000 \mathrm{rpm}$ in der Tischzentrifuge bei RT pelletierte die Zellbestandteile. Der Überstand wurde aliquotiert in neue Reaktionsgefäße und bei $-80^{\circ} \mathrm{C}$ eingefroren. Die Abschätzung der relativen Proteinmengen konnte bei dieser Extraktionsmethode lediglich auf der Basis eines Coomassie-gefärbten SDS-PAGE erfolgen (Abgleichgel). Hierfür wurden Volumina von 5-15 $\mu \mathrm{l}$ des Extraktes in einem SDS-PAGE aufgetrennt, gefärbt und anhand der Bandenstärke der relative Proteingehalt der einzelnen Proben untereinander nivelliert.

\subsubsection{Kernproteinextrakte, nativ}

Alle Arbeitsschritte sind bei $4^{\circ} \mathrm{C}$ durchzuführen. Das aus Kapitel 4.4 resultierende Zellkernpellet wurde in $4 \mathrm{ml}$ Lysispuffer $(110 \mathrm{mM} \mathrm{KCl,} 15 \mathrm{mM}$ HEPES pH 7.6, $5 \mathrm{mM} \mathrm{MgCl}$, $1 \mathrm{mM}$ DTT, $40 \mu \mathrm{l}$ Planzen-Proteinase-Inhibitormix [Sigma-Aldrich]) resuspendiert und mit dem Dounce-Homogenisator für eine Minute auf Eis homogenisiert. Nach Überführung in ein $25 \mathrm{ml}$ Becherglas mit Minirührfisch wurde 1/9 Volumen einer $4 \mathrm{M}$ Ammoniumsulfatlösung tröpfchenweise hinzugegeben. Die nach einer Stunde anschließende 30 minütige Zentrifugation im Rotor SS34 bei $20.000 \mathrm{x}$ g in der Sorvall pelletierte die Kernmembranen. Eine folgende Ultrazentrifugation im Rotor TFT 65.13 bei $55.000 \mathrm{rpm}$ in der Kontron Ultrazentrifuge sorgte für eine ausreichende Pelletierung der chromosomalen DNA. Der resultierende Überstand wurde wiederum im Becherglas langsam mit $0,37 \mathrm{~g} / \mathrm{ml}$ gemörsertem Ammoniumsulfat versetzt und über Nacht unter langsamen Rühren gefällt. Die Zentrifugation bei $16000 \mathrm{rpm}$ für $30 \mathrm{~min}$ pelletierte die gefällten Proteine, bzw. ließ sie als schmierigen Film oberhalb der flüssigen Phase erscheinen. Die Abnahme des überschüssigen Puffers erfolgte mit einer $10 \mathrm{~cm}$ langen Pasteurpipette. Das Pellet wurde in 100-200 $\mu$ l Dialysepuffer (100 mM KCl, 20 mM HEPES pH 7.6, $0.2 \mathrm{mM} \mathrm{EDTA,} 10 \%$ v/v 
Glycerin, 0,5 mM DTT) aufgenommen, gelöst und gegen 2x1 l Dialyspuffer über Nacht dialysiert. Eine Konzentrationsbestimmung erfolgte bei dieser Extraktionsmethode durch einen Bradford-Test.

\subsubsection{Denaturierende Gesamtzellextrakte aus Tabakblättern}

Für eine Präparation wurden ca. $100 \mathrm{mg}$ frisches Blattmaterial verwendet. Unter flüssigem Stickstoff wurde die Probe im Mörser zu einem Pulver zerrieben und ein EppendorfReaktionsgefäß bis zur Hälfte damit angefüllt. Dann wurden 300-400 $\mu$ l Extraktionspuffer (4 M Harnstoff, $16.6 \% \mathrm{v} / \mathrm{v}$ Glycerin, $5 \% \mathrm{v} / \mathrm{v}$ ß-Mercaptoethanol, $5 \% \mathrm{w} / \mathrm{v}$ SDS, $0.05 \%$ $\mathrm{w} / \mathrm{v}$ Bromphenolblau) hinzugegeben und stark gevortext, bis sämtliches Pulver gelöst war. Eine anschließende Inkubation für 10 min bei $65^{\circ} \mathrm{C}$ unter Schütteln löste die Proteine aus dem Zellverband. Durch eine 20 minütige Zentrifugation bei $13000 \mathrm{rpm}$ in der Tischzentrifuge wurden unlösbare Zellbestandteile pelletiert. Der Überstand wurde direkt abgenommen und bei $-80^{\circ} \mathrm{C}$ gelagert. Durch die Zusammensetzung des Protein-Extraktionspuffers ist eine Bestimmung der Proteinkonzentration durch den Bradford-Test nicht möglich. Zur Abschätzung relativer Proteinmengen bei verschiedenen Ansätzen wurde eine densiometrische Auswertung vorgenommen, bei der 5-15 $\mu$ l des Proteingemisches im SDS-PAGE aufgetrennt, in Coomassie gefärbt und anschließend die Bandenstärke einer ausgesuchten Bande in Relation zu den anderen gesetzt wurde. Zur genauen Kalkulation wurde das Gel gescannt und die Bandenstärke mit dem Programm TINA 2.0 bestimmt.

\subsubsection{Proteinextrakte für MUG-Assay}

2-3 Blattscheiben wurden in einem Eppendorf-Reaktionsgefäßmit $300 \mu$ l GUS-Extraktionspuffer (10 mM EDTA, $0.1 \%$ v/v Triton X-100, $0.1 \%$ v/v Sarcosyl, $0.05 \%$ v/v ß-Mercaptoethanol, $50 \mathrm{mM} \mathrm{NaHPO}_{4} \mathrm{pH}$ 7.0) überschichtet und durch Verwendung eines rotierenden Pistills homogenisiert. Die Zelltrümmer wurden für $15 \mathrm{~min}$ bei $13000 \mathrm{rpm}$ abzentrifugiert. Der Überstand konnte direkt für die Proteinbestimmung nach Bradford eingesetzt werden, bzw. ein MUG-Assay durchgeführt werden.

\subsubsection{Konzentrationsbestimmung von Proteinextrakten}

Proteine, die in gepufferten Lösungen ohne störende Agenzien wie Detergenzien vorliegen, können mit einem Konzentrationstest, der von BRADFORD (1976) entwickelt wurde, bestimmt werden. Der Test beruht auf der Verschiebung des Absorptionsmaximums von Coomassie Brilliant Blue G-250 vom Bereich $465 \mathrm{~nm}$ zu $595 \mathrm{~nm}$ nach dessen Bindung an Protein. Hierzu wurden Verdünnungen der Proteinlösung in einer 96er Miktotiterplatte auf insgesamt $160 \mu \mathrm{l}$ mit $\mathrm{H}_{2} \mathrm{O}$ augefüllt und mit $40 \mu \mathrm{l}$ konzentrierter Bradford-Reagenz (Roth) vermischt. Nach einer 3 minütigen Inkubation konnte die optische Dichte der Proben in Relation zu einem BSA-Standard (1, 4 und $8 \mu \mathrm{g}$ BSA) im Spektralphotometer (MRX Dyney Plate Reader) bestimmt werden. 


\subsubsection{Diskontinuierliche SDS-Polyacrylamid-Gelelektrophorese}

Bei der diskontinuierlichen SDS-Polyacrylamid-Gelelektrophorse werden Proteine unter denaturierenden Bedingungen in einem aus Sammel- und Trenngel bestehenden Polyacrylamidgel der Größe nach aufgetrennt (LAEMMLI, 1970). In der vorliegenden Arbeit wurden mehrere Gelsysteme verwendet. Zum einen fanden kleine Trenngele der Größe 9x6 cm Verwendung. Sie besitzen je nach verwendeten Kamm 10 oder 15 Taschen besitzen und können im System der Firma AGS verwendet werden. Des weiteren wurden Trenngele der Größe 18,5x7 cm verwendet (Eigenbau der Werkstatt). Die 2D-Gele wurden in Verbindung des Systems „Protean XL“ der Firma Bio-Rad benutzt. Die Gelzusammensetzung erfolgtee nach den Vorgaben aus SAMBROOK et al., (1989). Sofern nicht anders angegeben, wurden $10 \%$ PAA-Gele benutzt. Vor dem Auftragen wurden die Proben in einem SDS-PAGE-Puffer vermischt. Je nach Konzentration des aufzutragenden Proteins fanden zwei Pufferkonzentrationen Verwendung. 2X SDS-PAGE: 0.09 M Tris/HCl pH 6.8, $20 \%$ Glycerin, $2 \%$ SDS, $0.02 \%$ Bromphenolblau, 0.1 M DTT; 5X SDS-PAGE: $0.225 \mathrm{M}$ Tris/HCl pH 6.8, 50 \% Glycerin, $5 \%$ SDS, $0.05 \%$ Bromphenolblau, 0.25 M DTT. Die Proben wurden direkt vor der Auftragung für $5 \mathrm{~min}$ bei $95^{\circ} \mathrm{C}$ denaturiert. Harnstoffextrakte wurden ebenfalls einem Denaturierungsschritt unterzogen, jedoch musste hier kein Puffer hinzugeführt werden. Die elektrophoretische Auftrennung des Gels erfolgte bei 120-140 V für kleine Gele, bei 160-170 V für große Gele und bei konstanten 15-30 mA für 2D-Gele. Verwendet wurde 1X SDS-Laufpuffer (25 mM Tris, $192 \mathrm{mM}$ Glycin, 0.1\% w/v SDS. Als Proteinstandard wurde $6 \mu \mathrm{l}$ Prestained Protein Ladder (Fermentas) verwendet.

\subsubsection{Kolloidal-Coomassie-Färbung von Proteinen}

Die Färbung mit dem Coomassie Brilliant Blue G-250 Farbstoff bietet eine gute und reproduzierbare Detektion von Proteinen im SDS-PAAG. Das auf HERBERT et al (2001) aufbauende Protokoll benutzt eine Färbelösung (17\% w/v Ammoniumsulfat, $3 \% \mathrm{w} / \mathrm{v}$ Phosphorsäure, $0.1 \% \mathrm{w} / \mathrm{v}$ Coomassie Brilliant Blue G-250) wurde vor Gebrauch mit $34 \%$ $\mathrm{v} / \mathrm{v}$ Methanol aktiviert und zusammen mit dem Gel über Nacht auf der Wippe inkubiert. Die Entfärbung erfolgte mit 1\% v/v Essigsäure.

\subsubsection{Silberfärbung von Proteinen im SDS-Gel}

Die Silberfärbung bietet im Gegensatz zur Färbung mit Coomassie Brilliant Blue G-250 einen weitaus feineren Auflösungsbereich durch eine zehnfach höhere Empfindlichkeit. Mit ihr können Proteine bereits ab 5 ng nachgewiesen werden. BLUM et al (1987) entwickelte das Protokoll sowohl für Proteine als auch für RNA und DNA. Die Lösungen sollten alle frisch angesetzt werden, das Formaldehyhd aber immer erst kurz vor Gebrauch dazugegeben werden. Silbernitrat gehört gesondert entsorgt. Das SDS-PAAG wurde für mindestens 90 min in die Fixierlösung (50\% v/v Ethnaol, $12 \%$ Essigsäure, $0.05 \%$ Formaldehyd) gelegt und dabei bewegt. Bei Bedarf konnte auch bei $4{ }^{\circ} \mathrm{C}$ über Nacht fixiert werden. Es erfolgte anschließend eine Waschung von 3x20 min mit $50 \%$ Ethanol. Die Imprägnierung 
findet im Anschluß statt für $60 \mathrm{~s}$ mit dem Imprägnierungspuffer $\left(0.01 \% \mathrm{w} / \mathrm{v} \mathrm{Na} \mathrm{Na}_{2} \mathrm{O}_{3}-5\right.$ $\mathrm{H}_{2} \mathrm{O}$ (Natriumthiosulfat). Auch hier erfolgte eine Waschung von $3 \times 20 \mathrm{~s}$ mit $\mathrm{H}_{2} \mathrm{O}_{\text {bidest. }}$. Die Färbung wurde $20 \mathrm{~min}$ vorgenommen mit der Färbelösung $\left(0.1 \% \mathrm{w} / \mathrm{v} \mathrm{AgNO}_{3}, 0,075 \%\right.$ $\mathrm{v} / \mathrm{v}$ Formaldehyd) und anschließend für 3x20 s mit $\mathrm{H}_{2} \mathrm{O}$ bidest. gewaschen. Das Gel konnte nun mit der Entwicklerlösung $\left(3 \% \mathrm{w} / \mathrm{v} \mathrm{Na} \mathrm{CO}_{3}, 0.05 \% \mathrm{v} / \mathrm{v}\right.$ Formaldehyd, $2^{*} 10^{-4} \% \mathrm{w} / \mathrm{v}$ $\mathrm{Na}_{2} \mathrm{~S}_{2} \mathrm{O}_{3}-5 \mathrm{H}_{2} \mathrm{O}$ ) für 1-10 min, je nach Signalstärke, behandelt werden. Ist die Färbung ausreichend, muss sofort mit $10 \mathrm{mM}$ EDTA abgestoppt werden. Die Lagerung der Gele erfolgte in $\mathrm{H}_{2} \mathrm{O}_{\text {bidest. }}$ oder es folgt eine einstündige Behandlung mit $10 \% \mathrm{v} / \mathrm{v}$ in $\mathrm{H}_{2} \mathrm{O}_{\text {bidest. }}$. mit anschließendem Trocknen auf Whatman-Filter im Geltrockner.

\subsection{Western-Blot-Analyse}

\subsubsection{Semi-Dry Blotting von Proteinen}

Für die in dieser Arbeit gezeigten immunologischen Detektionen wurden Proteine ausschließlich nach der Semi-Dry-Blot Methode auf PVDF-Membranen übertragen (KYSE und ANDERSON, 1984). SDS-Gele (s.Kapitel 4.10.6 wurden hierfür für $15 \mathrm{~min}$ in Transferpuffer (s. Puffer und Lösungen Kapitel 3.8) inkubiert. Die zugeschnittenen WhatmanFilter sowie die PVDF-Membran (aktiviert in Methanol) wurden ebenfalls in Transferpuffer getränkt. Der Transfer erfolgte zwischen zwei Grafitplatten (Eigenbau der Werkstatt). Der Blot wurde in folgender Reihenfolge, von der Plus-Elektrode beginnend, aufgebaut: 3 Lagen Whatman-Filter, PVDF-Membran, SDS-PAAG, 3 Lagen Whatman-Filter. Der Transfer erfolgte bei konstanten $1 \mathrm{~mA}$ pro $\mathrm{cm}^{2}$-Membran für $85 \mathrm{~min}$. Anschließend wurde die Membran zwischen zwei Lagen Whatman-Filter für mindestens 45 min getrocknet. Die Banden des Farbmarkers können mit dem Antikörper-Markerstift im Anschluß markiert werden. Hierfür berührt man die Membran ganz leicht mit dem Stift. Der selbst hergestellte Stift enthält eine Mischung aus Kaninchen-Präimmunserum und 1xPBST im Verhältnis 1:1 sowie $0,02 \%$ Natriumazid und wurde bei $4{ }^{\circ} \mathrm{C}$ gelagert.

\subsubsection{Antikörper-Detektion von geblotteten Proteinen}

Die PVDF-Membran aus Kapitel 4.11.1 wurde kurz in Methanol aktiviert und über Nacht bei $4{ }^{\circ} \mathrm{C}$ oder mindestens $1 \mathrm{~h}$ bei RT in $5 \%$ Magermilchpulver in $1 \mathrm{x}$ PBST auf der Wippe inkubiert. Dieser Schritt sorgt für eine Blockierung freier Bindestellen der Membran. Direkt im Anschluß daran erfolgte die Inkubation der Membran mit dem Antikörper. Die verwendeten Antiseren $\alpha \mathrm{TGA} 2-\mathrm{C}, \alpha \mathrm{VP}$ sowie der affinitätsgereinigte Antikörper $\alpha 2.2 \mathrm{C}$ wurden in der Verdünnung 1:1000 eingesetzt in 0.5\% Magermilchpulver in 1xPBST. Die Inkubation erfolgtee bei RT für $2 \mathrm{~h}$. Daraufhin wurde die Membran für 4x5 min mit $25 \mathrm{ml}$ 1xPBST gewaschen und die Inkubation mit dem Antikörper $\alpha$ hobbit in der Verdünnung 1:25000 für eine Stunde durchgeführt. Überschüssige Antikörper wurden durch 5x5 min Waschungen mit $25 \mathrm{ml}$ 1xPBST entfernt. Im direkten Anschluß daran konnten die Antikörper mit dem Antikörper-Detektions-Kit ECL-Plus der Firma Amersham detektiert 
werden. Hierzu wurde direkt vor Applikation die Lösung A durch Zugabe von Lösung B im Verhältnis 40:1 aktiviert und auf die Membran gegeben und für 5 min bei RT inkubiert. Durch die Reaktion wurde eine Chemolumineszenz erzeugt, die mit einen Röntgenfilm (Cronex 10T) sichtbar gemacht werden konnte.

\subsection{Messung der ß -Glucuronidase (GUS)-Aktivität}

Der Nachweis der GUS-Reportergenaktivität erfolgte durch einen modifizierten GUSAssay (Jefferson et al., 1987). Der GUS-Assay erlaubt die Quantifizierung der Aktivität des Enzyms ß-Glucuronidase als Produkt des GUS-Reportergens. Auf diese Weise lässt sich indirekt die Aktivität des mit dem GUS-Gen fusionierten Promotors bestimmen. Neben natürlichen Substraten akzeptiert die ß-Glucuronidase auch künstliche Substrate. Verwendet man 4-Methylumbelliferyl-ß-Glucuronid (4-MUG), so wird nach Hydrolyse das fluoreszierende Produkt 4-Methylumbelliferyl (4-MU) freigesetzt, welches sich in einem Fluorimeter quantitativ bestimmen läßst. Die Reaktion wurde in Mikrotiterplatten durchgeführt. $100 \mu \mathrm{l}$ Proteinextrakt wurden in jeweils ein Well einer Mikrotiterplatte geben und je $100 \mu \mathrm{l} 4 \mathrm{mM}$ 4-MUG (gelöst in GUS-Ex-Puffer) zugefügt. Die Inkubation erfolgte bei $37^{\circ} \mathrm{C}$ im Dunkeln. Nach 15 min (die Enzymreaktion verläuft jetzt im linearen Bereich) wurde der Ansatz halbiert und die Enzymreaktion eines Halbansatzes durch Zugabe von $100 \mu \mathrm{l} 0.2 \mathrm{M} \mathrm{Na}_{2} \mathrm{CO}_{3}$ gestoppt. Die abgestoppten Ansätze dienten als $\mathrm{t}_{0}$-Wert der Reaktion. Der restliche Reaktionsansatz wurde bei $37^{\circ} \mathrm{C}$ für 60 min inkubiert und danach ebenfalls durch Zugabe von $0.2 \mathrm{M} \mathrm{Na}_{2} \mathrm{CO}_{3}$ abgestoppt ( $\mathrm{t}_{60}$ Wert). Die Mikrotiterplatte mit den Ansätzen wurde bis zur weiteren Auswertung bei $4{ }^{\circ} \mathrm{C}$ im Dunkeln aufbewahrt. Die Messung der Fluoreszenzwerte erfolgte automatisch mit dem Fluoreszenzmeßgerät Cytofluor der Firma Perseptive. Zur Eichung des Gerätes wurde bei jeder Messung ein Fluoreszenzstandard aus $10^{-6}-10^{-4}$ Verdünnungen einer $100 \mathrm{mM}$ 4-MU-Lösung in GUSStop-Puffer mitgemessen. Dabei wurde in der Probenlösung enthaltenes 4-MU bei einer Wellenlänge von $360 \mathrm{~nm}$ zur Fluoreszenz angeregt, die ihr Maximum bei $460 \mathrm{~nm}$ erreicht. Die relative Strahlungsintensität bei dieser Wellenlänge wurde vom Fluorimeter gemessen. Die GUS-Aktivität A wurde in pmol 4-MU min ${ }^{-1} \mathrm{mg}^{-1}$ Protein angegeben. Die Berechnung erfolgtee nach der Formel:

$$
A=\frac{\Delta F_{\left(t_{60}-t_{0}\right)}}{m_{\text {Protein }} \times t}
$$

wobei $\mathrm{A}=$ GUS-Aktivität (pmol 4-MU $\mathrm{min}^{-1} \mathrm{mg}^{-1}$ Protein), $\mathrm{t}=$ Zeit $(\mathrm{min}), \mathrm{m}_{\text {Protein }}$ = eingesetzte Proteinmenge (mg) im halbierten Ansatz, $F=$ Fluoreszenz $\left(t_{60}-t_{0}\right)$ des gebildeten 4-MU (pmol). Wurden hohe GUS-Aktivitäten erwartet, so wurde mit Verdünnungen der Proteinextrakte gearbeitet, um zu jedem Zeitpunkt der Reaktion eine Substratsättigung zu gewährleisten. Dies ist die Voraussetzung dafür, dass das Enzym ß-Glucuronidase immer mit maximaler Reaktionsgeschwindigkeit arbeitet und eine Abnahme der Substratmenge sich nicht begrenzend auf die zu bestimmende GUS-Aktivität auswirkt. 


\subsection{D-Gelelektrophorese (2D-GE)}

Bei der 2D-Gelelektrophorese handelt es sich um eine relativ neue Methode im proteinbichemischen Bereich, welches es dem Experimentatot möglich macht, Proteingemische nicht nur nach Molekulargewicht aufzutrennen, sondern die Proteine ihrem jeweiligen isoelektrischen Punkt - also einem speziellen pH-Wert - zuzuordnen. Für die vorliegenden Arbeiten wurden ausschließlich Geräte und Material der Firma Bio-Rad verwendet. Details über Material oder Geräte können dem Begleitheft „2D Electrophoresis for Proteomics - A Methods and Product Manual" entnommen werden. Weitere Protokolle können aus bei GÖRG (2003) entnommen werden.

\subsubsection{Probenaufbereitung}

Das aus Kapitel 4.4 vorliegende Zellkernpellet wurde einer speziellen Harnstoff-Extraktionsmethode für die 2D-PAGE unterzogen. Hierzu wurden $2 \mathrm{ml}$ Extraktionspuffer (8 M Harnstoff, $2 \mathrm{mM}$ Tributylphosphine, $4 \%$ CHAPS, $0.2 \%$ Transport-Ampholyte, $0.0002 \%$ Bromphenolblau) zum Pellet hinzugegeben und resuspendiert. Es erfolgte eine 20 minütige Inkubation auf Eis, wobei alle 5 min stark gevortext wurde. Mit einem „Dounce“-Homogenisator konnte nun das Chromatin geschert werden. Eine sich anschließende Zentrifugation bei RT in der Tischzentrifuge bei $13000 \mathrm{rpm}$ für 20 min sorgte für eine Pelletierung der Kernmembranen. Der aliquotierte Überstand konnte nun direkt für die isoelektrische Fokussierung eingesetzt oder einfach bei $-80^{\circ} \mathrm{C}$ eingefroren werden. Eine Konzentrationsbestimmung ist durch den Bradford-Test zur Konzentrationsbestimmung der Extrakte ist bedingt möglich, da Harnstoff stark mit dem verwendeten Coomassie-Farbstoff interagiert. Bei höheren Konzentrationen ist ein ungefährer Vergleich mit BSA-Proben, die ebenfalls Extraktionspuffer enthalten, möglich - jedoch nicht genau. Ein speziell für diese Anwendung konzipierter modifizierter Bradford-Test der Firma Bio-Rad ist käuflich zu erwerben.

\subsubsection{Isoelektrische Fokussierung (1. Dimension)}

Bei der isoelektrischen Fokussierung (IEF) werden die Proteine des bei Kapitel 4.13.1 hergestellten Proteingemischs auf einem pH-Gradienten-Gelstreifen nach ihrem isoelektrischen Punkt aufgetrennt. Der isoelektrische Punkt gibt den $\mathrm{pH}$-Wert an, bei dem die Summe der Ladungen eines Proteins gleich null ist. Das heißt, die Proteinen können im Gel bei Anlegung einer starken Spannung zu ihrem isoelektrischen Punkt wandern. Die IEF erfolgte in der IEF-Einheit, ein programmierbares Gerät mit Fassung für IEF-Gelträger verschiedener Länge. Für die Auftrennung des Kernproteoms wurden Gel-Streifen „PROTEAN Ready Gel precast gels" des pH-Wertes 3-10 (Katalog \# 163-2007) bzw. 3-10 NL (Katalog \# 163-2009) verwendet, wobei NL für nicht-linear steht, der pH-Gradient also in den Randbereichen eher progressiv ansteigt. Die Gelstreifen der Länge $17 \mathrm{~cm}$ liegen getrocknet vor und werden zusammen mit dem Proteinextrakt für $12 \mathrm{~h}$ bei $50 \mathrm{~V}$ rehydriert. Hierzu werden $300 \mu \mathrm{l}$ Gesamtvolumen an Proteingemisch in eine einzelne Tasche des Gelträgers pipettiert und auf die ganze Länge verteilt. Der Gelstreifen konnte nun 
von einer Seite her beginnend luftblasenfrei über das Proteingemisch gelegt werden. Die Überschichtung mit 1,5 ml Silikon-Mineralöl verhindert die Verdunstung der Probe. Mit einem Deckel wurde der Träger verschlossen und in der IEF-Einheit arretiert. Nach 5-7 Stunden ist bereits der gesamte Probenansatz in das Gel eingezogen und die Vorbereitung für die eigentliche IEF konnte beginnen. Hierzu werden die gequollenen Streifen aus dem Träger entnommen und kurz auf Whatman-Papier geblottet um das Öl abzustreifen. In eine neue Tasche des Trägers werden nun zwei kleine Stück Whatman-Filter (,electrode wicks") auf beide Elektroden gelegt, dass der Draht der Elektrode genau in der Mitte des

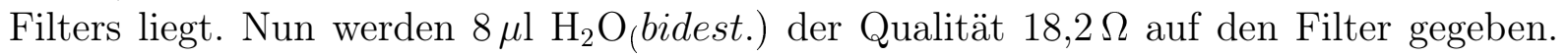
Diese Filter saugen später eventulell vorhandene Ionen auf, die das Laufverhalten der Proteine beeinflussen könnten. Der Gelstreifen wurde nun in die neue Tasche direkt auf die Elektrodenfilter gelegt, mit 1,5 ml Öl überschichtet und das Rehydrierungsprogramm weitergefahren. Die anschließende IEF beginnt mit einem Vorlauf von $2500 \mathrm{~V}$ für $15 \mathrm{~min}$. Für die IEF wurde ein linearer Anstieg von Zeit gegen Spannung gewählt, wobei allerdings keine Zeitvorgabe erfolgte, sondern das Integral beider Werte mit $50000 \mathrm{Vh}$ vorgebenen wurde. Nach Erreichen dieses Wertes werden die Proteine bis zur Weiterverwendung bei $500 \mathrm{~V}$ arretiert. Die fertigen Streifen können entweder sofort für 2. Dimension verwendet werden, oder bei $-80^{\circ} \mathrm{C}$ gelagert werden.

\subsubsection{Auftrennung nach Molekulargewicht (2. Dimension)}

Die Auftrennung in der 2. Dimension erfolgte nach dem Prinzip der in Kapitel 4.10.6 beschriebenen SDS-Gelelektrophorese. Die Proteine in den IEF-Streifen müssen jedoch speziell behandelt werden, damit ein Gellauf erfolgen kann. Hierzu werden die Streifen jeweils 10 min nacheinander in Äqulibrierungspuffer 1 (6 M Harnstoff, 0.375 M Tris pH8.8, $2 \%$ SDS, $20 \%$ Glycerin, $2 \mathrm{mM}$ Tributylphosphine) und danach in Äqulibrierungspuffer 2 (6 M Harnstoff, 0.375 M Tris pH8.8, 2\% SDS, $20 \%$ Glycerin, 2.5\% Jodacetamid) inkubiert. Danach können sie in die vorbereiteten SDS-PAAG eingebaut und mit flüssiger Agarose (0.5\% Agarose, 0.0002\% Bromphenolblau in 1x SDS-Laufpuffer aufgekocht) luftblasenfrei überschichtet werden. Der Gellauf erfolgte bei $15 \mathrm{~mA}$ für $30 \mathrm{~min}$ zum Einlaufen der Proteine und danach bei $30 \mathrm{~mA}$ bis zum gewünschten Zeitpunkt.

\subsubsection{Detektionsmöglichkeiten von Proteinen in 2D-Gelen}

Nach erfolgter Auftrennung durch die 2. Dimension konnte nun das Gel mit den Proteinen diversen Nachweismethoden unterworfen werden. Zum einen bietet sich die CoomassieFärbung nach der klassischen Methode oder der sensitiveren kolloidalen Variante an. Bei weniger abundanten Proteinen liefert die Silberfärbung (Kapitel 4.10.8 eine weitaus feinere Auflösung. Ebenfalls können die Proteine wie in Kapitel 4.11 beschrieben auf eine PVDFMebran geblottet wurden und einer Immuno-Detektion nach Kapitel 4.11.2 unterzogen wurden. 


\section{$5 \quad$ Ergebnisse}

\subsection{Herstellung eines Antiserums gegen die C-termini von TGA2.1 und TGA2.2}

Um das Bindungsverhalten der TGA-Faktoren zu untersuchen, wurde ein Antiserum benötigt, welches sowohl in der Western-Detektion als auch in der ChIP verlässliche Ergebnisse liefert. Zur Detektion der TGA-Faktoren TGA2.1 und TGA2.2 wurde der hochkonservierte C-Terminus inklusive der bZIP-Domäne als Antigen ausgewählt. Vortests mit fünf Prä-Immunseren per Western-Analyse von denaturierten Harnstoffextrakten, Chromatinextrakten und rekombinanten Protein zeigten, dass für die Kaninchen SA4284 und SA4286 kaum nachweisbare Kreuzhybridisierungen detektierbar waren. Sie wurden für die Immunisierung ausgewählt. Nach Expression der von NICKOLOV (2002) beschriebenen GST-Expressionsvektoren in E.coli BL21 wurde das Antigen über Glutathion-Sepharose affinitätsaufgereinigt. Die Eluate der Aufreinigung wurden über ein $10 \%$ SDS-PAAG aufgetrennt und mit Kolloidal-Coomassie gefärbt. Es zeigte sich, dass das Antigen nicht degradiert war (Daten nicht gezeigt). Über die parallele Auftragung eines BSA-Standards wurde die Konzentration des Antigens ermittelt und im Bradford-Test bestätigt. Die Immunisierung der Kaninchen erfolgte mit einer Mischung beider Antigene mit jeweils $125 \mu \mathrm{g}$ Protein, also $250 \mu \mathrm{g}$ pro Injektion, und wurde durchgeführt nach Standard-Protokoll der Fa. Eurogentec (Seraing, Belgien). 


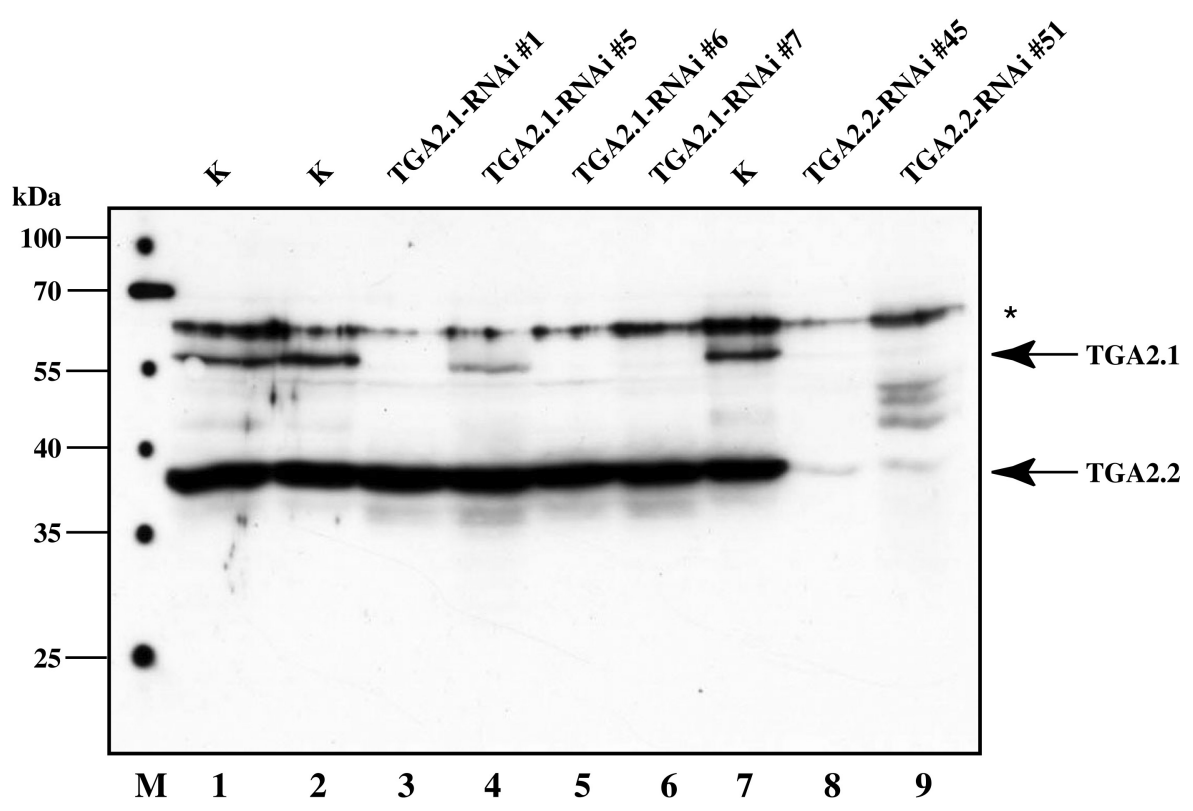

Abbildung 5.1: Western-Blot-Analyse von denaturierten Zellkern-Proteinextrakten mit Antiserum $\alpha$ TGA2-C. Die Quantifizierung der Extrakte erfolgte über ein Coomassie-gefärbtes Abgleichgel. Von der schwächsten Konzentration wurden $15 \mu \mathrm{l}$ und entsprechende Äquivalente aufgetragen. Verwendet wurden Extrakte der Pflanzenlinien SNN as-1::GUS (K), SNN TGA2.1-RNAi und SNN TGA2.2-RNAi. Die Auftrennung der Proteine erfolgte im $10 \%$ SDS-PAAG. Die Proteine wurden daraufhin per Western-Blot auf eine PVDF-Membran übertragen und die Immundetektion mit Antiserum $\alpha$ TGA2-C (1:1000 Verdünnung in $0.5 \%$ Milchpulver/PBST) durchgeführt. Das Sternchen markiert unspezifische Kreuzhybridisierungen des Antikörpers mit unbekannten Proteinen.

Abb. 5.1 zeigt eine Western-Analyse des Serums der finalen Blutung von Kaninchen SA4284, welches die beste Immunantwort lieferte. Für die Western-Blot-Analyse wurden jeweils abgeglichene Harnstoffextrakte aus SNN as-1::GUS, sowie SNN TGA2.1-RNAi und SNN TGA2.2-RNAi (THUROW et al., 2005) über ein $10 \%$ SDS-PAAG aufgetrennt und auf PVDF-Membran geblottet. Die Immundetektion erfolgte mit dem Serum TGA2-C. In den Spuren der Kontrollen SNN as-1::GUS 1,2 und 7 (Abb. ??) sieht man zwischen der 35 und 40kDa-Bande ein hochabundantes Protein. In den SNN TGA2.1-RNAi-Linien ist es im Gegensatz zu den SNN TGA2.2-RNAi ebenso vorhanden. Dies deutet daraufhin, dass es sich bei dem Protein um TGA2.2 handelt, welches außerordentlich gut vom Antikörper erkannt wird (s. Pfeil TGA2.2). TGA2.1 (s. Pfeil) wird ebenso in den Spuren 1, 2 und 7 erkannt, fehlt aber in den TGA2.1-RNAi-Linien. Auffällig hierbei ist auch das Fehlen des TGA2.1 in den TGA2.2-RNAi-Linien. Es scheint, dass durch den RNAi-Ansatz die Expression verwandter Faktoren unterbunden wird (THUROW et al., 2005). 
Das Serum SA4284 zeigte sich in späteren Experimenten als ChIP-tauglich (s. Kapitel 5.6 und wurde als TGA2-C bezeichnet.

NIGGEWEG et al. (2000b) konnten zeigen, dass $80 \%$ des as-1-bindenden SARP aus TGA2.2 bestehen. Die restlichen $20 \%$ fallen TGA2.1 und eventuell weiteren, unbekannten Komponenten zu. Das in Kapitel 5.1 hergestellte Antiserum wurde für den Großteil der ChIP-Experimente verwendet. Es ist gegen die hochkonsvervierten C-Termini der TGAFaktoren TGA2.1 und TGA2.2 gerichtet und erkennt beide Proteine gleichermaßen. Dies konnte von THUROW et al. (2005) durch Immunodetektion von E. coli-Extrakten gezeigt werden. In Abb. 5.1 ist eine Immundetektion von dentaurierten Zellkernextrakten abgebildet, welche ebenso die prozentuale Verteilung der beiden Faktoren wiedergibt, wie sie NIGGEWEG et al. (2000b) für Supershift-Analysen und Western-Blot-Analysen von aufgereinigtem SARP beschrieben hat. Es ist davon auszugehen, dass die gefundenen Ergebnisse der ChIPs mit dem Antiserum $\alpha$ TGA2-C die Beteiligung von beiden Faktoren widerspiegeln. Aus diesem Grund werden die Ergebnisse der ChIP-Experimente nicht allein auf ein Protein, sondern auf die Klasse-2-TGA-Faktoren („TGA-K2“) zurückgeführt.

\subsection{Herstellung eines Antiserums gegen die Aktivierungsdomäne VP16 aus Herpes simplex}

Für die in Kapitel 5.6.5 beschriebenen Experimente mit transgenen Tabakpflanzen SNN TGA2.2-VP16 wurde ein Serum benötigt, welches in der Lage ist, die Aktivierungsdomäne VP16 aus Herpes simplex zu detektieren. Zu diesem Zweck wurde ein GSTExpressionsvektor kloniert (bereitgestellt von C.Thurow, unveröffentlicht) und in E.coli BL21 transformiert. Durch eine Affinitätsaufreinigung des Proteins über Glutathion-Sepharose wurde eine erste Aufreinigung vorgenommen und die erhaltenen Eluate mittels eines $10 \%$ SDS-PAAG aufgetrennt und mit Kolloidal-Coomassie gefärbt. Es zeigte sich, dass ein zusätzliches Protein mit einem Molekulargewicht von etwa $34 \mathrm{kDa}$ auftrat (s. Abb. 5.2). Hierbei kann es sich um ein Zwischenprodukt handeln, welches entweder durch Proteindegradation oder durch ein zweites Start-Codon im Konstrukt entstanden sein kann. Um GST handelt es sich nicht, da GST ein Molekulargewicht von etwa $25 \mathrm{kDA}$ besitzt. Für die Immunisierung musste eine weitere Aufreinigung erfolgen. 


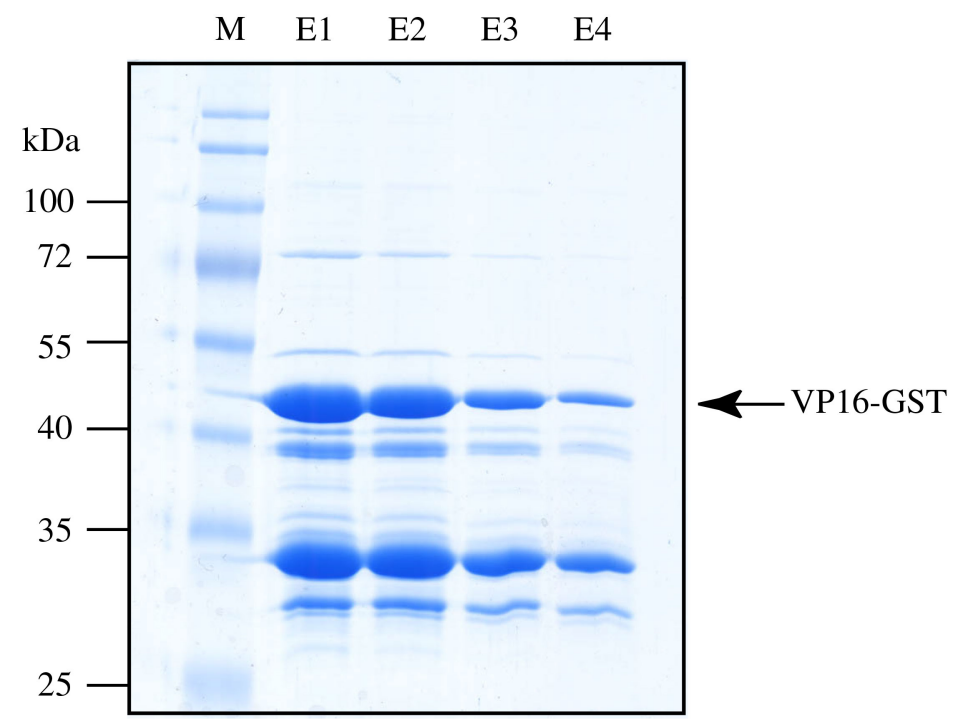

Abbildung 5.2: Analyse von affinitätsaufgereinigtem Protein VP16-GST. Nach Aufreinigung über Glutathion-Sepharose wurden je $5 \mu \mathrm{l}$ der Eluate E1-E4 VP16-GST im $10 \%$ SDS-PAGE aufgetrennt. Die Anfärbung der Proteine erfolgte durch Kolloidal-Coomassie

Daher wurden die Eluate zusammengeführt und in einem großen $10 \%$ SDS-PAAG erneut elektrophoretisch aufgetrennt, mit Kolloidal-Coomassie gefärbt, die abundante Proteinbande auf der rechnerischen Höhe des Molekulargewichts des VP16-GST (etwa 45 kDa) ausgeschnitten und einer Elekroelution unterzogen. Die Auftrennung über ein $10 \%$ SDSPAAG mit anschließender Coomassie-Färbung zeigte keine Degradation (Daten nicht gezeigt). Die Proteinkonzentration wurde im Anschluss mittels Bradford-Test ermittelt. Wie schon in Kapitel 5.1 beschrieben, wurden pro Injektion $125 \mu \mathrm{g}$ Protein eingesetzt. Die Immunisierung erfolgte ebenso bei Fa. Eurogentec (Seraing, Belgien). Das Serum aus der letzten Blutung wurde mittels Western-Blot-Analyse untersucht. Hierfür wurde ein SDSPAAG mit Chromatinextrakten aus SNN TGA2.2-VP16 F1, SNN TGA2.2-VP16 F2 sowie rekominanten Protein als Antigen beladen. Als Negativkontrolle wurde ein Chromatinextrakt aus SNN as-1::GUS verwendet (s. Abb. 5.3). 


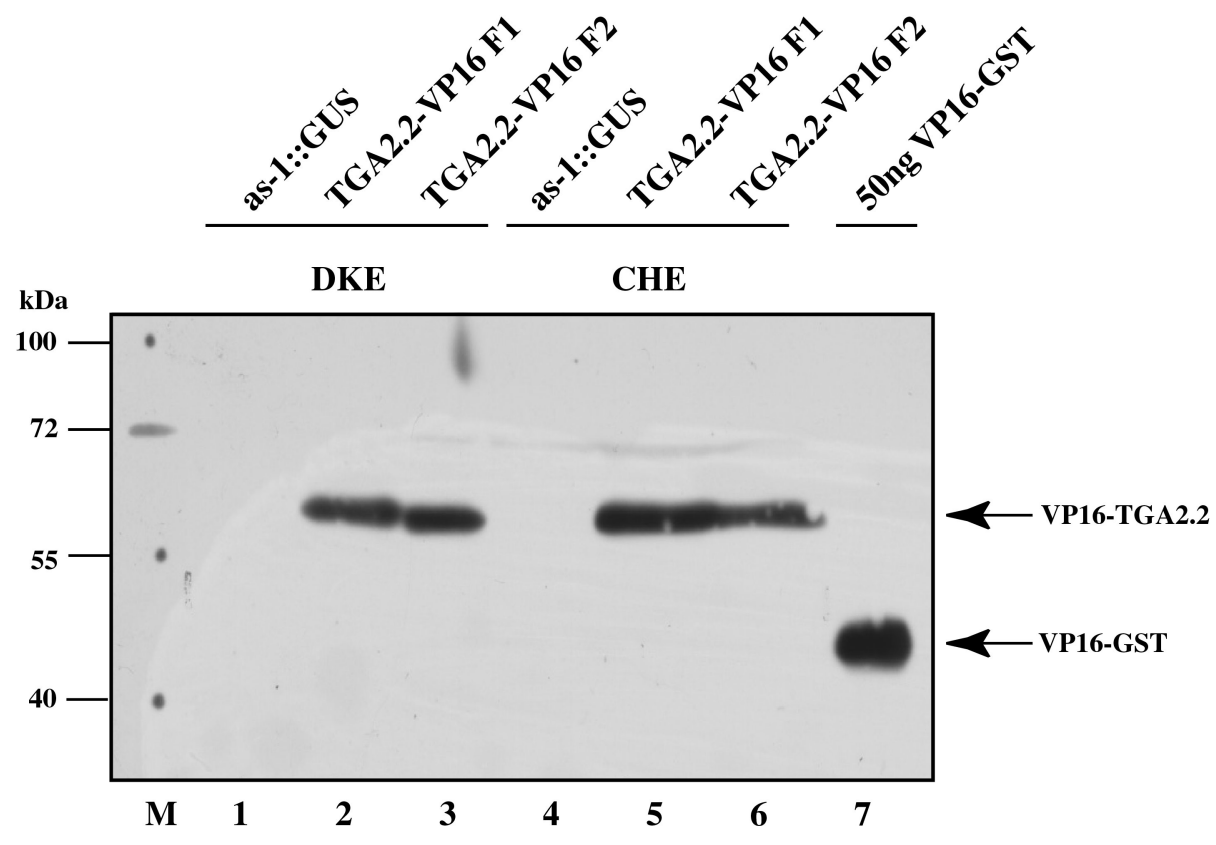

Abbildung 5.3: Western-Blot-Analyse von denaturierten Zellkern-Proteinextrakten (DKE), Chromatinextrakten (CHE) sowie rekombinanten Protein mit Antiserum $\alpha$ VP16. Die Quantifizierung der Extrakte erfolgte über ein Coomassie-gefärbtes Abgleichgel. Von der schwächsten ermittelten Konzentration wurden $15 \mu \mathrm{l}$ und entsprechende Äquivalente aufgetragen. Verwendet wurden Extrakte der Pflanzenlinien SNN as-1::GUS, SNN TGA2.2-VP16 F1, SNN TGA2.2-VP16 F2 und 50 ng rekombinantes Protein VP16-GST. Die Auftrennung der Proteine erfolgte im $10 \%$ SDS-PAAG. Die Proteine wurden daraufhin per Western-Blot auf eine PVDF-Membran übertragen und die Immundetektion mit Antiserum $\alpha$ VP16 (1:1000 Verdünnung in $0.5 \%$ Milchpulver/PBST) durchgeführt. 


\subsection{Die Chromatin-Immunopräzipitation}

\subsubsection{Grundlagen}

Die grundlegende Technik, die in dieser Arbeit etabliert und angewendet wurde ist die Chromatin-Immunopräzipitation (ChIP). Sie liefert dem Experimentator eine neue Technik, mit deren Hilfe es möglich ist, Protein-DNA-Interaktionen in vivo nachzuweisen. Als zentraler Punkt dieser Technik ist, dass Formaldehyd die Eigenschaft besitzt, DNAassoziierte Proteine z.B. Transkriptionsfaktoren, kovalent mit der gebundenen DNA zu vernetzen. Ferner können auch Protein-Protein-Interaktionen kovalent vernetzt werden (engl. ,crosslinking“"oder „X“; ORLANDO et al. 2000). Das sehr reaktive dipolare Formaldehyd besitzt ein zentrales Kohlenstoffatom, welches als nucleophiles Zentrum vorliegt. Amino- und Iminogruppen der Aminosäure Lysin, Arginin und Histidin sowie vornehmlich Adenin und Cytosin der DNA bilden über Formaldehyd eine Schiffsche Base aus. Dieses Zwischenprodukt kann nun mit sekundären Aminogruppen bis hin zur Ausbildung eines DNA-Protein-Komplexes reagieren (McGHEE und VON HIPPEL, 1975a, McGHEE und HIPPEL, 1975b). Der Vorteil von Formaldehyd liegt hauptsächlich in der Möglichkeit der Vernetzungs-Reversion, d.h. durch eine Hitzebehandlung werden die Protein-DNAQuervernetzungen aufgehoben. Ein ausführliches Protokoll findet sich im Methodenteil unter Kapitel 4.3 

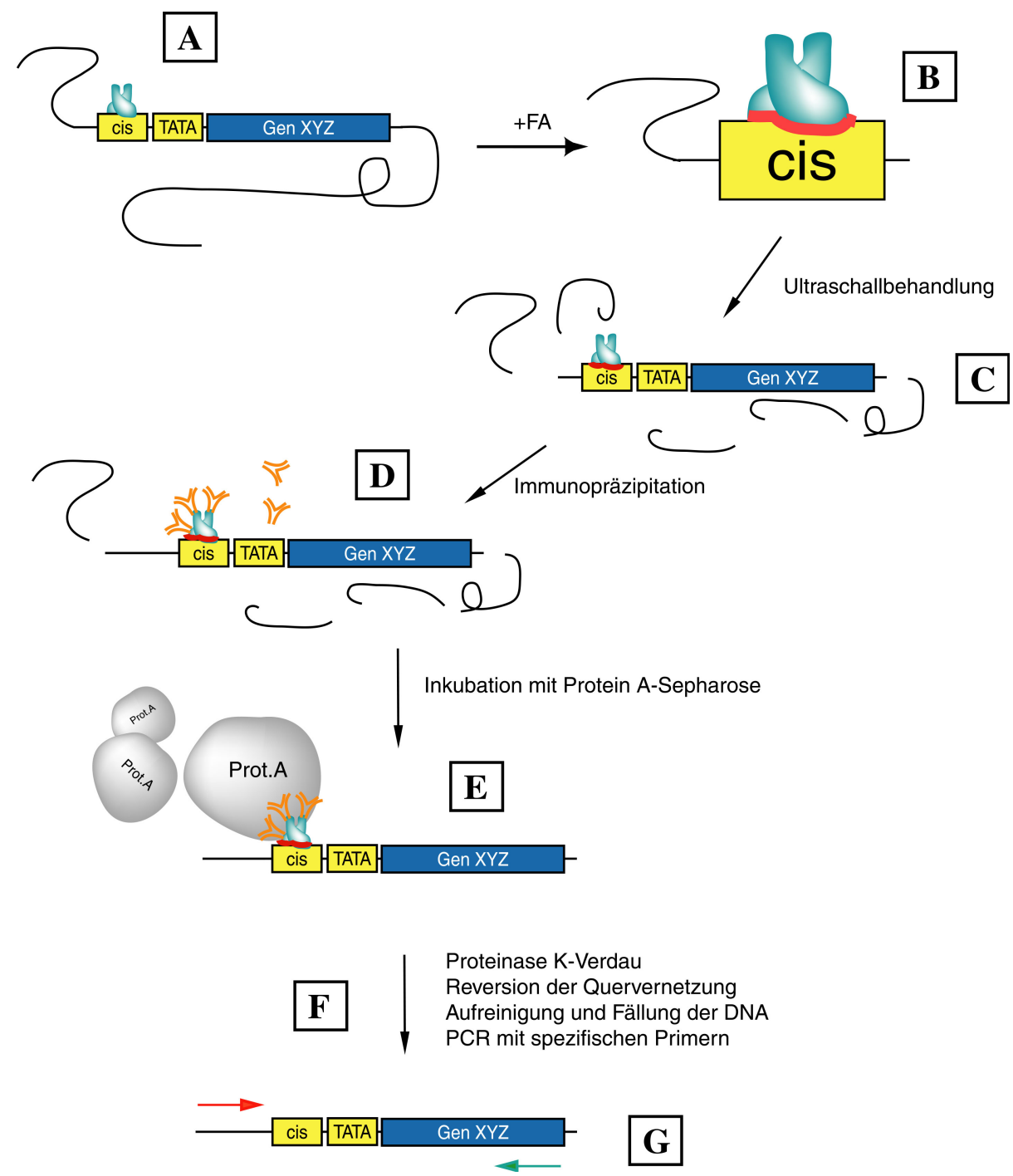

Abbildung 5.4: Prinzip der Chromatin-Immunopräzipitation (ChIP) am Beispiel der Besetzung des Gens XYZ (bestehend aus cis-Element, TATA-Box und Kodierregion) durch ein Protein. (A,B): Das Protein (grün) bindet das cis-Element und wird durch Behandlung mit Formaldehyd (FA) mit der DNA quervernetzt. (C): Nach Präparation des Chromatins wird durch Ultraschall-Behandlung das Chromatin in kleine Fragmente geschert. (D): Erkennung des Proteins durch Inkubation mit spezifischen Antikörpern. (E): Präzipitation des Antikörper-Protein-DNA-Komplexes durch Protein A-Sepharose. (F): Aufreinigung und Fällung der präzipitierten DNA (G): PCR mit spezifischen Primern, welche das cis-Element flankieren. 
In der vorliegenden Arbeit wurde die in vivo-Bindung der bZIP-Transkriptionsfaktoren TGA2.1, TGA2.2 und TGA2.2-VP16 (LENK, 2001) am as-1-Element sowie an Promotorelementen von frühen und späten Genen (s. Kapitel 2.6) nach Salizylsäurestimulus untersucht. Hierzu wurde mit transgenen Tabaklinien der Kultivare SNN und W38 gearbeitet, die ein Reportergenkonstrukt bestehend aus dem as-1-Element fusioniert mit einem Minimalpromotor (TATA-Box) und dem GUS-Reportergen tragen. Sie werden als SNN as-1::GUS und W38 $\Delta 35 \mathrm{~S}:$ :GUS bezeichnet. Ferner wurden doppelt transformierte SNN-Pflanzen verwendet, die nebem dem as-1::GUS-Reportergenkonstrukt noch das Konstrukt 35S::TGA2.2-VP16 enthielten (LENK, 2001). Sie exprimierten den TGA2.2 mit der starken Aktivierungsdomäne VP16 aus Herpes simplex unter Kontrolle des 35SPromotors.

Die Pflanzen wurden nach Standardbedingungen kultiviert und geerntete Blätter mit $1 \mathrm{mM}$ Salizylsäure (SA) (vgl. Kapitel 4.2) behandelt. Die Quervernetzung erfolgte durch Vakuuminfiltration mit einem formaldehydhaltigen Puffers nach Kapitel 4.3. Nach erfolgter Zellkernisolation und Chromatinextraktion konnte die ChIP mit verschiedenen Antiseren durchgeführt und die erhaltenen DNA-Fragmente über PCR mit sequenzspezifischen Primern amplifiziert werden.

\subsubsection{Formaldehyd-Quervernetzung}

Die mit SA induzierten Blätter wurden wie beschrieben in Kapitel 4.3 über Vakuuminfiltration mit Formaldehyd behandelt. Dieser Prozess ist für den Erfolg der ChIP von entscheidener Bedeutung. Ein Übermaß an Quervernetzung führt zu einer Assoziation des Chromatins mit der Zellkernmatrix und kann die nachfolgende Chromatin-Ausbeute reduzieren. Hochmolekulare Komplexe sind nicht mehr in der Lage, in Lösung zu gehen. Findet eine verringerte Quervernetzung statt, so werden in der späteren ChIP weniger Fragmente präzipitiert und somit liegt weniger Ausgangsmaterial für die anschließende PCR-Analyse vor (ORLANDO, 2000). Da in der Arbeit mit Blattmaterial gearbeitet wurde, musste die Quervernetzung durch empirische Tests ermittelt werden. Im Gegensatz zu Suspensionskulturen (JOHNSON, et al (2001)), befinden sich Blätter in verschiedenen Entwicklungszuständen. Es spielen Faktoren wie Licht, Luftfeuchtigkeit und Pflege eine große Rolle. Kleine Veränderungen sorgen bereits für eine gewisse Inhomogenität des Materials, so ist z.B. ist die Kutikula bei stärkerem Licht mehr ausgeprägt. Aber auch der physiologische Zustand der Pflanzen kann im Vergleich zu schwachem Licht bei starkem 
Licht anders sein. Für erste Tests wurde zunächst eine Inkubationsdauer des Blattmaterials mit Formaldehyd von 10 min aus der Literatur übernommen (JOHNSON et al. 2001). Als Kontrolle des Quervernetzungs-Ereignisses kann die DNA der Chromatinextrakte in einem Agarosegel aufgetrennt und begutachtet werden. Hierzu wurden Aliquots von quervernetztem Chromatin gegen Chromatin aufgetragen, bei welchem die Quervernetzung durch Wärmebehandlung aufgehoben wurde (Abb. 5.5).
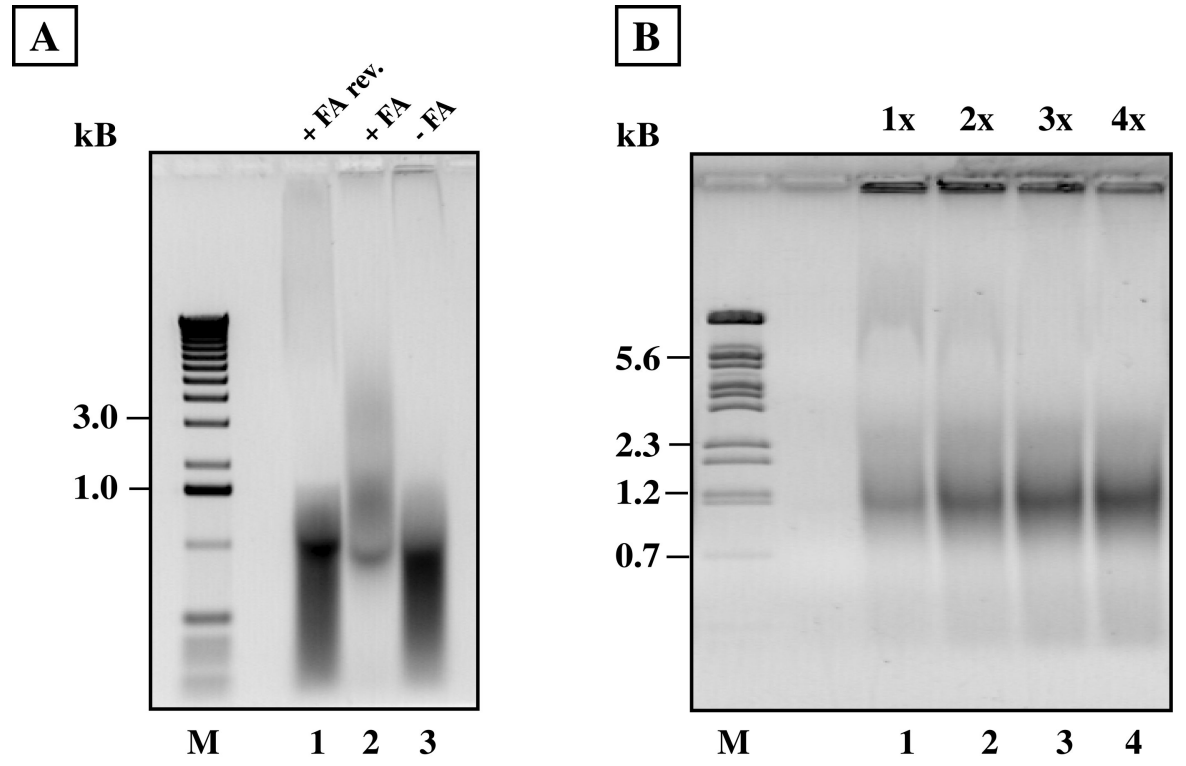

Abbildung 5.5: (A): Chromatinextrakte von Formaldehyd (FA)-behandelten (10 min) und unbehandelten Blättern aus SNN. Es wurden je $10 \mu \mathrm{l}$ Extrakt aufgetragen. Spur 1: Reversion der FA-Quervernetzung durch $16 \mathrm{~h}$ Inkubation bei $65^{\circ} \mathrm{C}$. Spur 2: Chromatin-Rohextrakt, quervernetzt. Spur 3: Extrakt eines nicht behandelten Blattes. Marker: 1kB DNA-ladder GIBCO/BRL. Die Auftrennung erfolgte im $1 \%$ Agarosegel. Die DNA wurde mit Ethidiumbromid angefärbt. (B): Ultraschall-behandelte Chromatinextrakte von FA-behandelten (10 min) Blättern aus SNN nach verschiedenen Zyklen der Ultraschallbehandlung. Es wurden je $10 \mu \mathrm{l}$ Extrakt aufgetragen. Gezeigt ist die Zunahme an freier DNA mit zunehmender Ultraschallbehandlung. Marker: $\lambda$ /Eco91I. Die Auftrennung erfolgte im 1\% Agarosegel. Die DNA wurde mit Ethidiumbromid angefärbt.

Die DNA des quervernetzten Chromatins wird durch die Formaldehyd-gebundenen Proteine im Laufverhalten behindert. Im Gegensatz dazu kann die wärmebehandelte DNA ungehindert das Agarosegel durchlaufen. Ebenso kann man einem solchen Gel entnehmen, in wie weit die in Kapitel 4.7.1 beschriebene Ultraschall-Behandlung erfolgreich war. Idealerweise liegen die gescherten Chromatin-Fragmente in Bereichen von 500 - 3000bp vor. Im Laufe der Experimente zeigte sich jedoch, dass es Ausfälle bei der ChIP gab. Bei der finalen ChIP-PCR konnten keine Fragmente amplifiziert werden. Eine Verlängerung der 
Inkubationszeit auf 20 Minuten reduzierte die Chromatin-Ausbeute, jedoch konnten nun DNA-Fragmente nachgewiesen werden. Sämtliche ChIP-Experimente bzw. deren PCR die in dieser Arbeit gezeigt werden (sofern nicht ausdrücklich anders erwähnt), wurden nach diesem Verfahren durchgeführt.

\subsection{Etablierung der ChIP}

\subsubsection{Anwendung der ChIP am Tetrazyklin-induzierbaren Expressionssystem}

Mit dem bei GATZ et al (1992) beschriebenen Tetrazyklin-induzierbaren Expressionssystem lag ein sehr gutes Modell vor, mit dem die Anwendung der ChIP getestet werden konnte. Das System besteht aus stabil transformierten W38-Tabakpflanzen die zwei unterschiedliche Konstrukte tragen: zum einen die Kodierregion des tet-Repressor (TetR) unter der Kontrolle des 35S-Promotors und zum anderen einen modifizierten 35S-Promotor, der flankierend zur TATA-BOX drei TetR-Bindeelemente (tet-Operatoren) besitzt. Als Reportergen dient das GUS-Gen. Im normalen uninduzierten Zustand bindet TetR an die tet-Operatoren. Dadurch wird die Expression über den starken 35S-Promotor reprimiert. Der Transkriptionsapparat wird von den Operatoren verdrängt. Erfolgt nun die Induktion durch Tetrazyklin (Tc), so bindet TetR das Tetrazyklin. Dies geht einher mit einer Konformationsänderung, welche den Verlust der Bindungsaffinität von TetR zum tet-Operator nach sich zieht. Das Ablösen von TetR ist die Folge, die Transkription des GUS-Gens kann über den 35S-Promotor erfolgen. Enzymaktivitätstests (MUG-Assays) mit Blattmaterial aus uninduzierten und mit Tetrazyklin $(10 \mathrm{mg} / \mathrm{l})$ behandelten Pflanzen zeigten, dass nach Tetrazyklingabe die Expression des GUS-Reportergens erfolgt. Abb. 5.7 enthält die gemittelten Ergebnisse. 

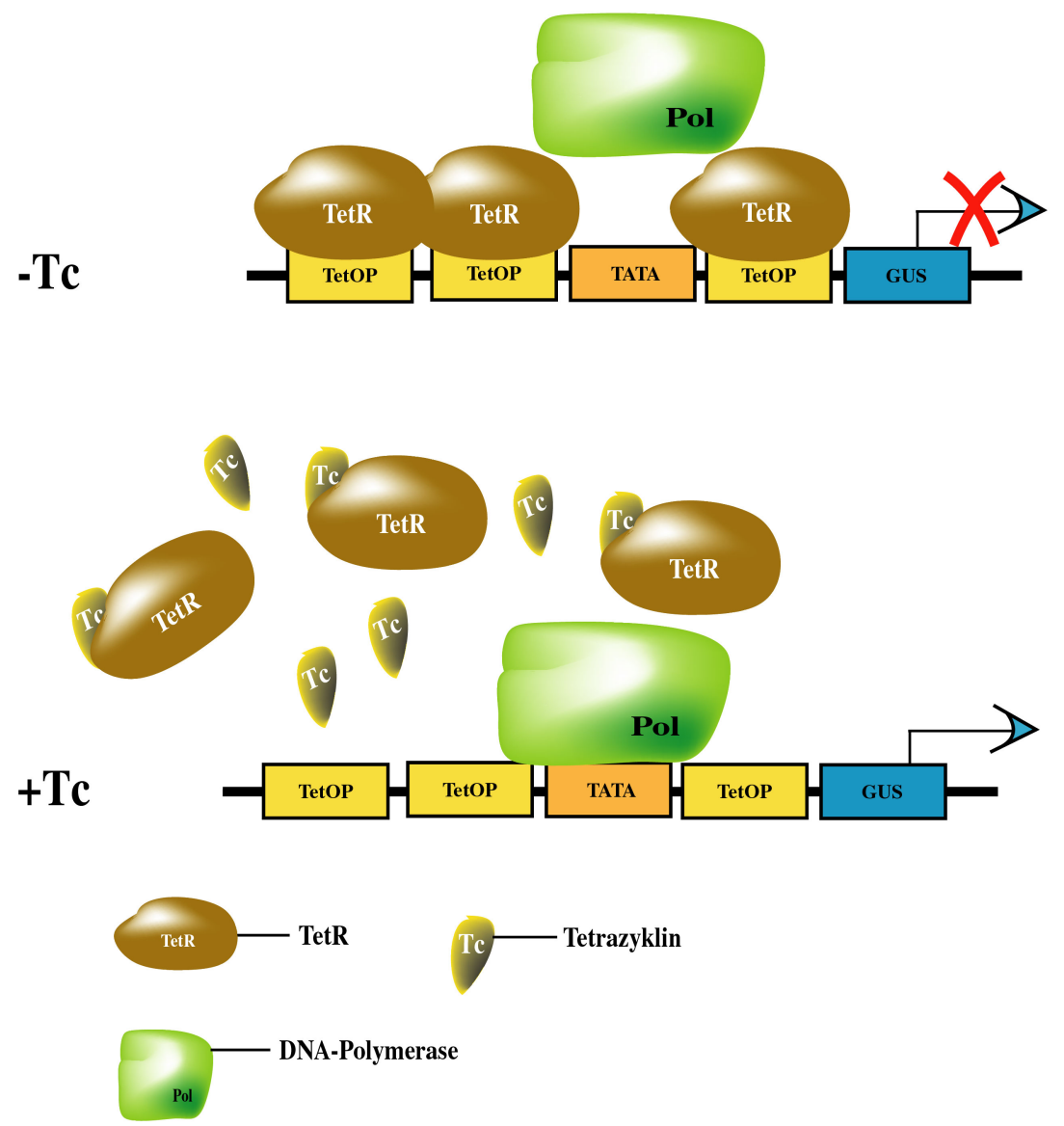

Abbildung 5.6: Prinzip des TetR-Systems. (-Tc): Die Tet-Repressoren (TetR) besetzen die tet-Operatoren und verhindern die Transkription des GUS-Reportergens durch Verdrängung des Polymerasekomplexes $(+\mathrm{Tc})$ : Die Bindung der Tet-Repressoren mit Tetrazyklin sorgt für eine Konformationsänderung. Die Ablösung von den tet-Operatoren ist die Folge und die Transkription kann erfolgen. 


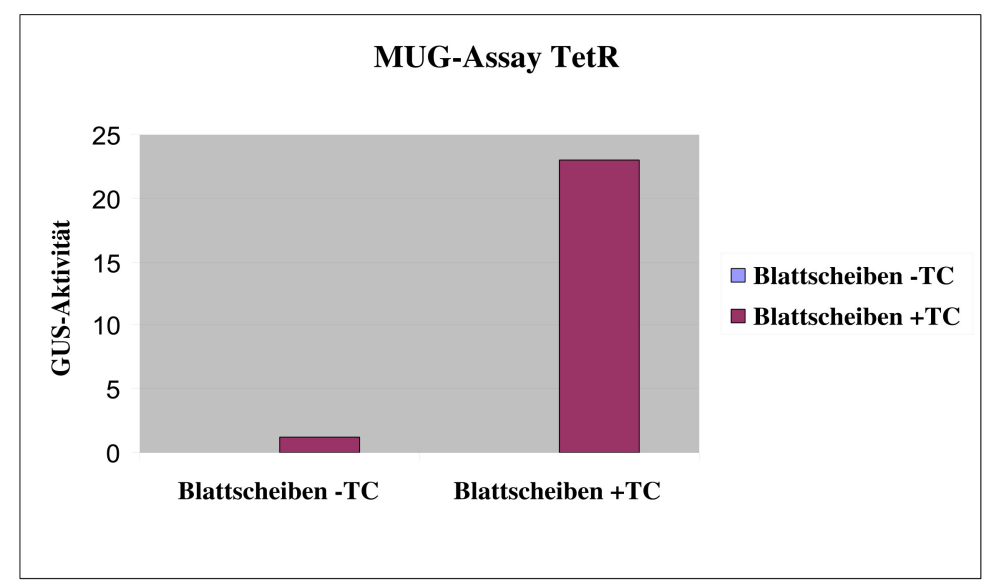

Abbildung 5.7: MUG-Assay von Blattscheiben transgener W38 TX2::GUS +/- Tetrazyklin-Behandlung. Hierzu wurden Blattscheiben $4 \mathrm{~h}$ mit Citratpuffer $+/-$ Tetrazyklin $(10 \mathrm{mg} / \mathrm{l})$ vakuuminfiltriert und mit den präparierten Proteinextrakten ein MUG-Assay durchgeführt. Die gezeigte Induktion des GUSReportergens (y-Achse) erfolgte wie in Kapitel 5.4.1 beschrieben

Basierend auf dem System konnten nun zwei Zustände beschrieben werden: Uninduzierter Zustand, wobei der TetR direkt an tet-Operatoren gebunden ist und der induzierte Zustand, wo keinerlei Bindung mehr nachweisbar bzw. mindestens eine Verringerung detektierbar sein sollte (Prinzip s. Abbildung 5.6). Über eine ChIP unter Verwendung eines spezifischen Antikörpers gegen das TetR-Protein sollten sich demnach bei der PCR mit Primern, die stromaufwärts vor den tet-Operatoren und stromabwärts im GUS-Gen liegen, deutliche Unterschiede in der Signalstärke beobachten lassen.

Das Ergebnis des ChIP-Experimentes zeigt Abb. 5.8. Für die ChIP wurde ein Antiserum gegen den Tet-Repressor eingesetzt. Zudem wurde Chromatin von zwei unterschiedlichen Pflanzenlinien verwendet. Die Inkubationszeit für die Formaldehyd-Quervernetzung betrug 30 Minuten. Die Quantifizierung des Chromatingehalts erfolgte durch Abschätzung von Chromatinextrakten, die in einem $1 \%$ Agarosege aufgetrennt wurden. Darauf wurde die DNA mit Ethidiumbromid angefärbt (s. Abb. 5.8 A). 

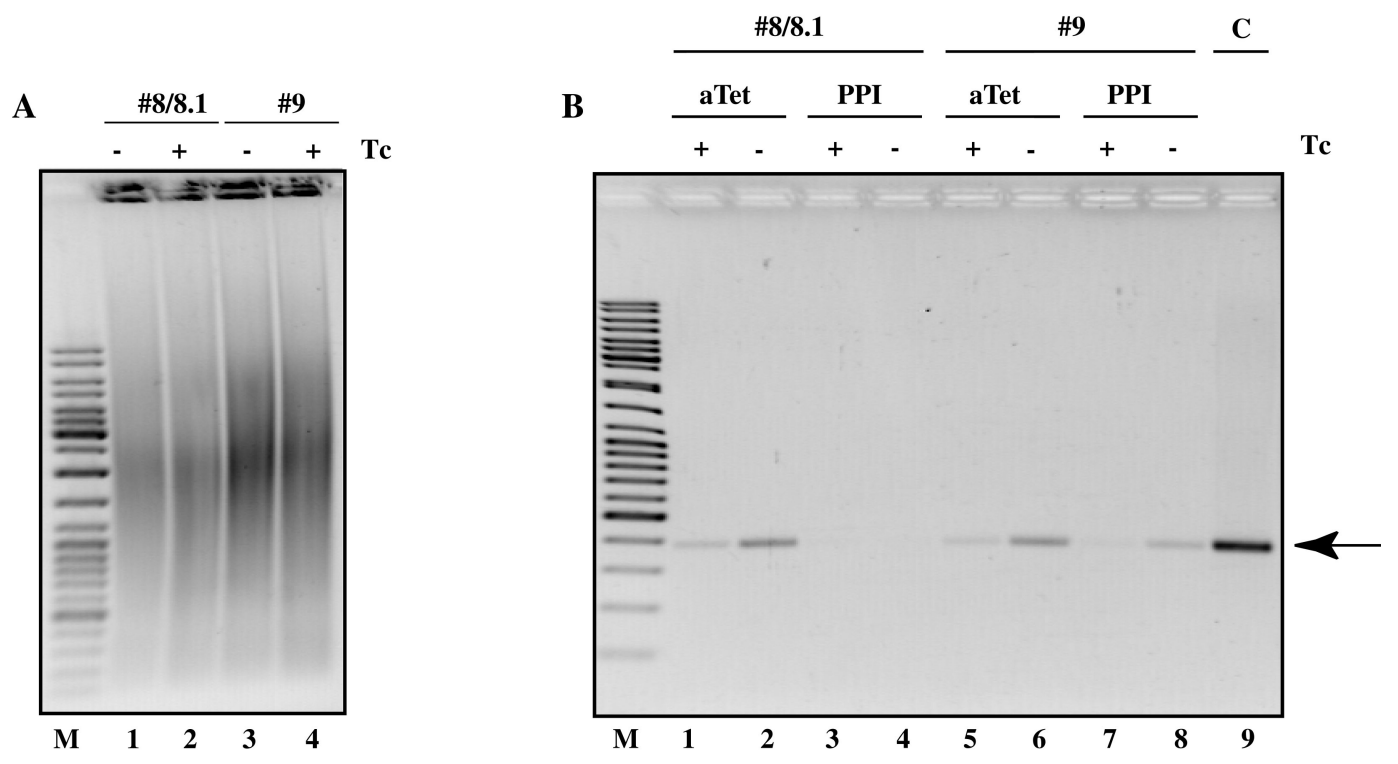

Abbildung 5.8: (A): Chromatinextrakte von Formaldehyd (FA)-behandelten (10 min) der transgenen Pflanzenlinien W38 TX2::GUS F2\#8/8.1 und \#9. Es wurden je $15 \mu \mathrm{l}$ Extrakt aufgetragen. Die Auftrennung erfolgte im 1\% Agarosegel. Die DNA wurde mit Ethidiumbromid angefärbt. (B): Analyse der DNA nach Antikörper $\alpha$ TetR-Immunopräzipitation. Das Chromatin wurde aus FA-quervernetzten (10 min] Blättern extrahiert, die +/- Tetrazyklin behandelt wurden. Die DNA wurde nach Reversion der Quervernetzung durch $16 \mathrm{~h}$ Inkubation bei $65 \mathrm{C}^{\circ}$ aufgereinigt und eine PCR mit den Primern 35SI/20381N für 30 Zyklen durchgeführt. Die Auftrennung erfolgte im 1\% Agarosegel + 0.7\% HEC. Die DNA wurde mit Ethidiumbromid angefärbt.

Abb.5.8 zeigt deutliche Signal-Unterschiede für die PCR. Da die Primer den Bereich stromaufwärts der TATA-Box - also die tet-Operatoren - bis in den Bereich des GUSReportergens umspannen, kann über ein Bindungsereignis des Tet-Repressors eine Aussage getroffen werden. Vergleicht man die Spuren 1 und 2 bzw. 5 und 6, so ist deutlich zu erkennen, dass bei der Gabe von Tetrazyklin eine Ablösung des TetR erfolgt. Das PCR-Signal verliert deutlich an Stärke. Dies ist darauf zurückzuführen, dass kein DNAbesetzendes Protein quervernetzt wurde und somit in der ChIP vom Antikörper keine Protein-DNA-Komplexe immunopräzipitiert werden konnten. Als Kontrolle für die unspezifische Immunoreaktion diente das Prä-Immunserum vom Antikörper $\alpha$ TGA2.1/2.2C (NICKOLOV, 2002). Hier sollten keine PCR-Signale erwartet werden, bzw. nur sehr schwache Signale, die als DNA-Kontamination vorliegen können. Die Spuren 3 und 4 bzw. 7 und 8 zeigen dies. Die Kontroll-PCR in Spur 9 erfolgte mit $1 \mu$ l genomischer CTAB-DNA (s. Kapitel 4.6.5) unter denselben PCR-Bedingungen. Insgesamt sind die Signale jedoch sehr schwach ausgefallen z.B. im Vergleich zu den Experimenten in Abb. 5.16. 


\subsubsection{Unterschiede der verwendeten Protokolle}

Für die Experimente mit dem induzierbaren Expressionssystem TetR (s. Kapitel 5.4.1) wurde ein Protokoll nach WANG et al. (2002) gewählt. Hierbei werden die isolierten Zellkerne in einem Sonifizierungspuffer (10 mM Kaliumphosphatpuffer pH 7.0, 0.1 M NaCl, 0.5\% Sarkosyl, 10 mM EDTA, 1 mM PMSF) aufgenommen. Die Chromatinextrakte wurden mit gleichem Volumen Kinzler-IP-Puffer (KINZLER und VOGELSTEIN (1989); $50 \mathrm{mM}$ HEPES pH 7.5, $150 \mathrm{mM} \mathrm{KCl,} 5 \mathrm{mM} \mathrm{MgCl}_{2}, 10 \mu \mathrm{M} \mathrm{ZnSO} 4,1 \%$ Triton X-100, $0.05 \%$ SDS) verdünnt. Nach erfolgter Immunopräzipitation wurde mit Kinzler-IP-Puffer 5x10 min gewaschen und die gebundenen Komplexe mit Glycin-Elutionspuffer (0.1 M Glycin, $0.5 \mathrm{M} \mathrm{NaCl}, 0.05 \%$ Tween20, pH 2.8) eluiert. Danach erfolgte eine 16 h-Inkubation bei $65{ }^{\circ} \mathrm{C}$ und eine Aufreinigung der DNA mittels Ethanol-Fällung. Die PCR-Signale bei Verwendung dieser Pufferkombinationen sind insgeamt niedrig ausgefallen. Zudem sind leichte Hintergrundbanden des Prä-Immunserums erkennbar (s. Abb. 5.8 B; Spur 8). Diese traten bei Verwendung des Protokolls nach TURCK et al.(2004) nicht auf. Hierbei werden die isolierten Zellkerne in einem Sonifizierungspuffer mit 0.5\% SDS aufgenommen, für 20 min mit Urltaschall behandelt und dann mit einem Sonifizierungspuffer ohne SDS aufgenommen. Die Gesamtkonzentration an SDS betrug also 0.25\%. Im Protokoll nach WANG et al. (2002) lag die Ausgangskonzentration an Sarkosyl zwar auch bei 0.25\%, jedoch enthielten sie zum Zeitpunkt der Immunopräzpitation (IP) $0.5 \%$ Triton X-100. Es kann bei hohen Detergenzkonzentrationen zur Denaturierung des Antikörpers kommen. Die IP ist somit nicht mehr vergleichsweise sensitiv. Das Protokoll nach TURCK et al. (2004) sieht nach der IP eine stringente Waschung mit RIPA-Puffer (50 mM HEPES/NaOH pH 7.4, $140 \mathrm{mM} \mathrm{NaCl}, 1 \mathrm{mM}$ EDTA, $1 \%$ Triton X-100, 0.1\% Deoxycholat, $0.1 \%$ SDS) vor. Diese Waschung verläuft wesentlich effektiver, da keine Kontaminationen festgestellt werden konnten. Des weiteren sieht das Protokoll die Entnahme von Aliquots vor. Das Protokoll wurde für die weiteren ChIP-Experimente verwendet.

\subsubsection{Anwendung der ChIP am Tetrazyklin-reprimierbaren Expressionssys- tem pTAX}

Mit dem von BÖHNER et al.(1999) beschriebenen pTAX-Expressionssystem stand ein weiteres nützliches Werkzeug zum Test der ChIP-Methode zu Verfügung. Das pTAXSystem besteht ebenso wie das TetR-System aus zwei Komponenten. Zum einen exprimiert die Pflanze den artifiziellen Transkriptionsfaktor tTA, welcher eine Fusion des 
bereits beschriebenen TetR-Repressors mit der starken Aktivierungsdomäne VP16 aus Herpes simplex darstellt. Des weiteren trägt die Pflanze das tTA-responsive Konstrukt in Form eines künstlichen Promotors, bestehend aus einer 4fachen Wiederholung von tet-Operatoren stromaufwärts vom CaMV 35S(-46)-Promotor, fusioniert mit dem GUSReportergen. Durch die Bindung des TetR an die tet-Operatoren mit Präsenz der starken VP16-Aktivierungsdomäne findet eine starke, vom CaMV 35S-Promotor getriebene Expression des GUS-Reportergens statt. Blattscheiben, die mit und ohne Tetrazyklin behandelt wurden, zeigen bei einer GUS-Färbung die unterschiedlichen Zustände (s. Abb.5.9).

\section{W38 pTAX::GUS \#10}

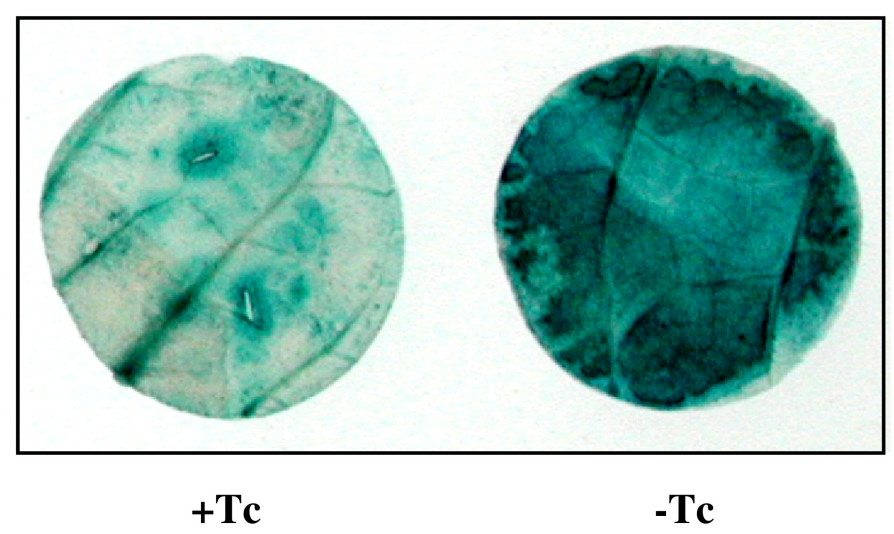

Abbildung 5.9: GUS-Färbung von Blattscheiben transgener Pflanzen W38 pTAX::GUS +/- TetrazyklinBehandlung. Hierzu wurden Blattscheiben für $6 \mathrm{~h}$ mit Citratpuffer $+/-$ Tetrazyklin $(10 \mathrm{mg} / \mathrm{l})$ inkubiert und eine GUS-Färbung durchgeführt.

Findet nun eine Tetrazyklin-Gabe statt, so wird der tTA von Tetrazyklin gebunden und erfährt hierbei eine Konformationsänderung. Diese geht einher mit einer starken Herabsetzung der DNA-Bindefähigkeit bis hin zur völligen Ablösung von der DNA. Da keine Aktivierungsdomäne mehr vorliegt, wird die Expression bis auf ein Mindestmaß gedrosselt bzw. kommt völlig zum Erliegen. Bei einer GUS-Färbung von Tetrazyklin-behandeltem Gewebe kann man diese Abnahme beobachten (s. Abb. 5.9). Genau diese beiden Zustände sollten in der späteren ChIP nachzuweisen sein, da bei einer Formaldehyd-Behandlung die DNA-Bindung von tTA im jeweiligen Bindungszustand quasi eingefroren werden kann. Über Primer, die den Bereich der tet-Operatoren bis zum GUS-Reportergen umfassen, würde sich so über die PCR-Analyse die Bindung nachweisen lassen. Das Prinzip dieses Systems wird in Abb. 5.10 anschaulich gemacht. Es zeigt den $p T A X$-Promotor mit den 
exprimierten tTA in Interaktion.
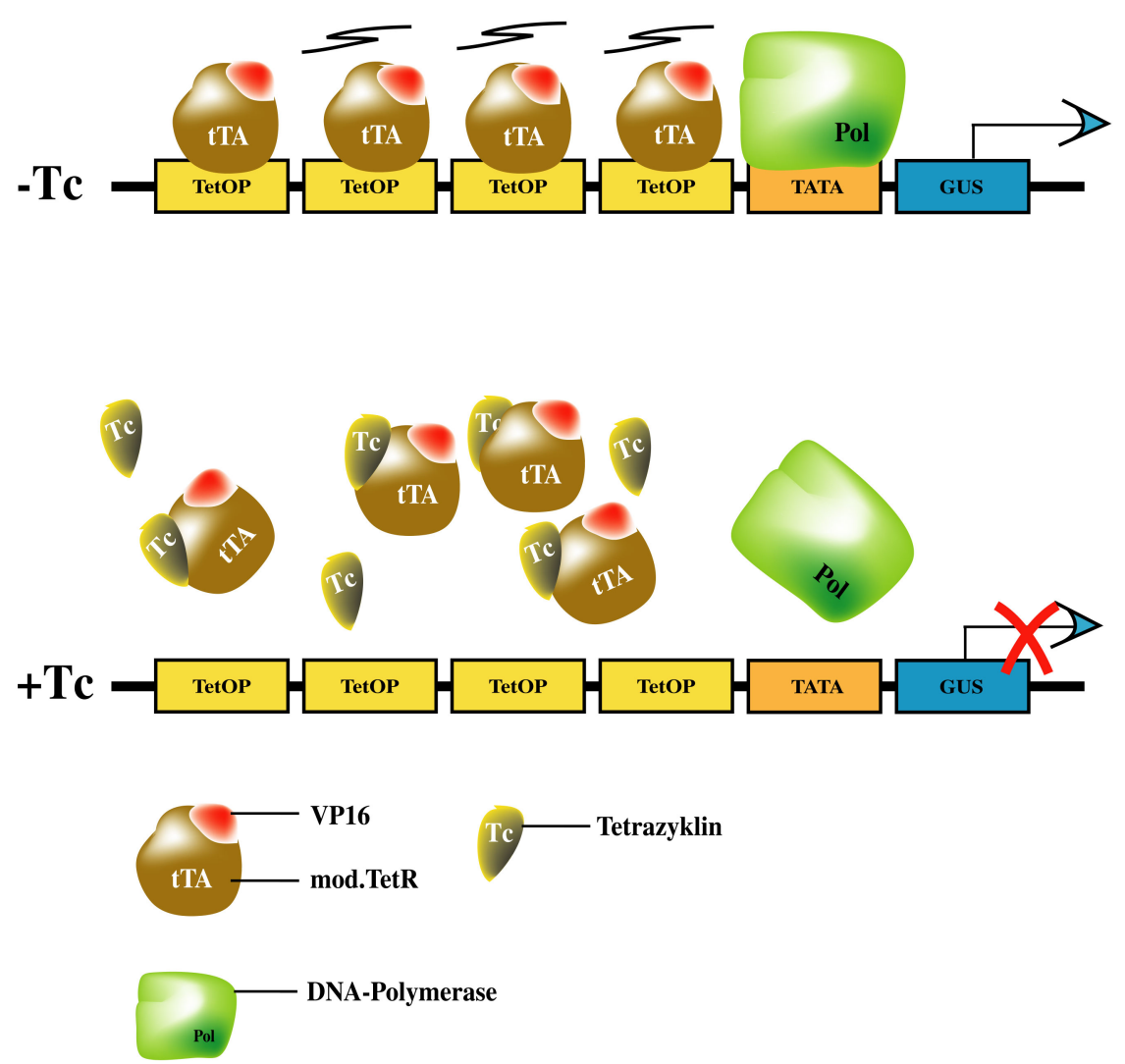

Abbildung 5.10: Prinzip des pTAX-Systems. (-Tc): Die modifizierten Tet-Repressoren (tTA) mit der Aktvierungsdomäne VP16 besetzen die tet-Operatoren und stimulieren die Transkription des GUSReportergens durch die Aktivierungsdomäne. Eine konstitutive GUS-Expression findet statt. $(+\mathrm{Tc})$ : Die Bindung des tTA mit Tetrazyklin sorgt für eine Konformationsänderung. Die Ablösung von den tetOperatoren ist die Folge und die Transkription wird gestoppt.

Mithilfe dieses Systems konnte also ein weiterer Test über das angewendete ChIP-Protokoll gurchgeführt werden. Ferner wurde es durch dieses Experiment auch möglich gemacht, eine Aussage über die potentielle ChIP-Tauglichkeit des neu generierten Antiserums $\alpha$ VP16 gegen die Aktivierungsdomäne VP16 treffen zu können. 


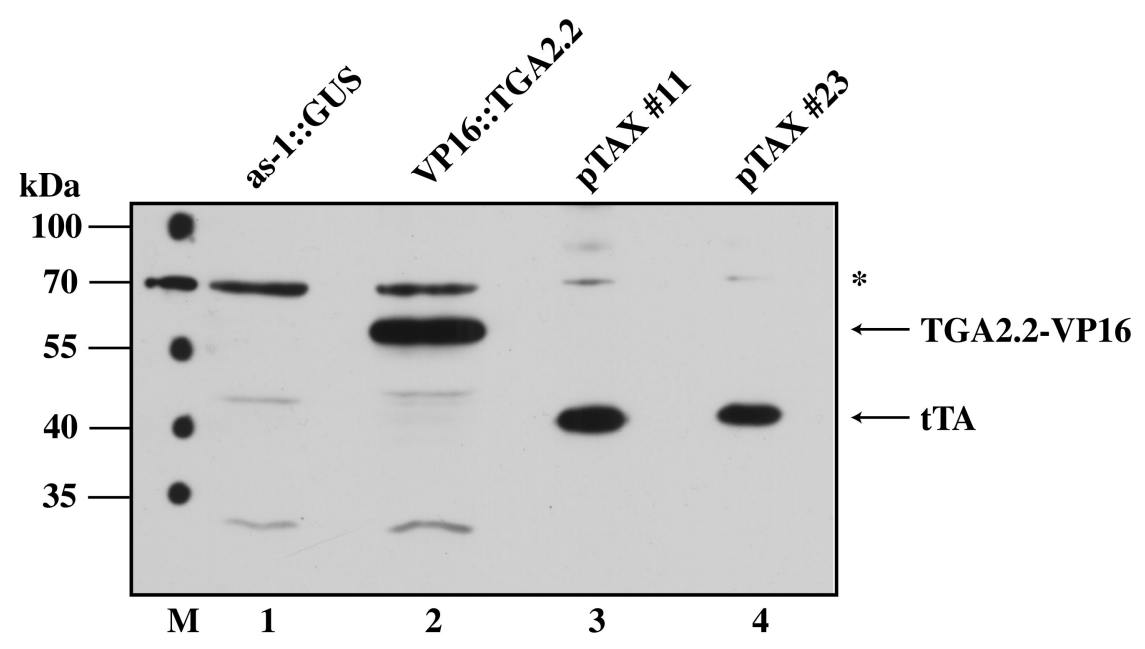

Abbildung 5.11: Western-Blot-Analyse von Chromatinextrakten mit Antiserum $\alpha$ VP16. Die Quantifizierung der Extrakte erfolgte über ein Coomassie-gefärbtes Abgleichgel. Von der schwächsten ermittelten Konzentration wurden $15 \mu \mathrm{l}$ und entsprechende Äquivalente aufgetragen. Verwendet wurden Extrakte der Pflanzenlinien SNN as-1::GUS, SNN TGA2.2-VP16 F1 sowie W38 pTAX \#11 und \#23. Die Auftrennung der Proteine erfolgte im $10 \%$ SDS-PAGE. Die Proteine wurden daraufhin per Western-Blot auf eine PVDF-Membran übertragen und die Immundetektion mit Antiserum $\alpha$ VP16 (1:1000 Verdünnung in $0.5 \%$ Milchpulver/PBST) durchgeführt. Das Sternchen kennzeichnet Kreuzhybridisierungen des Antikörpers mit einem unbekannten Protein. Die Pfeile markieren die Lage des TGA2.2-VP16 sowie des artifiziellen Transkriptionsfaktors tTA

Abb.5.11 zeigt eine Western-Blot-Analyse von Chromatinextrakten wie sie Verwendung finden in der späteren ChIP. Hierfür wurden je $15 \mu$ l Extrakt von SNN as-1::GUS (Spur 1), SNN TGA2.2-VP16 F2 (Spur 2) und jeweils W38 pTAX \#11 (Spur 3) und W38 pTAX \#23 (Spur 4) in einem $10 \%$ SDS-PAAG aufgetrennt und auf PVDF-Mebran geblottet. Die Immunodetektion erfolgte mit dem Serum ,SA4134“. Erwartungsgemäß wird bei der Linie SNN as-1::GUS kein Signal sichtbar, da die Pflanze kein Konstrukt mit VP16 enthält, wohl aber bei SNN TGA2.2-VP16 F2. Diese Pflanze exprimiert den TGA2.2 fusioniert mit der Aktivierungsdomäne VP16. Der tTA in den W38 pTAX-Linien \#11 und \#23 wird ebenso vom Serum gut erkannt. Ein Abbau der Proteine ließ sich dabei nicht beobachten. Das Serum wurde nach diesem Test für qualitativ gut befunden und konnte nun in der ChIP eingesetzt werden. Dafür wurde das über Western-Blot-Analyse getestete Chromatin verwendet. 
Im Zuge der Weiterentwicklung der Methode kam es zur Einführung einer DNAQuantifizierung, welche es erlaubte, den genauen Gehalt an freier DNA im Chromatinextrakt zu bestimmen. Dadurch war die Homogenität der eingesetzten DNA-Menge gewährleistet. Es zeigten sich jedoch auch hier Schwankungen durch Verluste während der Aufreinigung. Im Gegensatz zu früheren Protokollen, bei welcher die PCR als reine Kontrolle auf genomischer DNA durchgeführt wurde, konnte durch die Aufarbeitung eines Aliquots an Chromatinextrakt (s. Kapitel ??) sichergestellt werden, dass die gleiche Menge an DNA in den einzelnen ChIP-Reaktionen vorlag. Für eine ChIP-Reaktion wurden in der Regel $15 \mu \mathrm{g}$ DNA eingesetzt. Des weiteren wurden Kompetitionsansätze bei jeder ChIP parallel mitgeführt. Als Kompetitionsansatz wird eine vorinkubierte Mischung aus Antiserum und korrespondierenden, rekombinanten Protein (Antigen) bezeichnet. In diesem reagiert der spezifische Antikörper bereits vor der ChIP mit seinem Antigen und eine Detektion des endogenen Antigens kann somit ausgeschlossen werden.

Abb.5.12 zeigt das Ergebnis der ChIP mit $15 \mu \mathrm{g}$ DNA aus Chromatinextrakten der Pflanzen W38 pTAX \#11 und \#23 mit dem Antiserum $\alpha$ VP16 unter Verwendung des ChIP-Protokolls von TURCK et al. (2004). Die PCR auf der präzipitierten DNA erfolgte über die Primerkombination uni24/20381N. Die ChIP mit den Linien \#11 und \#23 wurde mit jeweils $4 \mu \mathrm{l}$ Antiserum $\alpha$ VP16 (SA4134) durchgeführt (Spur 1,2 und 8,9). Als Kontrolle für die Spezifität des Antiserums wurden weiterhin $30 \mu \mathrm{g}$ rekombinantes Protein mit dem Antiserum vorinkubiert. Durch diese Kompetition ist eine Detektion des endogenen tTA über die VP16-Domäne ausgeschlossen und somit ebenfalls kein amplifizierbares Präzipitat (Spur 3,4 und 10,11) per PCR nachzuweisen. Eine weitere Kontrolle stellt die ChIP mit dem Prä-Immunserum dar, da auch hier keine Signale erwartet werden (Spur 5,6 und 12,13). Als PCR-Kontrolle wurde die Input-DNA eingesetzt. Die PCR auf den Proben der einzelnen Input-DNA kommt einer Ladungskontrolle gleich, weil sie Rückschlüsse darüber zulässt, ob die für die ChIP eingesetzte Menge an DNA gleich ist (s. auch Kapitel ??). 


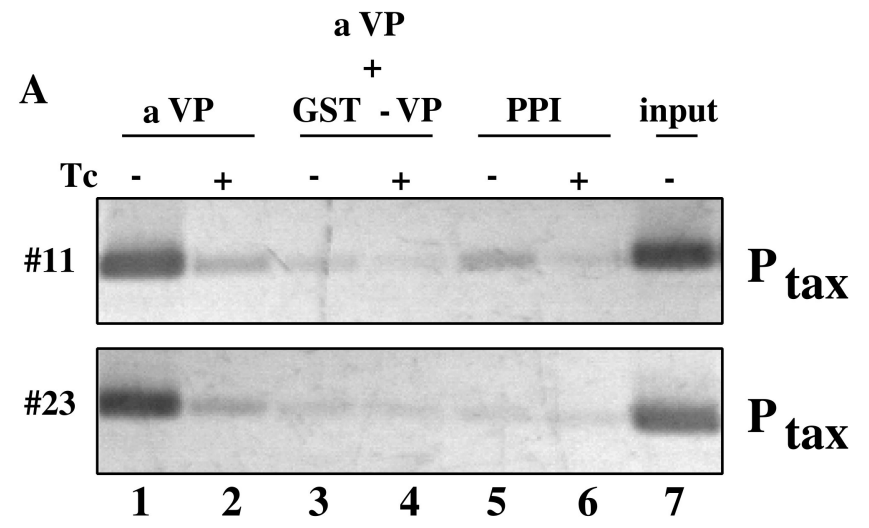

B

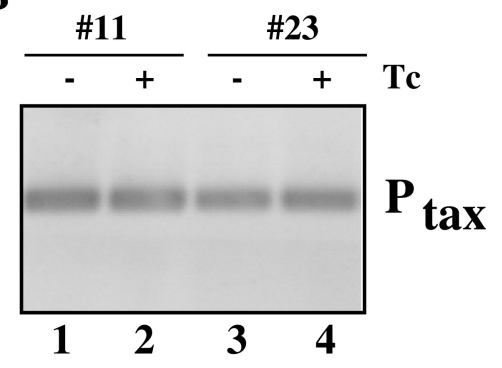

Abbildung 5.12: (A): Analyse der DNA nach Antikörper $\alpha$ VP16-Immunopräzipitation und 15 $\mu$ g DNA. Das Chromatin wurde aus FA-quervernetzten (20 min) Blättern extrahiert, die +/- Tetrazyklin (10 mg/l) behandelt wurden. Die DNA wurde nach Reversion der Quervernetzung durch $16 \mathrm{~h}$ Inkubation bei $65 \mathrm{C}^{\circ}$ aufgereinigt und eine PCR mit den Primern uni24/20381N für 30 Zyklen durchgeführt. Die Auftrennung erfolgte im 1\% Agarosegel. Die DNA wurde mit Ethidiumbromid angefärbt.(B): PCR-Kontrolle der Input-DNA. Als Input-Kontrolle wurden je $50 \mu \mathrm{l}$ Chromatin des Immunserum-Ansatzes der ChIP (Linie \#11: Spur 1, 2; Linie \#23: Spur 1,2) verwendet. Die DNA wurde nach Reversion der Quervernetzung durch $16 \mathrm{~h}$ Inkubation bei $65 \mathrm{C}^{\circ}$ aufgereinigt und eine PCR mit den Primern uni24/20381N für 30 Zyklen durchgeführt. Die Auftrennung erfolgte im 1\% Agarosegel. Die DNA wurde mit Ethidiumbromid angefärbt. 


\subsection{Anwendung der ChIP zum Bindungsverhalten der TGA-Fak- toren}

Durch die Ergebnisse der Vortests konnte nun die in vivo-Bindung der TGA-Faktoren an Promotoren, die as-1-ähnliche Elemente besitzen, erfolgen. Damit die Bindung an das isolierte as-1-Element nach SA-Behandlung untersucht werden konnte, wurden transgene Pflanzen, die das Konstrukt as-1::GUS tragen, verwendet. Als Zeitpunkte der ersten Experimente wurden zunächst 0, 1, 3, 5, 12 und $24 \mathrm{~h}$ ausgewäglt. Spätere Versuche beschränkten sich jedoch auf die Zeitpunkte $3 \mathrm{~h}$ und $12 \mathrm{~h}$. Diese Zeitpunkte repräsentieren den Expressions-Verlauf der frühen und späten Gene der SA-Antwort (NIGGEWEG et al. 2000b). Hierzu wurden Tabakblätter mit einem Kaliumphosphatpuffer mit SA (1 mM) überschichtet und nach Ablauf der Zeit durch Vakuuminfiltration mit Formaldehyd quervernetzt. Die Lagerung der behandelten Blätter erfolgte entweder in flüssigem Stickstoff oder das Blattmaterial wurde sofort weiterverarbeitet. Nach der Zellkernisolation und der sich anschließenden Chromatinpräparation wurden die Proben aliquotiert und bei $-80{ }^{\circ} \mathrm{C}$ gelagert.

\subsubsection{ChIP mit affinitätsaufgereinigten $\alpha$ TGA2.2C}

Bedingt durch eine hohe Kreuzhybridisierungen des Antiserums $\alpha$ TGA2.1/TGA2.2-C (NICKOLOV, 2002) in vorherigen ChIP-Experimenten (Daten nicht gezeigt) wurden spezifische Antikörper gegen den C-Terminus von TGA2.2 aus dem Serum über eine Affinitätschromatografie aufgreinigt. Hierzu wurde eine Cyanogenbromid-aktivierte Sepharose (Fa. Pharmacia) mit rekombinanten Protein TGA2.2-HIS6 beladen und das Protein kovalent gekoppelt. Nach einem von HARLOW und LANE (1999) beschriebenen Protokoll (s. Kapitel 4.9.3) wurde somit ein affinitätsaufgereingter Antikörper gewonnen, der die Hintergrundpräzipitate nicht mehr aufweisen sollte. Durch die Wahl eines His6-markierten TGA2.2-Volllängen-Proteins als Antigen für die Affinitätsaufreinigung wurde die parallele Anreicherung von GST-Antikörpern ausgeschlossen. Per Western-Blot-Analyse (Abb. 5.13) wurde die Affinität des Antikörpers bei verschiedenen denaturierenden Gesamtzellextrakten untersucht. Die so gewonnen Aliquots an Antikörpern wurden zur besseren Lagerungsmöglichkeit in lyophilisierter Form bei $4{ }^{\circ} \mathrm{C}$ trocken gelagert und bei Bedarf mit gleichem Volumen $\mathrm{H}_{2} \mathrm{O}$ rehydriert. 


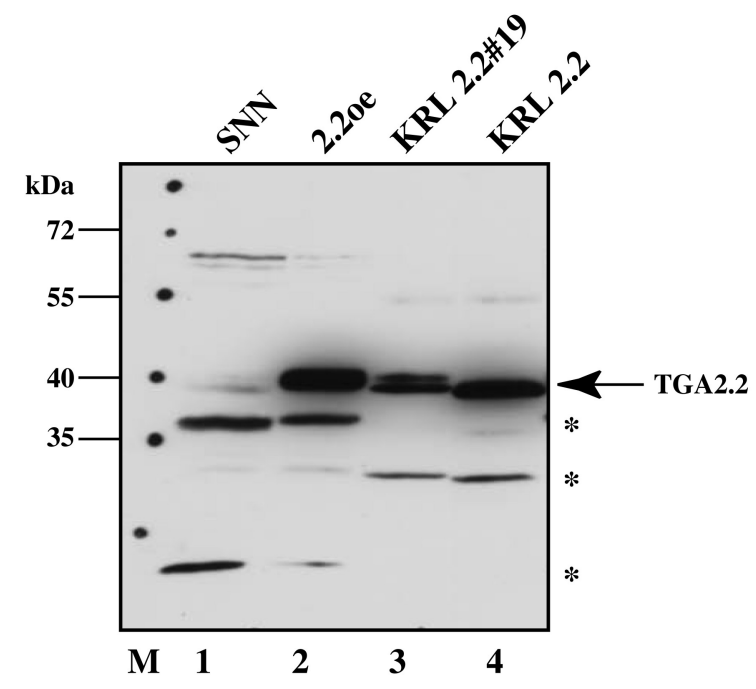

Abbildung 5.13: Western-Blot-Analyse von denaturierten Zellkern-Proteinextrakten und in vitro translatierten Protein aus Kaninchen-Reticulocytenlysat (KRL) mit affinitätsaufgereinigtem Antikörper $\alpha 2.2 \mathrm{C}$. Die Quantifizierung der Extrakte erfolgte über ein Coomassie-gefärbtes Abgleichgel. Von der schwächsten ermittelten Konzentration wurden $15 \mu \mathrm{l}$ und entsprechende Äquivalente aufgetragen. Verwendet wurden Extrakte der Pflanzenlinien SNN, SNN TGA2.2oe \#8, in vitro translatiertes Protein TGA2.2\#19 sowie TGA2.2. Bei TGA2.2\#19 handelt es sich um ein TGA2.2-Homolog (THUROW, 2001) Die Auftrennung der Proteine erfolgte im $10 \%$ SDS-PAAG. Die Proteine wurden daraufhin per Western-Blot auf eine PVDF-Membran übertragen und die Immundetektion mit affinitätsaufgereinigten Antikörper $\alpha 2.2 \mathrm{C}$ (1:1000 Verdünnung in $0.5 \%$ Milchpulver/PBST) durchgeführt.

Der endogene TGA2.2 mit einem berechneten Molekulargewicht von $36 \mathrm{kDa}$ liegt sowohl bei SNN als auch bei der Überexpressionspflanze vor. Desweiteren ist bei der Pflanze 2.2oe (Spur 2) sowie bei den Kaninchen-Retikulocyten-Lysaten (KRL) eine starke Signalstärke auf der Höhe von 40kDa sichtbar (Spur 3, 4). Bei diesem Signal handelt es sich bei 2.2oe (Spur 2) um das Transgen, welches den endogenen TGA2.2 scheinbar in der Expression negativ beeinflusst. Bei den KRL-Proben werden beide TGA2.2-Derivate erkannt. Somit erschien der Antikörper spezifisch genug, um ein ChIP-Experiment durchzuführen. Bedingt durch die schwachen Signale aus vorhergehenden Experimenten wurde die PCR allerdings mit radioaktiv markierten Nukleotiden durchgeführt. Diese Nachweisform ist weitaus sensitiver. 


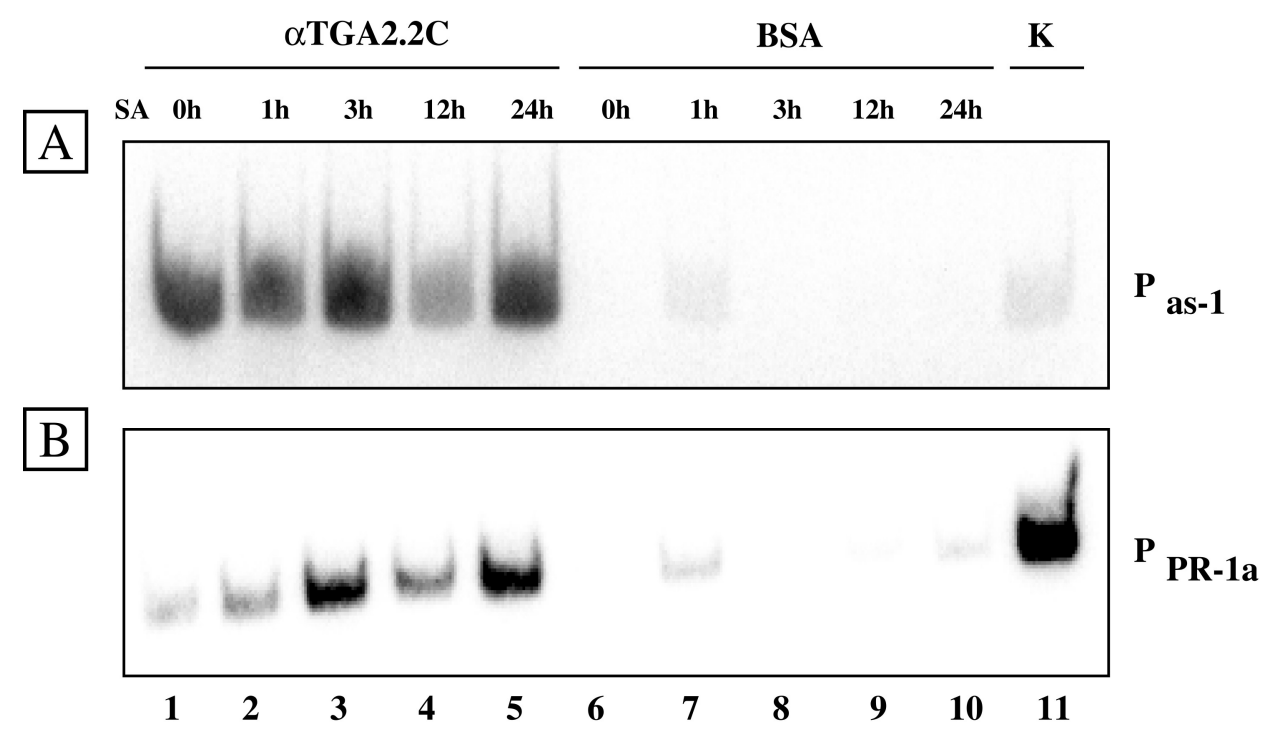

Abbildung 5.14: Analyse der DNA nach Antikörper $\alpha 2.2 \mathrm{C}-$ Immunopräzipitation und 20 AE (260) DNA. Das Chromatin wurde aus FA-behandelten (10 min)) Blättern aus W38 $\Delta 35 \mathrm{~S}$ ::GUS extrahiert, die mit SA (1 mM) für die angegebenen Zeitpunkte behandelt wurden. Die DNA wurde nach Reversion der Quervernetzung durch $16 \mathrm{~h}$ Inkubation bei $65 \mathrm{C}^{\circ}$ aufgereinigt und eine radioaktive PCR mit den Primern uni24/20381N und PR-1a s/PR-1a as für 27 Zyklen durchgeführt. Dem PCR-Ansatz wurden 12,5 pmol $\alpha^{32}$-dATP $(800 \mathrm{Ci} / \mathrm{mol})$ zugeführt. Die Auftrennung erfolgte mittels eines $5 \%$ PAAG (nativ). Die Detektion erfolgte durch Auflegen eines Phosphoimager-Screens.

Zum Zeitpunkt des Experiments befand sich das Protokoll in einem Stadium, welches das Mitführen einzelner Input-DNA-Kontrollen als Ladungskontrolle nicht vorsah. Die Kontroll-PCR (Abb. 5.14) wurde mit genomischer DNA (präpariert nach Kapitel 4.6.5) durchgeführt. Die Kontroll-PCR ist im Fall des as-1-Elements (Spur 11; Abb. 5.14 A) sehr schwach ausgefallen um Gegensatz zum PR-1a-Signal (Spur 11; Abb. 5.14 B). Die Kontrollen für die ChIP-Reaktionen wurden mit Rinderserum-Albumin anstelle Antikörper durchgeführt. Da wegen der Unspezifität des Albumins keine oder nur geringe Mengen an DNA präzipitiert werden dürften, kann man durch diese Kontrolle Aussagen über DNAKontaminationen machen.

Für das as-1-Element ist ein relativ starkes Signal über den gesamten Induktionsverlauf zu verzeichnen, lediglich der $12 \mathrm{~h}$-Wert ist schwächer ausgefallen. Da der $12 \mathrm{~h}$-Wert jedoch auch im PR-1a-Signal an Signalstärke einbüßt, muss von einer Degradation der DNA oder des eingesetzten Chromatins ausgegangen werden. Für die Signale von $P R$-1a lässt sich eine stetige Zunahme des PCR-Signals beobachten. Besonders in den anfänglichen Werten $0 \mathrm{~h}$ bis $3 \mathrm{~h}$ lässt sich diese Zunahme erkennen. Die Signalstärke erreicht bereits bei $3 \mathrm{~h}$ die Stärke, die sich auch bei $24 \mathrm{~h}$ finden lässt. 
Zusammenfassend lässt sich zu diesem Ergebnis sagen, dass der Antikörper $\alpha$ TGA2.2C spezifisch das as-1-Element als auch das as-1-ähnliche Element des PR-1a-Promotors über quervernetzte TGA2.2-Proteine präzipitieren konnte. Dabei ist eine konstitutive Besetzung des as-1-Elements sichtbar, während für den $P R$-1a-Promotor eine induzierbare detektiert wurde.

\subsection{ChIP mit Antiserum TGA2-C}

\subsubsection{Das Bindeverhalten der TGA-K2 am isolierten as-1-Element}

Die in diesem Kapitel beschriebenen Experimente wurden mit dem neu generierten Antiserum $\alpha$ TGA2-C gegen die C-Termini von TGA2.1/TGA2.2 durchgeführt. Western-BlotAnalysen mit anschließender Immunodetektion von denaturierten Kernextrakten wurden eingehend in Kapitel 5.1 beschrieben, welches von der Herstellung und Tests des Serums handelt. Da gezeigt wurde, dass das Antiserum $\alpha$ TGA2-C die rekombinanten Proteine TGA2.1HIS und TGA2.2HIS in der Immunodetektion gleichermaßen gut erkennt (THUROW et al., 2005) muss davon ausgegangen werden, dass es sich bei den Ergebnissen um die Betrachtung beider Proteine handeln muss. Daher wird zur Beschreibung der Experimente der Terminus „TGA-K2“ als Bezeichnung für TGA2.2 und TGA2.1 eingeführt. Für annähernd jedes Experiment wurden Kontroll-Reaktionen mitgeführt, welche die Spezifität der ChIP bzw. des Antiserums zeigten. Zum einen liefert die Reaktion mit Prä-Immunserum einen guten Hinweis auf die Kontamination der Protein A-Sepharose mit DNA, zum anderen zeigt die Kompetition des Antikörpers mit rekomibanten Protein durch eine Signalabnahme der PCR an, wie spezifisch die Reaktion verlaufen ist. Abb. 5.15 zeigt exemplarisch eine solche Kompetitionsreihe. Hierfür wurde eine ChIP mit Proben von $12 \mathrm{~h}$ und $24 \mathrm{~h}$ einer SA-Induktionsreihe mit $5 \mu$ l Antiserum $\alpha$ TGA2-C durchgeführt. Die Kompetition erfolgte mit $20 \mu \mathrm{g}$ des rekombinanten Proteins GST-TGA2.2C sowie mit den jeweiligen vom Molekulargewicht abhängigen molaren Mengen an TGA2.2HIS, GST und BSA. Die PCR erfolgte mit Primern, die stromaufwärts vor dem as-1-Element liegen, bzw. stromabwärts im GUS-Gen. 


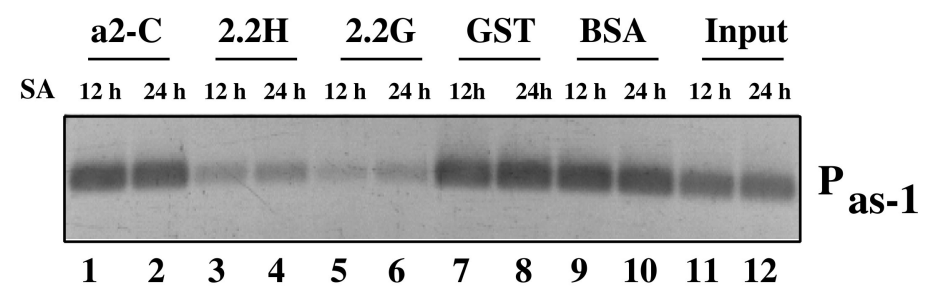

Abbildung 5.15: Analyse der DNA nach Antiserum $\alpha$ TGA2-C-Immunopräzipitation mit ChromatinProben äquivalent zu $15 \mu \mathrm{g}$ DNA. Das Chromatin wurde aus FA-quervernetzten (20 min) Blättern der Linie SNN as-1::GUS extrahiert, die mit SA (1 mM) für die angegebenen Zeitpunkte behandelt wurden. Die DNA wurde nach Reversion der Quervernetzung durch $16 \mathrm{~h}$ Inkubation bei $65 \mathrm{C}^{\circ}$ aufgereinigt und eine PCR mit den Primern near-as1/20381N für 29 Zyklen durchgeführt. Einigen ImmunopräzipitationsAnsätzen wurden rekombinantes Protein als Kompetitor zugesetzt: Spuren 3,4 15,1 $\mu \mathrm{g}$ TGA2.2HIS (2.2H); Spuren 5,6: $20 \mu \mathrm{g}$ TGA2.2C (2.2G); Spuren 7,8: $9.6 \mu \mathrm{g}$ GST sowie Spuren 9, 10: $24.5 \mu \mathrm{g}$ BSA. Die Auftrennung erfolgte im $1 \%$ Agarosegel. Die DNA wurde mit Ethidiumbromid angefärbt.

Eine deutliche Abnahme der Signalstärke ist für die Kompetition (Abb. 5.15 des Antiserums mit TGA2.2HIS (Spur 3, 4) und GST-TGA2.2C (Spur 5, 6) zu beobachten. ChIPReaktionen mit unspezifische Proteinen wie GST (Spur 7, 8) oder BSA (Spur 9, 10) zeigen keinerlei Signalabnahme verglichen mit den alleinigen Antiserum-Reaktionen (Spur 1, 2). Dies spricht deutlich für eine sehr spezifische Immunopräzipitation des Protein-DNAKomplexes. Die Hintergrundaktivität (s. Abb. 5.15 Spuren 4-6) lässt jedoch vermuten, dass eine unspezifische Bindung von DNA an Protein A-Sepharose erfolgte.

Für die nachfolgenden ChIP-Experimente wurden SNN as-1::GUS aber auch Pflanzen der Linie W38 $\Delta 35 \mathrm{~S}$ ::GUS verwendet. Sie wurden nach der in Kapitel 4.2 beschriebenen Weise mit SA induziert und verarbeitet. Die ChIP wurde mit $15 \mu \mathrm{g}$ DNA sowie $4 \mu$ l Antiserum $\alpha$ TGA2-C durchgeführt. Als Kompetitor des Antiserums diente das rekombinante Protein GST-TGA2.2C, welches auch für die Immunisierung eingesetzt wurde. Diese Kompetitionskontrollen wiesen in den wenigsten Fällen Hintergrundaktivität auf und ließen somit den Schluss zu, dass die ChIP-Experimente sehr spezifisch abliefen (Daten nicht gezeigt). 


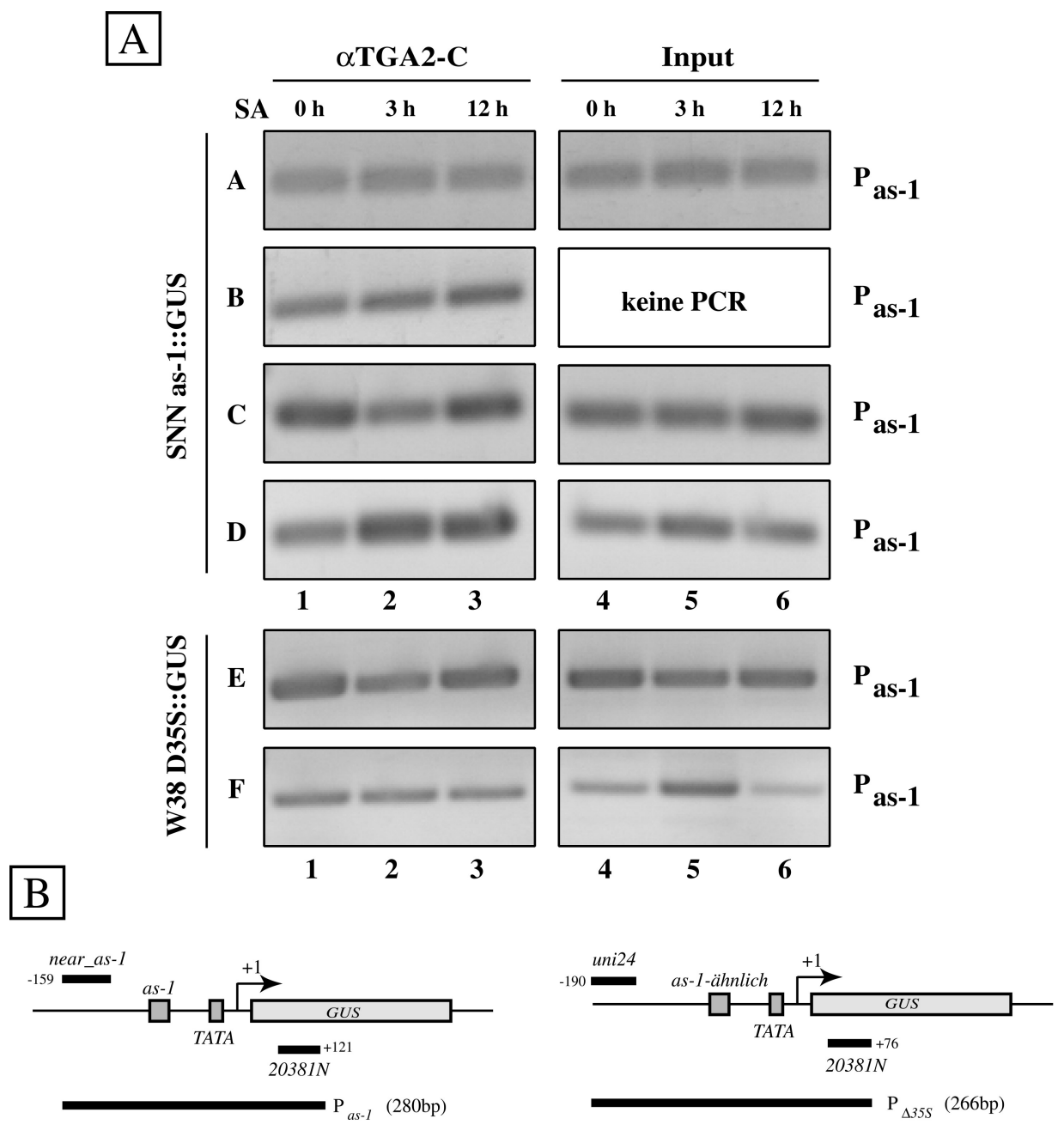

Abbildung 5.16: (A): Analyse der DNA nach Antiserum $\alpha$ TGA2-C-Immunopräzipitation mit $15 \mu \mathrm{g}$ DNA. Das Chromatin wurde aus FA-behandelten (20 min) Blättern der Linie SNN as-1::GUS und W38 $\Delta 35 \mathrm{~S}:$ :GUS extrahiert, die mit SA $(1 \mathrm{mM})$ für die angegebenen Zeitpunkte behandelt wurden. Die DNA wurde nach Reversion der Quervernetzung durch $16 \mathrm{~h}$ Inkubation bei $65 \mathrm{C}^{\circ}$ aufgereinigt und eine PCR mit den Primern near-as1/20381N (A,B,C,D) und uni24/20381N (E,F) für 29 Zyklen durchgeführt. Die Spuren 1, 2 und 3 zeigen die Immunopräzipitationen, die Spuren 4, 5 und 6 die dazugehörige PCR der Input-DNA. Die Auftrennung erfolgte im 1\% Agarosegel. Die DNA wurde mit Ethidiumbromid angefärbt.(B:) Als Orientierung sind die Skizze der Reportergenkonstrukte mit den Primer-Ansatzstellen gezeigt.

In den Reaktionen A, B und F lässt sich ein durchgängiges PCR-Signal der gleichen Stärke feststellen. Dies deutet auf eine konstitutive Bindung der TGA-K2 am isolierten as-1Element hin, da in den ChIP-Reaktionen mit dem Chromatin der Zeitwerte 0, 3 und $12 \mathrm{~h}$ die gleiche Menge an DNA präzipitiert werden konnte. Die Input-Kontrollen von A und B (Spuren 3, 4 und 5) erreichen die gleiche Signalstärke wie die ChIP (Spuren 1, 2 und 3), 
während sie bei F schwankt. Diese Schwankungen traten ebenso in den Input-Kontrollen der Reaktion D auf. Leichte Schwankungen sind ebenfalls bei E sichtbar. Reaktion C weist eine Abnahme der Signalstärke bei 3 h auf, gefolgt von einer Steigerung des PCR-Signals für den $12 \mathrm{~h}$-Wert, welcher bis hin zur Stärke des $0 \mathrm{~h}$-Wertes reicht. Die Signalstärke der ChIP-PCR reichte in manchen Fällen an die Stärke der PCR-Signale der Input-Kontrolle heran. Dies kann bedeuten, dass sich die PCR nicht mehr in der exponentiellen Phase befindet, sondern bereits die Phase der Sättigung ereicht haben kann. Aus diesem Grund wurde mit zusammengeführtem Material ( $3 \mathrm{~h}$ und $12 \mathrm{~h}$ ) der ChIP aus Abb. 5.16 A eine PCR mit Primern near-as1/20381N für verschiedene Anzahl an Zyklen durchgeführt. In Abb. 5.17 sieht man, dass die PCR mit 29 Zyklen genau im Mittelfeld der Signalstärken liegt. Es konnte somit gezeigt werden, dass die PCR nicht in die Phase der Sättigung hineinreicht.

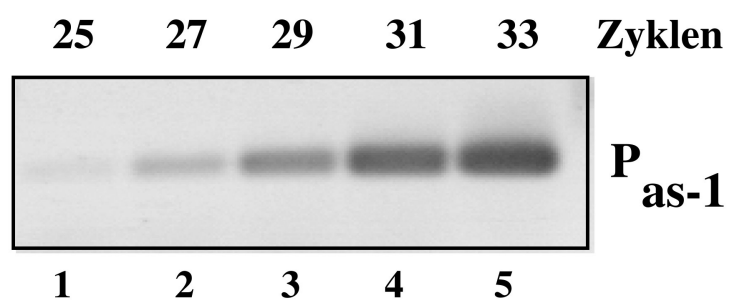

Abbildung 5.17: Analyse der DNA nach Immunopräzipitation mit $4 \mu \mathrm{l}$ Antiserum $\alpha$ TGA2-C und Chromatin-Proben äquivalent zu $15 \mu \mathrm{g}$ DNA. Das Chromatin wurde aus FA-quervernetzten (20 min) Blättern der Linie SNN as-1::GUS extrahiert, die mit SA (1 mM) für $3 \mathrm{~h}$ und $12 \mathrm{~h}$ behandelt wurden. Die DNA wurde nach Reversion der Quervernetzung durch $16 \mathrm{~h}$ Inkubation bei $65 \mathrm{C}^{\circ}$ aufgereinigt. Eine PCR mit den Primern near-as1/20381N wurde für die angegebenen Zyklen mit den zusammengeführten Zeitpunkten durchgeführt. Die Auftrennung erfolgte im 1\% Agarosegel. Die DNA wurde mit Ethidiumbromid angefärbt. 
Ein ähnliches Experiment zeigt Abb. 5.18. Es wurde eine PCR auf der ChIP-DNA aus Reaktion A der Abb. 5.16 sowie den korrespondierenden Input-Kontrollen mit den Primern near-as1/20381N zu verschiedenen Zyklenzahlen durchgeführt. Es konnte gezeigt werden, dass sich sowohl die Input-Kontrollen als auch die ChIP-DNA mit 29 Zyklen nicht in der Sättigungsphase der PCR befunden haben. Vielmehr stellt die gewählte Anzahl an Zyklen einen günstigen Wert dar. Würde die PCR mit weniger Zyklen durchgeführt werden, wären kaum oder nur sehr schwache Signale detektierbar. Bei mehr als 29 Zyklen wäre die PCR-Reaktion unquantifizierbar, da eine Sättigung erreicht ist und die Signale sich einem Maximalwert angleichen. Zusammenfassend kann für das as-1-Element eine konstitutive Bindung der TGA-K2 postuliert werden. Eine Induktion mit SA zeigt keine Änderung des Bindungsverhaltens.

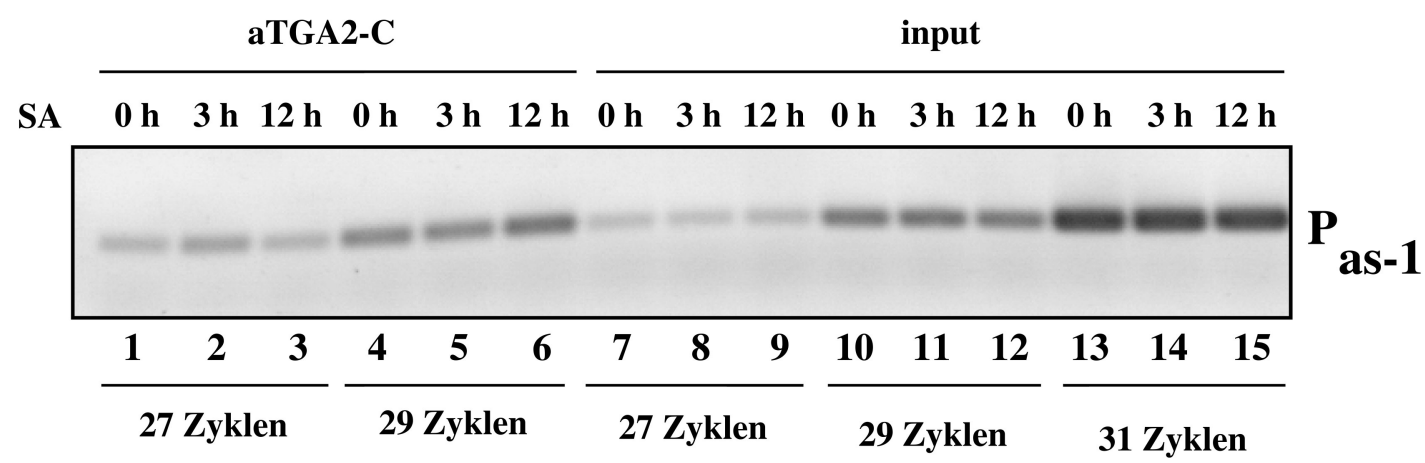

Abbildung 5.18: Analyse der DNA nach Immunopräzipitation mit $4 \mu \mathrm{l}$ Antiserum $\alpha$ TGA2-C und Chromatin-Proben äquivalent zu $15 \mu \mathrm{g}$ DNA. Das Chromatin wurde aus FA-behandelten (20 min) Blättern der Linie SNN as-1::GUS extrahiert, die mit SA (1 mM) für die angegebenen Zeitpunkte behandelt wurden. Die DNA wurde nach Reversion der Quervernetzung durch $16 \mathrm{~h}$ Inkubation bei $65 \mathrm{C}^{\circ}$ aufgereinigt und eine PCR mit den Primern near-as1/20381N für die angegebenen Zyklen durchgeführt. Die Spuren 1-6 zeigen die Immunopräzipitationen, die Spuren 7-15 die dazugehörige PCR der Input-DNA. Die Auftrennung erfolgte im 1\% Agarosegel. Die DNA wurde mit Ethidiumbromid angefärbt. 


\subsubsection{Das Bindeverhalten des TGA-K2 am as-1-ähnlichen Element $\operatorname{im} \operatorname{par} A$-Promotor}

Mit der ChIP-DNA aus Abb. 5.16 wurden PCR-Reaktionen mit Primern durchgeführt, welche das as-1-ähnliche Element des früh exprimierten Gens parA flankieren. Ebenso sollte hier die Bindungsaktivität der TGA-K2 durch die ChIP aufgelöst werden.

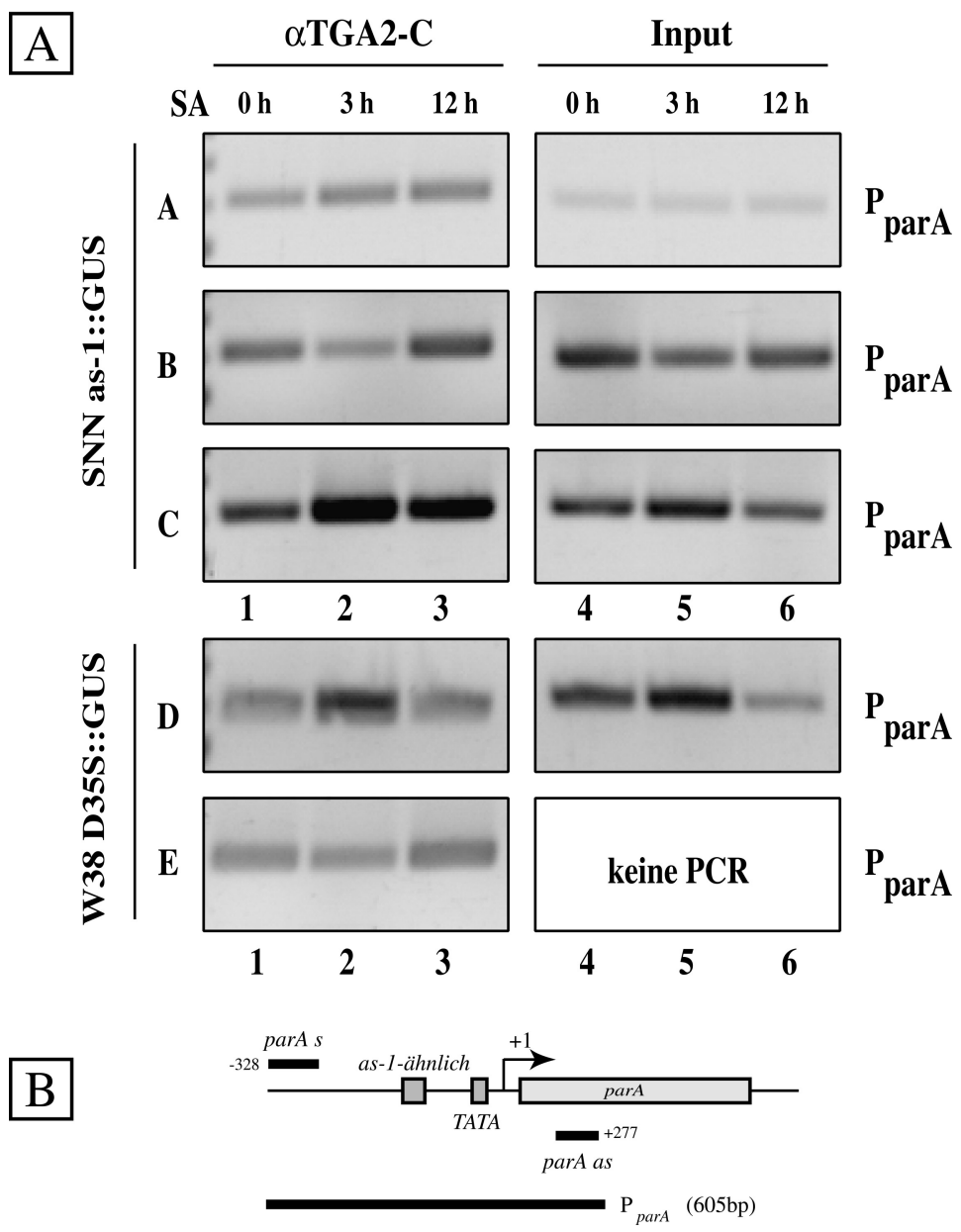

Abbildung 5.19: Analyse der DNA nach Immunopräzipitation mit $4 \mu$ l Antiserum $\alpha$ TGA2-C und Chromatin-Proben äquivalent zu $15 \mu \mathrm{g}$ DNA. Das Chromatin wurde aus FA-behandelten (20 min) Blättern der Linie SNN as-1::GUS extrahiert, die mit SA (1 mM) für die angegebenen Zeitpunkte behandelt wurden. Die DNA wurde nach Reversion der Quervernetzung durch $16 \mathrm{~h}$ Inkubation bei $65 \mathrm{C}^{\circ}$ aufgereinigt und eine PCR mit den Primern parA s/parA as für 29 Zyklen durchgeführt. Die Spuren 1, 2 und 3 zeigen die Immunopräzipitationen, die Spuren 4, 5 und 6 die dazugehörige PCR der Input-DNA. Die Auftrennung erfolgte im 1\% Agarosegel. Die DNA wurde mit Ethidiumbromid angefärbt.(B:) Als Orientierung ist die Skizze des Reportergenkonstruktes mit den Primer-Ansatzstellen gezeigt. 
Für die Reaktionen in Abb. 5.19 A und E (Spur 1, 2, 3] konnten konstante PCR-Signalstärken ermittelt werden. wobei sich der $0 \mathrm{~h}$-Wert in Reaktion A leicht unterhalb der anderen Signalstärken bewegt. Für die Reaktion B lässt sich eine Schwankung in der Signalstärke beobachten: Während der $0 \mathrm{~h}$-Wert den $12 \mathrm{~h}$-Wert widerspiegelt, ist für den $3 \mathrm{~h}$-Wert ein schächeres Signal detektierbar. Hierbei zeigt sich die weitere Bedeutung der InputKontrollen. Da die Reaktionen mit der Input-DNA in Spur B 4 und B 6 eine leichte Überladung zeigen, kann von einer ungleichen Beladung der ChIP-Reaktion bei diesem Experiment ausgegangen werden. Reduziert man die Signalstärke auf den $3 \mathrm{~h}$-Wert, so ist auch hier ein konstantes Signal über den gesamten Induktionszeitraum erkennbar. Für die ChIP-Reaktion D ist dies umgekehrt der Fall: Der 3 h-Wert erscheint höher als die beiden anderen Werte. Die Betrachtung der Input-Kontrollen hingegen liefert eine Überladung des 3 h-Wertes, sowie eine schwache Überladung des 0 h-Wertes. Zusammengenommen ergibt sich für die gezeigten Reaktionen A, B, D und E eine konstitutive Besetzung des as-1-ähnlichen Elements im parA-Promotor. Die Reaktion C hingegen zeigt sehr starke Schwankungen, die sich auch nicht durch Überladungen aus der ChIP-Reaktion erklären lassen. Dieses Experiment wurde mit Chromatinextrakten aus Pflanzen durchgeführt, die unter anderen Anzuchtbedingungen heranwuchsen. Ebenso wie in Reaktion D (Abb.5.16) ist die Besetzungskinetik des TGA2.2 scheinbar eine andere als bei Pflanzen, die in der Standard-Kammer aufgezogen worden waren.

\subsubsection{Das Bindeverhalten der TGA-K2 am as-1-ähnlichen Element im PR-1a-Promotor}

Für PR1- $a$ wurden insgesamt sehr klare Ergebnisse erzielt, die auf eine induzierte Bindung des PR-1a-Promotors während der SA-Induktion hinweisen. In sämtlichen Reaktionen in Abb.5.20 ist eine Signalzunahme erkennbar, die ihre maximale Stärke beim Wert $12 \mathrm{~h}$ erreicht. Die Input-Kontrollen zeigen bis auf Reaktion Abb. 5.20 A Spur 4 keine Auffälligkeiten. Vielmehr ist bei Reaktion E in Abb. 5.20 sogar eine leichte Unterbeladung der ChIP durch die Abnahme des Input-Signals erkennbar (Spur 4, 5 und 6), während das Signal in den Spuren Abb. 5.20 E 1, E 2 und E 3 ansteigt. Es zeigte sich, dass die Pflanzen des Kultivars W38 deutlich stärkere ChIP-Signale hervorbringen. Die Stärke der PCR-Signale übertrifft die von SNN bei weitem, trotz der gleichen eingesetzten Menge an Chromatin. Diese Ergebnisse sind konform zu den Beobachtungen die bei der ChIP mit dem affinitätsaufgereinigtem Antikörper $\alpha$ TGA2.2C in Kapitel 5.5.1 gemacht wurden. 

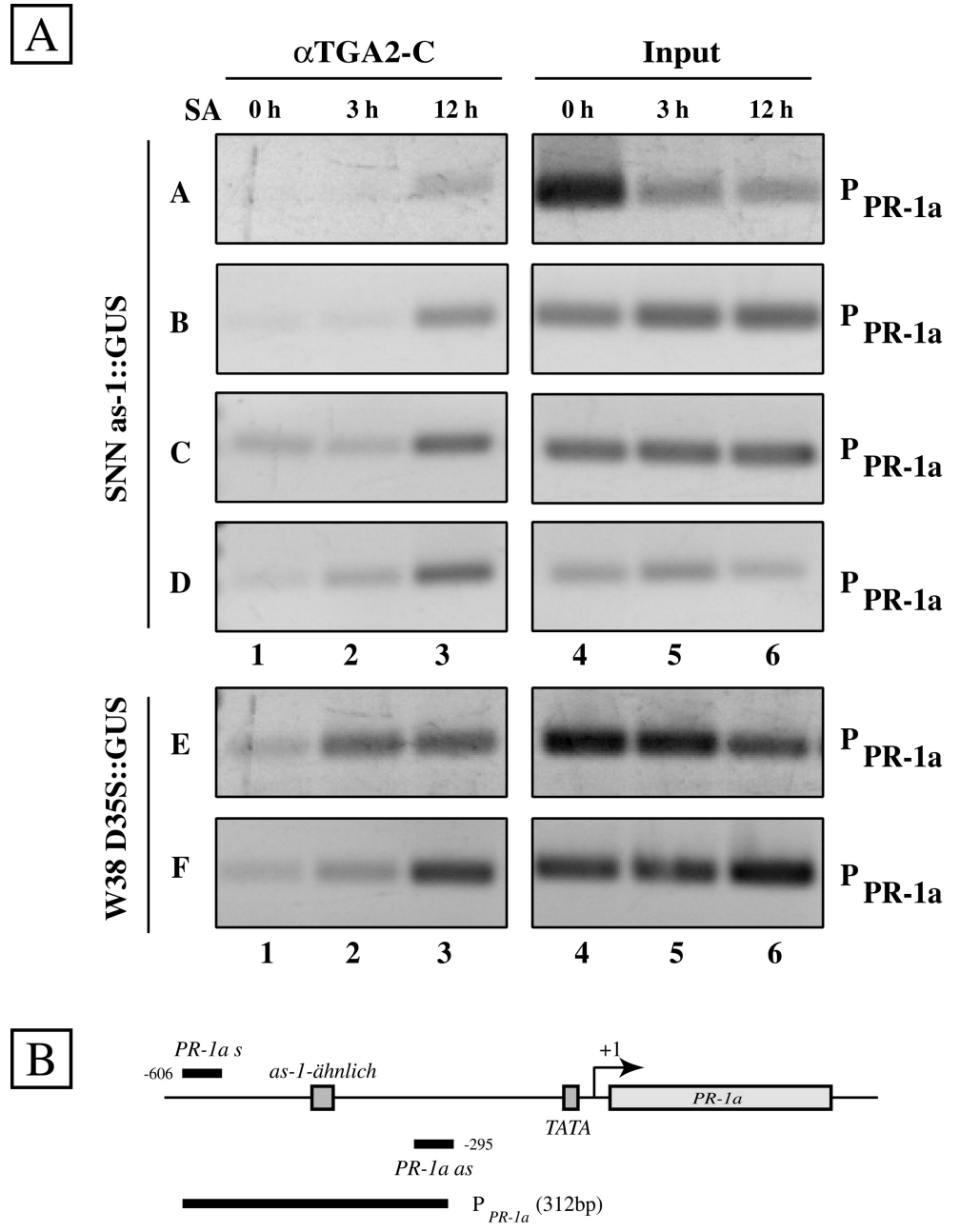

Abbildung 5.20: Analyse der DNA nach Immunopräzipitation mit $4 \mu \mathrm{l}$ Antiserum $\alpha$ TGA2-C und Chromatin-Proben äquivalent zu $15 \mu \mathrm{g}$ DNA. Das Chromatin wurde aus FA-behandelten (20 min) Blättern der Linie SNN as-1::GUS extrahiert, die mit SA $(1 \mathrm{mM})$ für die angegebenen Zeitpunkte behandelt wurden. Die DNA wurde nach Reversion der Quervernetzung durch $16 \mathrm{~h}$ Inkubation bei $65 \mathrm{C}^{\circ}$ aufgereinigt und eine PCR mit den Primern $P R-1 a s / P R-1 a$ as für 29 Zyklen durchgeführt. Die Spuren 1, 2 und 3 zeigen die Immunopräzipitationen, die Spuren 4, 5 und 6 die dazugehörige PCR der Input-DNA. Die Auftrennung erfolgte im 1\% Agarosegel. Die DNA wurde mit Ethidiumbromid angefärbt.(B:) Als Orientierung ist die Skizze des Reportergenkonstruktes mit den Primer-Ansatzstellen gezeigt. 


\subsubsection{Die Besetzung des as-1-Elements sowie as-1-ähnlicher Promotoren in TGA2.2RNAi-Linien}

Nachfolgend beschriebenes Experiment behandelte die Frage, ob sich in Pflanzen, die ein TGA2.2-RNAi-Konstrukt besitzen, gebundene as-1-Fragmente der korrespondierenden Promotoren präzipitieren lassen. THUROW et al (2005) konnten per Western-Analyse zeigen, dass die Menge an TGA2.2-Protein in diesen transgenen Linien deutlich reduziert ist. Expressionanalysen mittels Northern-Blot zeigten einen Verlust der Genexpression sowohl der frühen Gene as-1::GUS und Nt103-35 (GNT35) als auch des späten Gens PR-1a (THUROW et al., 2005).

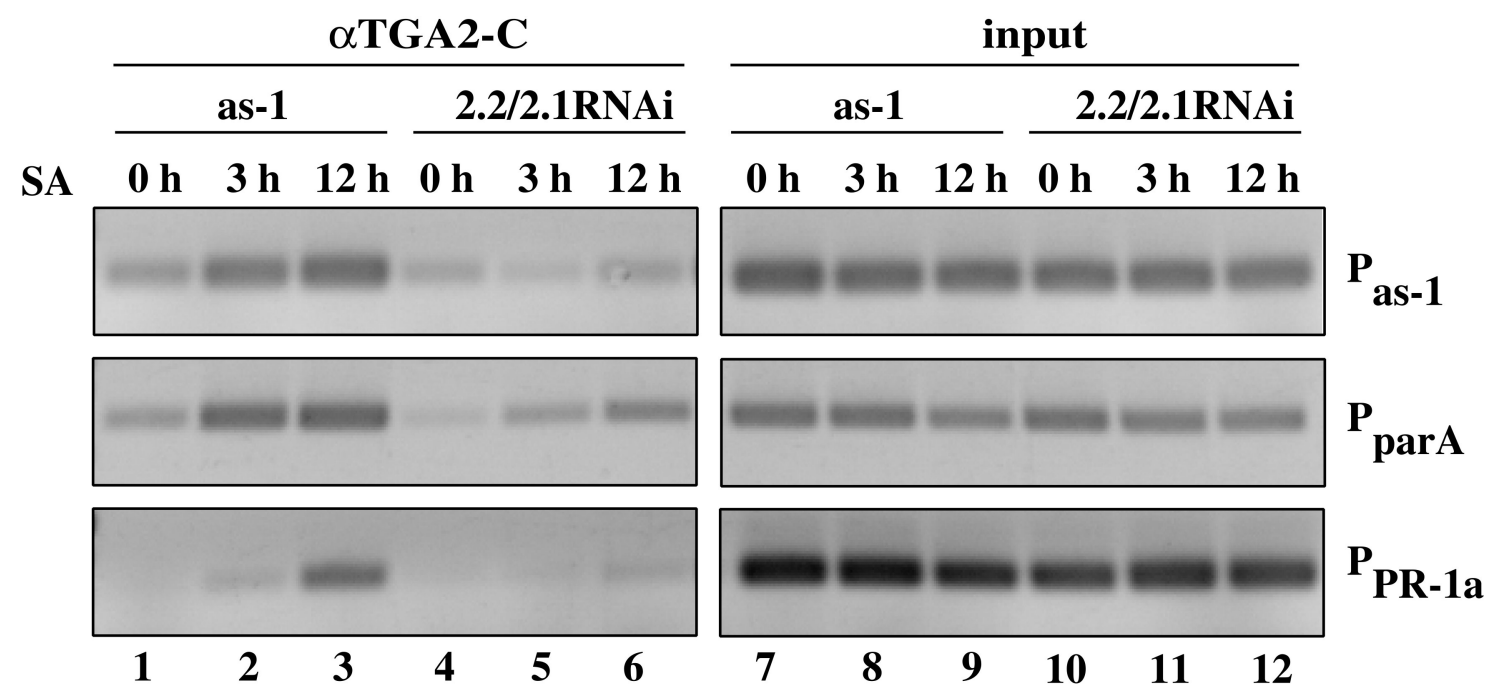

Abbildung 5.21: Analyse der DNA nach Immunopräzipitation mit $4 \mu$ l Antiserum $\alpha$ TGA2-C und Chromatin-Proben äquivalent zu $15 \mu \mathrm{g}$ DNA. Das Chromatin wurde aus FA-behandelten (20 min) Blättern der Linie SNN as-1::GUS und SNN TGA2.2/2.1-RNAi extrahiert, die mit SA (1 mM) für die angegebenen Zeitpunkte behandelt wurden. Die DNA wurde nach Reversion der Quervernetzung durch $16 \mathrm{~h}$ Inkubation bei $65 \mathrm{C}^{\circ}$ aufgereinigt und eine PCR mit den Primern near-as1/20381N, parA s/parA as sowie $P R$-1a s/PR-1a as für 29 Zyklen durchgeführt. Die Spuren 1-6 zeigen die Immunopräzipitationen, die Spuren 7-12 die dazugehörige PCR der Input-DNA. Die Auftrennung erfolgte im $1 \%$ Agarosegel. Die DNA wurde mit Ethidiumbromid angefärbt.

Es wurde eine vergleichende ChIP mit dem Antiserum $\alpha$ TGA2-C durchgeführt. Dazu wurden Pflanzen der Linien SNN as-1::GUS sowie SNN TGA2.2RNAi mit 1 mM Salizylsäure für $3 \mathrm{~h}$ und $12 \mathrm{~h}$ induziert. Als Kontrolle wurde unbehandeltes Blattmaterial geerntet. Die ChIP erfolgte mit $15 \mu \mathrm{g}$ DNA. Die PCR wurde mit den angegebenen Primern für 29 Zyklen durchgeführt. Abb. 5.21 zeigt das Ergebnis dieser ChIP. Die Input-Kontrollen 
sind relativ homogen, lediglich bei $P R 1 a$ lassen sich stärkere Signale bei den Zeitwerten $0 \mathrm{~h}$ und $3 \mathrm{~h}$ ausmachen (Spuren 7 und 8). Eine leichte Signalabnahme ist ebenfalls bei der Input-Kontrolle von parA beim Zeitwert $12 \mathrm{~h}$ (Spur 9) zu erkennen. Für die Besetzung des as-1-Elements (Spuren 1, 2 und 3) sieht man eine konstante Zunahme des PCR-Signals über die gesamten Zeitwerte, während in den Proben der RNAi-Linie kaum Signale erscheinen (Spuren 4, 5 und 6). Bei $P R-1 a$ ist diese Signalstärke nicht so stark ausgeprägt, sie erreicht aber ihren Maximalwert auch bei $12 \mathrm{~h}$ (Spur 3).

\subsubsection{Funktionsanalyse des VP16-TGA2.2}

Mit Hilfe der ChIP-Technik wurde das in vivo Bindungsverhalten der von LENK (2001) generierten TGA2.2-VP16 Fusionsproteine untersucht. Hierzu wurde das in Kapitel ?? getestete $\alpha \mathrm{VP} 16$-Antiserum in einer ChIP mit transgenen Pflanzen SNN TGA2.2-VP16 F1 und F2 verwendet. Da die F2-Pflanzen in ihrem Wuchs eindeutige Entwicklungsretardationen aufwiesen, wurde das geerntete Blattmaterial aus den Linien F1/F2 gemischt. Im Vorfeld wurden die einzelnen Linien auf eventuelle Unterschiede im Fusionsproteingehalt hin untersucht. Abb. 5.3 auf Seite 40 zeigte deutlich, dass beide Pflanzenlinien die gleiche Menge an Fusionsprotein exprimierten. Die ChIP wurde mit $18 \mu \mathrm{g}$ DNA und $4 \mu \mathrm{l}$ Antiserum $\alpha$ VP16 (SA4134) durchgeführt. 


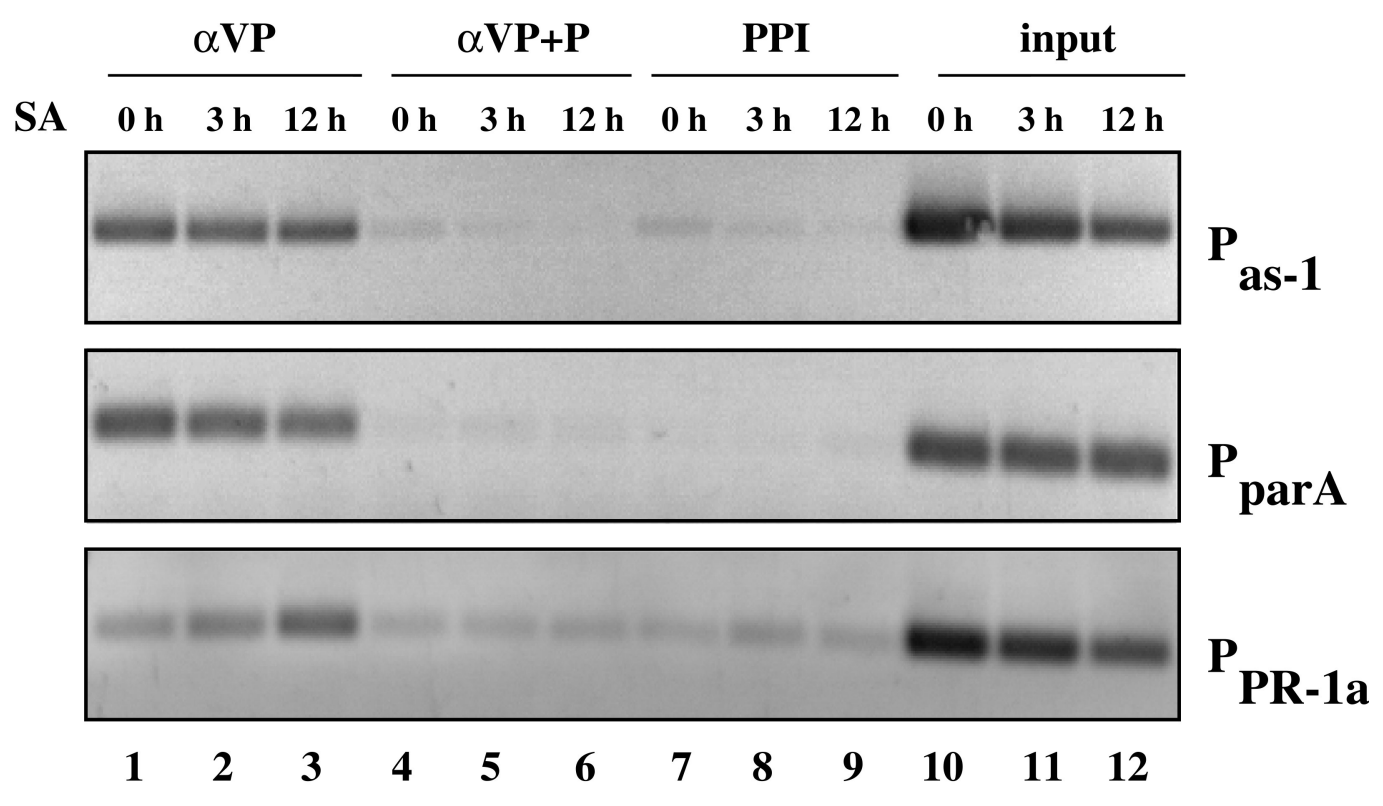

Abbildung 5.22: Analyse der DNA nach Immunopräzipitation mit $4 \mu$ l Antiserum $\alpha$ VP16 und ChromatinProben äquivalent zu $15 \mu \mathrm{g}$ DNA. Das Chromatin wurde aus FA-behandelten (20 min) Blättern der Linie SNN TGA2.2-VP16 extrahiert, die mit SA $(1 \mathrm{mM})$ für die angegebenen Zeitpunkte behandelt wurden. Die DNA wurde nach Reversion der Quervernetzung durch $16 \mathrm{~h}$ Inkubation bei $65 \mathrm{C}^{\circ}$ aufgereinigt und eine PCR mit den Primern near-as1/20381N, parA s/parA as sowie PR-1a s/PR-1a as für 29 Zyklen durchgeführt. Einigen Immunopräzipitations-Ansätzen wurden rekombinantes Protein als Kompetitor zugesetzt: Spuren 4-6 enthielten neben Antiserum zusätzlich $30 \mu \mathrm{g}$ VP16-GST. Die Spuren 7-9 zeigen die Immunopräzipitationen mit $4 \mu \mathrm{l}$ Prä-Immunserum VP16, die Spuren 10-12 die dazugehörige PCR der Input-DNA. Die Auftrennung erfolgte im 1\% Agarosegel. Die DNA wurde mit Ethidiumbromid angefärbt.

Das Ergebnis dieser ChIP zeigt Abb. 5.22 und Abb. 5.23 A. Die Input-Kontrollen zeigen eine leichte Überladung der Reaktion für den Zeitpunkt $0 \mathrm{~h}$ in Relation zu den übrigen Werten 3 und 12 h. Diese Überladung zeigt sich daraufhin in der PCR als stärkeres Signal, da während der ChIP mehr DNA präzipitiert werden konnte. Es konnte gezeigt werden, dass für TGA2.2-VP16 eine konstitive Bindung sowohl für as-1 als auch für parA vorliegt. Eine induzierbare Bindung liegt beim as-1-ähnlichen Element des $P R$-1a-Promotors vor. Andere unabhängig durchgeführte Experimente unter den gleichen Bedingungen ergaben die gleichen Ergebnisse (s. Abb. 5.23 B). 


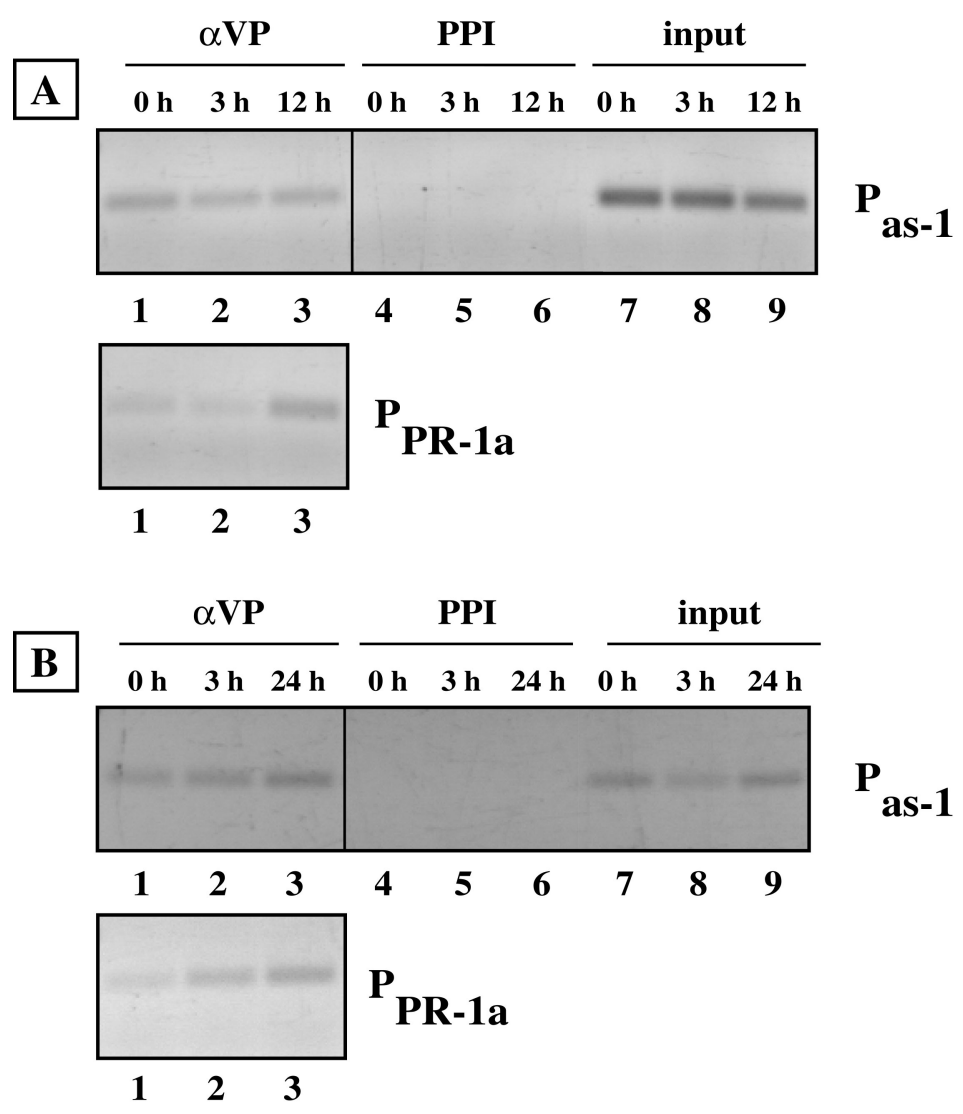

Abbildung 5.23: (A,B): Analyse der DNA nach Immunopräzipitation mit $4 \mu$ l Antiserum $\alpha$ VP16 und Chromatin-Extrakten äquivalent zu $15 \mu \mathrm{g}$ DNA aus. Das Chromatin wurde aus FA-behandelten (20 min) Blättern der Linie SNN TGA2.2-VP16 extrahiert, die mit SA $(1 \mathrm{mM})$ für die angegebenen Zeitpunkte behandelt wurden. Die DNA wurde nach Reversion der Quervernetzung durch $16 \mathrm{~h}$ Inkubation bei $65 \mathrm{C}^{\circ}$ aufgereinigt und eine PCR mit den Primern near-as1/20381N, parA s/parA as sowie PR-1a s/PR$1 a$ as für 28 Zyklen durchgeführt. Die Auftrennung erfolgte im 1\% Agarosegel. Die DNA wurde mit Ethidiumbromid angefärbt.

Bei den Experimenten in Abb. 5.23 A handelt es sich um eine PCR auf derselben ChIPDNA wie bereits in Abb. 5.22 beschrieben, die jedoch mit nur 28 Zyklen durchgeführt wurde. Demnach fielen die PCR-Signale für as-1 und $P R$-1a schwächer aus. Es konnte jedoch gezeigt werden, dass auch hier eine konstitutive Bindung am as-1-Element sowie eine induzierbare Bindung am PR-1a-Promotor vorlag. Abb. 5.23 B hingegen zeigt eine unabhängige ChIP mit $15 \mu \mathrm{g}$ DNA und $4 \mu \mathrm{l} \alpha \mathrm{VP} 16$-Antiserum. Bei dieser ChIP sind in den Spuren 4, 5 und 6 deutliche PCR-Produkte zu sehen. Bei den Spuren handelt es sich um die Kompetitionskontrollen mit rekombinanten Protein. Da das Protein in diesem Fall nicht erkannt wurde, kann von einer Degradation des Antigens ausgegangen werden. Es zeigte sich wiederum die gleiche konstitutive Bindung des TGA2.2-VP16 am as-1-Element, während der PR-1a-Promotor nach SA-Behandlung induzierbar gebunden wird. 


\subsection{Histon-Acetylierungen an Promotoren der frühen und späten Genantwort}

In den Zellkernen aller Eukaryoten liegt die DNA in verdichteter Form in Assoziation mit Proteinen vor. Man spricht vom Chromatin. Diese Verdichtung erfolgt durch Interaktion von Histonen und anderen Proteinen mit der DNA. Es handelt sich hierbei um keinen fest zusammengefügten Komplex, vielmehr um einen Zustand fortwährender dynamischer Veränderung. Ein Histon besteht aus einem Oktamer der Moleküle H2A, H2B, H3 und H4 (zwei von jedem). Sie bilden den Kern eines als Nukleosom bezeichneten Komplexes aus Histon und DNA, wobei zwei Umdrehungen der Doppelhelix eine Verbindung mit dem Histon eingehen. Die basischen Histone besitzen einen variablen N-Terminus spezifischer Ladung, welcher im Englischen als „histone tail“ bezeichnet wird (JENUWEIN und ALLIS, 2001). Dieser N-Terminus kann sehr spezifisch durch Enzyme verändert werden und dadurch seine Affinität zur DNA wechseln. Diese Zustandsänderung geht einher mit der Steigerung der transkriptionellen Aktivität (JOHNSON, 2000). Es können Acetylierungen, Phosphorylierungen aber auch Methylierungen stattfinden. Die Spezifität dieser Enzyme kann sich dabei auf nur wenige Aminosäuren beschränken (STRAHL und ALLIS, 2000; TURNER, 2000). Somit kann das Chromatin sehr spezifisch verändert werden. Man spricht dabei von Heterochromatin, wenn es in der verpackten, verdichteten Form vorliegt und von Euchromatin (griechisch: eu = fröhlich, gut), wenn es in einer offenen Form vorkommt. Der Unterschied dieser beiden Zustände liegt in dem Grade der Modifikation des $\mathrm{N}$-Terminus des Histons.

Besonderes Augenmerk liegt hierbei auf dem Acetylierungsgrad. Die spezifischen Enzyme hierfür sind zum einen die Histon-Acetyltransferase (HAT), welche eine Acetylierung von Lysinresten hervorufen kann, und zum anderen die antagonistisch wirkende HistonDeacetylase (HDAC). Wird z.B. Histon H3 oder H4 acteyliert, so wird u.a. die Bindung zur DNA gemildert und die DNA transkriptionell aktivierbar durch die Möglichkeit zur Bindung von Trankriptionsfaktoren oder anderen transkriptionellen Steuerproteinen. Hierbei können bis zu vier Lysinreste des N-Terminus vom Histon acetyliert werden.

Dies bedeutet, dass es neben der Basis-Regulation - der Genexpression - noch eine übergeordnete Regulation gibt. Es zeigte sich, dass es einen regelrechten Histon-Code gibt, der verschiedene Kombinationen an Modifikationen und somit verschiedene Zustände des Chromatins ermöglicht (STRAHL und ALLIS, 2000). Es konnte von UTLEY et al. (1998), VIGNALI et al. (2000) und IKEDA et al. (1999) gezeigt werden, dass Proteinkomplexe mit 
Acetyltransferase-Akitvität die Interaktion mit einem Transkriptionsaktivator benötigen, um die Transkription aktivieren zu können. Diese SAGA- und NuA4-Komplexe zeigten ebenso starke Interaktion mit der Aktivierungsdomäne VP16 aus Herpes simplex.

Eventuell könnte die Expression der frühen und späten Gene ebenso über einen solchen Mechanismus der höhergeordneten Chromatinregulation gesteuert werden. Aus diesem Grund wurden Chromatinextrakte aus SA induzierten Blättern der Pflanzenlinie SNN as-1::GUS gewonnen. Die Zeitwerte der Induktion betrugen wiederum $3 \mathrm{~h}$ und $12 \mathrm{~h}$. Ein 0 h-Wert wurde als Kontrolle präpariert. Die Quantifizierung der DNA erfolgte über die Aufreinigung eines $50 \mu \mathrm{l}$ Aliquots. Pro ChIP-Reaktion wurden $15 \mu \mathrm{g}$ DNA eingesetzt. Als Antikörper wurden $4 \mu \mathrm{l}$ eines polyklonalen Antiserums gegen hyperactelyierte Histone H4 verwendet (Cat. \#06-866; Firma Upstate-Biomol). Dieses Antiserum erkennt 3- bis 4fach acetylierte Histone H4. Der Antikörper präzipitiert in diesem Experiment demnach nur quervernetzte acetylierte H4-DNA-Komplexe. Je stärker also das PCR-Signal in der PCR ausfällt, desto höher der Acetylierungsgrad des Histons H4. Abb. 5.24 zeigt das Ergebnis dieses ChIP-Experiments.

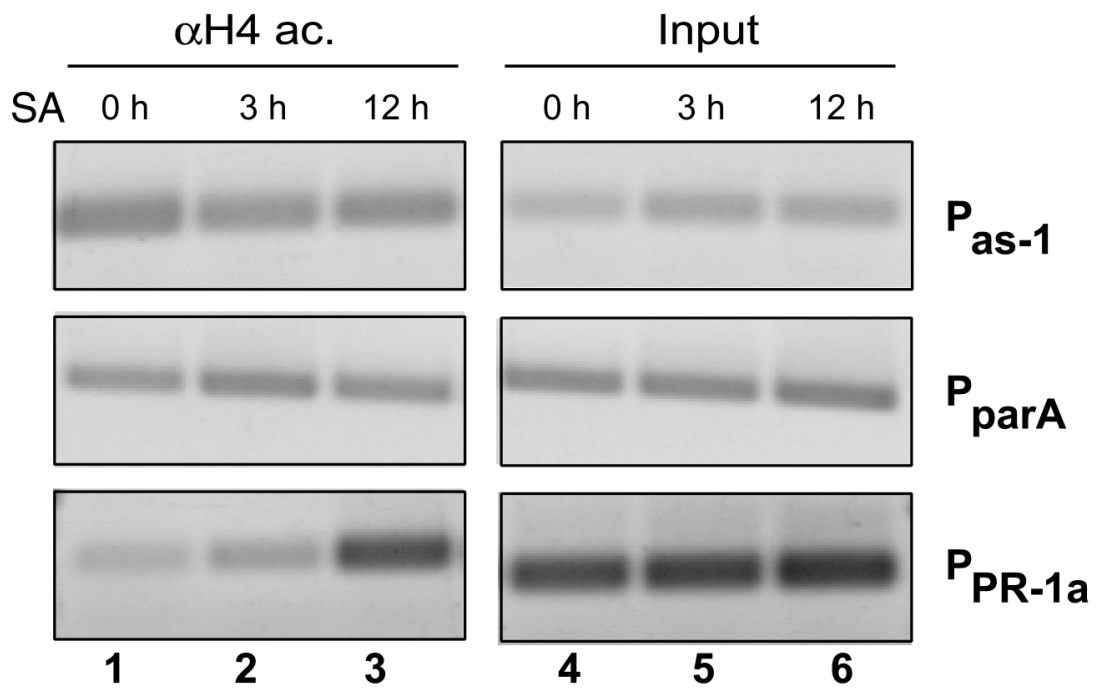

Abbildung 5.24: Analyse der DNA nach Immunopräzipitation mit $4 \mu$ l Antiserum $\alpha \mathrm{H} 4 \mathrm{ac}$ und ChromatinExtrakten äquivalent zu $15 \mu \mathrm{g}$ DNA. Das Chromatin wurde aus FA-behandelten (20 min) Blättern der Linie SNN as-1::GUS extrahiert, die mit SA (1 mM) für die angegebenen Zeitpunkte behandelt wurden. Die DNA wurde nach Reversion der Quervernetzung durch $16 \mathrm{~h}$ Inkubation bei $65 \mathrm{C}^{\circ}$ aufgereinigt und eine PCR mit den Primern near-as1/20381N, parA s/parA as sowie PR-1a s/PR-1a as für 29 Zyklen durchgeführt. Die Spuren 1-6 zeigen die Immunopräzipitationen, die Spuren 7-12 die dazugehörige PCR der Input-DNA. Die Auftrennung erfolgte im 1\% Agarosegel. Die DNA wurde mit Ethidiumbromid angefärbt. 
Für das as-1-Element ist keine signifikante Änderung des PCR-Signals erkennbar. Auch die Input-Kontrolle zeigt keinerlei nennenswerte Auffälligkeiten, einzig eine sehr geringe Unterbeladung des 0 h-Wertes. Für parA verhält es sich genauso, denn auch hier ist keine außergewöhnliche Zu- oder Abnahme des PCR-Signals sichtbar. Jedoch kann für den PR1a-Promotor festgestellt werden, dass eine deutliche Zunahme des PCR-Signals im Verlauf der SA-Induktion erfolgt. Die Input-Kontrollen sind in ihrer Signalstärke außergwöhnlich stark ausgefallen, lassen jedoch durch ihre Gleichmäßigkeit und einem leicht schwächernen 0-Wert darauf schließen, dass die ChIP mit ausgeglichenen DNA-Input durchgeführt wurde. Eine Kompetition mit rekombinanten Protein konnte bei diesen Experimenten generell nicht erfolgen, da kein geeignetes Peptid zur Verfügung stand.

Es stellte sich bei Betrachtung der Ergebnisse (Abb. 5.24) die Frage, ob TGA-K2 Einfluss auf den Acetylierungsgrad der Histone H4 besitzen. Somit wurde eine ChIP mit Extrakten einer SA-Induktion mit SNN as-1::GUS sowie SNN TGA2.2/2.1-RNAi durchgeführt. Wieder wurden ein uninduzierter Wert als Kontrolle, sowie ein $3 \mathrm{~h}$ und $12 \mathrm{~h}$-Wert nach SA-Stimulus verwendet. Die ChIP erfolgte mit $4 \mu$ l Antiserum $\alpha H 4 a c$.

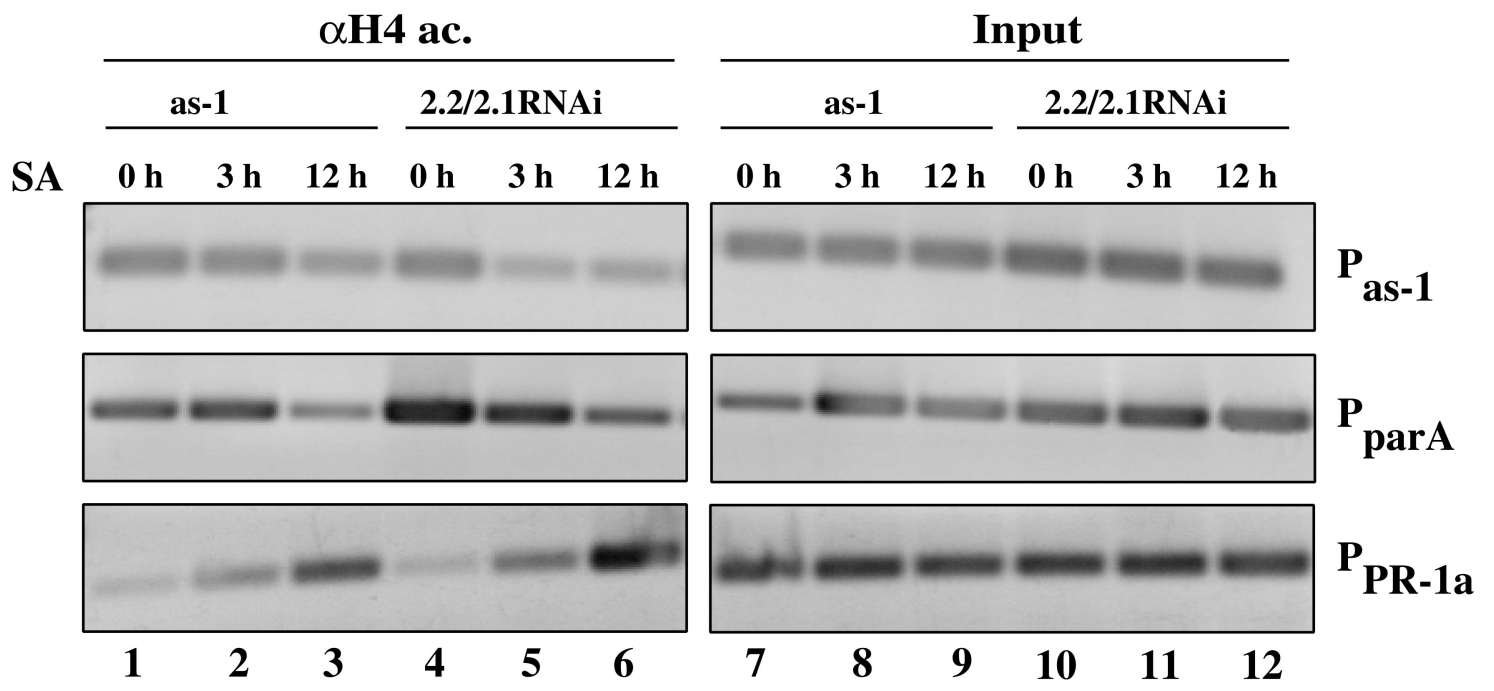

Abbildung 5.25: Analyse der DNA nach Immunopräzipitation mit $4 \mu \mathrm{l}$ Antiserum $\alpha \mathrm{H} 4 \mathrm{ac}$ und ChromatinExtrakten äquivalent zu $15 \mu \mathrm{g}$ DNA. Das Chromatin wurde aus FA-behandelten (20 min) Blättern der Linie SNN as-1::GUS und SNN TGA2.2/2.1-RNAi extrahiert, die mit SA (1 mM) für die angegebenen Zeitpunkte behandelt wurden. Die DNA wurde nach Reversion der Quervernetzung durch $16 \mathrm{~h}$ Inkubation bei $65 \mathrm{C}^{\circ}$ aufgereinigt und eine PCR mit den Primern near-as1/20381N, parA s/parA as sowie PR-1a $s / P R-1 a$ as für 29 Zyklen durchgeführt. Die Spuren 1-6 zeigen die Immunopräzipitationen, die Spuren 7-12 die dazugehörige PCR der Input-DNA. Die Auftrennung erfolgte im $1 \%$ Agarosegel. Die DNA wurde mit Ethidiumbromid angefärbt. 
Die Abb. 5.25 zeigt für die jeweiligen amplifizierten Bereiche des as-1-Elements, parA sowie PR-1a keine großen Unterschiede in der Signalstärke des PCR-Signals zwischen den Pflanzen SNN as-1::GUS und SNN TGA2.2/2.1-RNAi. Bei der PCR des as-1-Elements ist in beiden Fällen eine Abnahme des Signals beim $12 \mathrm{~h}$ Wert sichtbar. Auch für parA zeigt sich diese Abnahme, sowohl bei SNN as-1::GUS als auch bei SNN TGA2.2/2.1-RNAi. Lediglich die PCR mit Primern gegen das as-1-ähnliche Element des PR-1a-Promotors zeigt eine induzierbare Acetylierung der Histone H4. Die Input-Kontrollen zeigen in der parA-PCR eine Schwankung in der Signalstärke zwischen $0 \mathrm{~h}, 12 \mathrm{~h}$ und dem $3 \mathrm{~h}$-Wert. 


\subsection{Anwendung der 2D-Gelelektrophorese zur Identifizierung mög- licher Proteinmodifikation nach Induktion mit Salizylsäure}

Mittels 2D-Gelelektrophorese lassen sich Proteingemische in zwei unterschiedlichen, hintereinandergeschalteten Methoden sowohl nach ihrem isolektrischen Punkt als auch nach ihrem Molekulargewicht auftrennen. GÖRG et al. (2001) bietet eine breite Einführung in diese Technik. Zur Auftrennung von Tabak-Zellkernproteinen wurden Harnstoff-Extrakte nach Kapitel 4.13.1 angefertigt. Dazu wurde Blattmatererial der Pflanzen SNN as-1::GUS mit $1 \mathrm{mM} \mathrm{SA}$ für die Zeitwerte $3 \mathrm{~h}$ und $12 \mathrm{~h}$ induziert. Eine uninduzierte Kontrolle wurde ebenso genommen. Des weiteren wurde eine uninduzierte Probe von TGA2.2/2.1RNAi (THUROW et al., 2005)) aufgearbeitet. Eine Quantifizierung der Extrakte über ein Abgleichgel ließ sich, bedingt durch die Zusammensetzung des Extraktionspuffers nicht durchführen. Daher wurde eine Verdünnung des Proteinextraktes gegen einen BSAStandard mit der korrespondierenden Menge an Extraktionspuffer mittels Bradford-Test gemessen. Diese Konzentratonsbestimmung gibt allerdings erst verlässliche Werte ab einer Konzentration von etwa $0,8 \mu \mathrm{g} / \mu \mathrm{l}$, da im Bereich darunter die Interaktion des Extraktionspuffers mit dem Bradford-Reagenz eine zu starke Hintergrundfluoreszens ergibt. Für die isoelektrische Fokussierung wurden $300 \mu \mathrm{g}$ Zellkernproteine in einem $17 \mathrm{~cm}$ IPG-Streifen der Firma Bio-Rad aufgetrennt. Der pH-Bereich umfasste die Werte 3 - 10. Nach erfolgter Rehydrierung des Gels für $12 \mathrm{~h}$ erfolgte die Fokussierung mit $50.000 \mathrm{Vh}$ bei $20^{\circ} \mathrm{C}$. Im Anschluss wurden die Streifen bei $-80^{\circ} \mathrm{C}$ bis zur weiteren Verwendung gelagert. Vor der Auftrennung in der 2. Dimension erfolgt eine Inkubation der IPG-Streifen nacheinander in zwei Äquilibrierungspuffern. Puffer I enthält dabei zusätzlich zu Harnstoff als Hauptkomponenten das stark reduzierende Agenz Tributylphosphispin, welches für eine Reduktion der Sulfhydrylgruppen verantwortlich ist. In Puffer II ist als besonderer Bestandteil Iodacetamid enthalten, welches für eine Alkylierung der reduzierten Sulfydrylgruppen sorgt. In beiden Puffern ist zudem $2 \%$ SDS enthalten, damit die Proteine im SDS-PAGE aufgetrennt werden können. Die IPG-Streifen wurden daraufhin in einem $10 \%$ SDS-PAAG nach ihrem Molekulargewicht aufgetrennt. Der Gellauf erfolgte bei konstanten $15 \mathrm{~mA}$ für circa 30-45 min, gefolgt von $6 \mathrm{~h}$ bei konstanten $30 \mathrm{~mA}$. Im Anschluß daran wurden die aufgetrennten Proteine per Semi-Dry-Blot-Verfahren auf eine PVDF-Membran gelottet und über Nacht mit Milchpulver bei $4{ }^{\circ} \mathrm{C}$ inkubiert. Die Immunodetektion erfolgte mit den jeweils in den Abbildungsunterschriften genannten Antiseren. Für das in Abb. 5.26 gezeigte Experiment wurden Zellkernprotein-Extrakte von SNN as-1::GUS (Abb. 5.26 A, B und C 
und SNN TGA2.2/2.1RNAi (Abb. 5.26 D) hergestellt und über die 2D-PAGE aufgetrennt. Die Immunodetektion erfolgte mit dem affinitätsaufgreinigten Antikörper $\alpha 2.2 \mathrm{C}$. In den Abb. 5.26 A, B und C sind eine Ansammlung an Proteinen mit einem Molekulargewicht zwischen 35 und $40 \mathrm{kDa}$ erkennbar. Diese Ansammlung fehlt in der Linie TGA2.2RNAi (Abb. 5.26 B) gänzlich. Da die TGA2.2RNAi-Linien nachweislich nicht über das Protein TGA2.2 verfügen (THUROW et al., 2005), kann durch direkten Vergleich von Abb. 5.26 A, B, und C zu D festgestellt werden, dass es sich bei der Protein-Ansammlung um TGA2.2 handeln muss. Des weiteren lässt sich ein Hauptpunkt (Abb. 5.26 A, B und C) markiert mit einem Sternchen) mit demselben Molekulargewicht ausmachen, neben welchem jeweils in Richtung pH 3 als auch pH 10 weitere Proteine detektiert wurden. Sie sind in ihrer Stärke nicht so ausgeprägt.

Es zeigte sich bei allen drei Zeitpunkten ein nahezu gleiches Proteinmuster. Es kommt allerdings bei $3 \mathrm{~h}$ und $12 \mathrm{~h} \mathrm{SA}$ zu einer leichten Drift in Richtung pH 10 (Abb. 5.26). Versuch A und D sind parallel durchgeführt worden sowie B und C. Dies Phänomen kann bereits allein durch die experimentelle Varianz aufgetreten sein. 
pH 3

pH 10

SNN as-1::GUS 0h SA

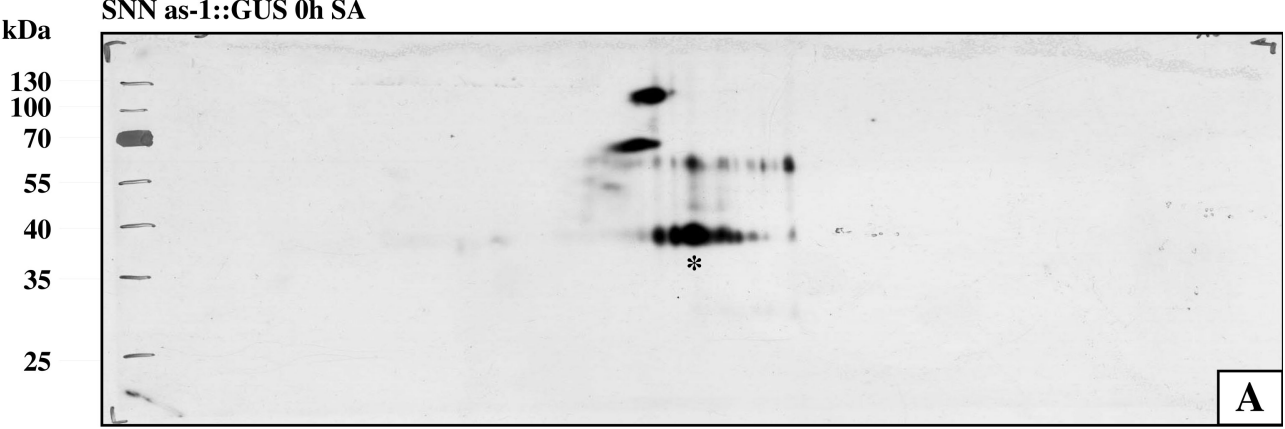

SNN as-1::GUS 3h SA

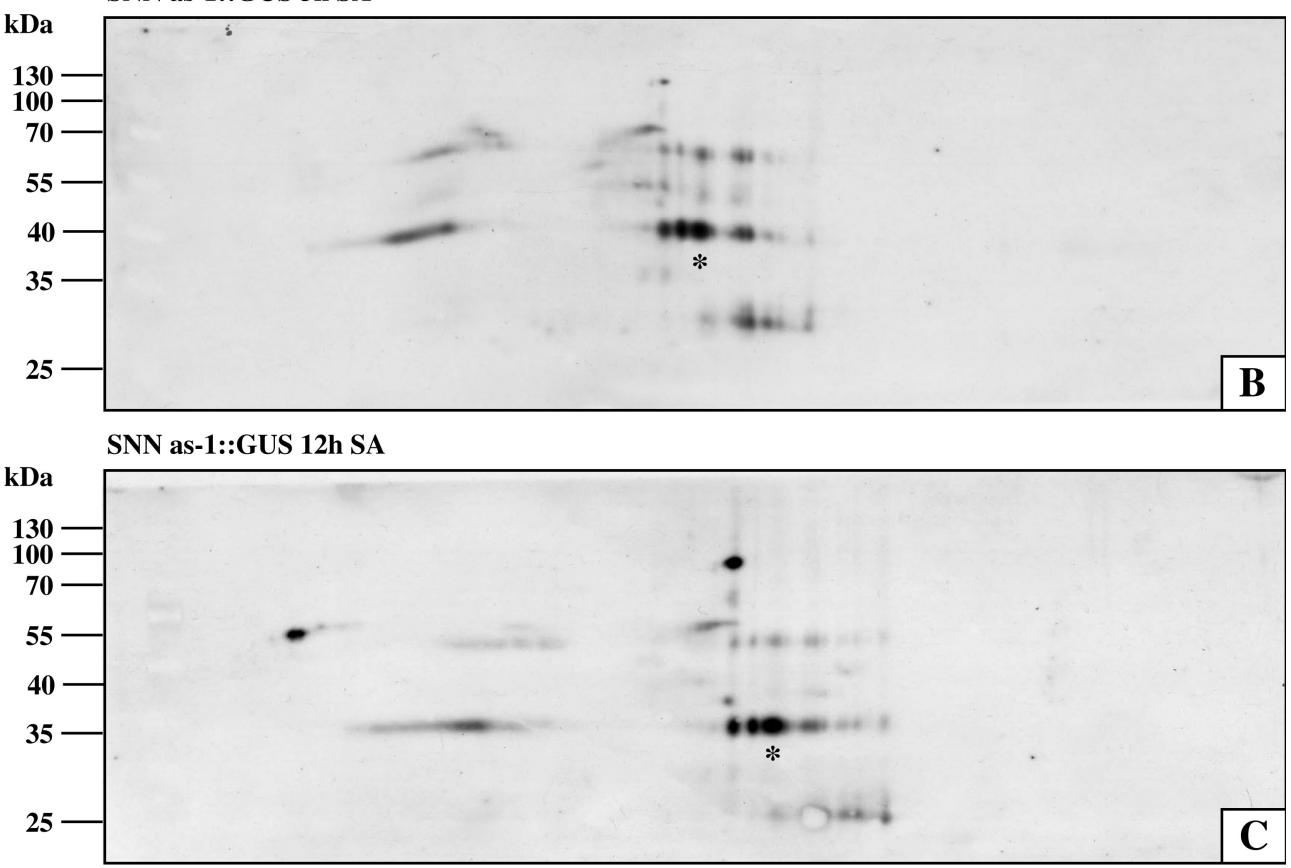

SNN TGA2.2RNAi/as-1::GUS 0h SA

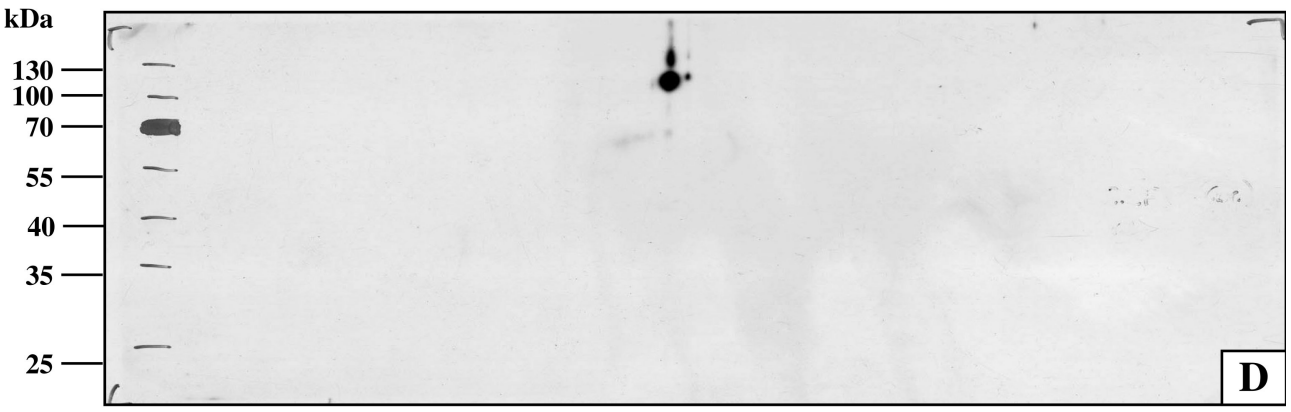

Abbildung 5.26: Western-Blot-Analyse von Harnstoff-2D-Proteinextrakten mit affinitätsaufgereinigtem Antikörper 2.2C. Es wurden jeweils $300 \mu \mathrm{g}$ denaturierte Harnstoff-2D-Extrakte aus Zellkernen SNN as1::GUS und SNN TGA2.2RNAi zu verschiedenen SA-Induktionszeiten isoelektrisch fokussiert ( $\mathrm{pH} 3-$ 10). Die Auftrennung der Proteine erfolgte im $10 \%$ SDS-PAAG. Im Anschluss wurden die Proteine mittels Western-Blot auf eine PVDF-Membran transferiert. Die Immundetektion wurde mit dem affinitätsaufgereinigtem Antikörper $\alpha 2.2 \mathrm{C}$ (1:1000 Verdünnung in 0.5\% Milchpulver/PBST) durchgeführt. Die Bestimmung des Molekulargewichts wurde über den parallelen Lauf von $6 \mu$ l PageRuler(Fa. Fermentas) ermittelt. 


\section{Diskussion}

\subsection{Die Chromatin-Immunopräzipitation als Technik zur Detek- tion von DNA-Protein-Interaktionen}

Ziel der Arbeit war es, die Bindung der Klasse-2-TGA-Faktoren TGA2.1 und TGA2.2 aus Nicotiana tabacum an das isolierte as-1-Element und an die Promotoren von parA (frühes Gen) und PR-1a (spätes Gen) in Abhängigkeit von Salizylsäure (SA) zu charakterisieren. Für diese Fragestellung wurde die Chromatin-Immunopräzipitation ausgewählt, da sie den in vivo-Zustand von Protein-DNA-Bindungen am besten wiedergibt.(ChIP; BOWLER et al., 2004). Aus der Literatur sind Beispiele bekannt, bei denen die ChIP bereits erfolgreich zur Untersuchung der Promotorregulation eingesetzt worden ist (WEINMANN und FARNHAM, 2001; WELLS und FARNHAM, 2002; TAVERNER et al., 2004). Diese Beispiele wurden mit Zellkulturen (z.B. HeLa-Zellen) oder Hefe (Saccharomyces cerevisiae) durchgeführt. Die Anwendung der ChIP für pflanzliche Modellorganismen entwickelte sich erst in den letzten Jahren. (JOHNSON et al., 2001b; CHUA et al., 2003; TURCK et al., 2004; DUROUX et al.; 2004).

Die Chromatin-Immunopräzipitation besteht aus mehreren Arbeitsschritten: Formaldahydbehandlung zur Quervernetzung der Proteine mit der DNA, Isolierung des Chromatins, Immunopräzipitation des Antigen-DNA-Komplexes mit spezifischen Antikörpern, Waschen des an Protein A-Sepharose gekoppelten Antikörper-Antigen-DNA-Komplexes, Elution des Protein-DNA-Komplexes, Reversion der Quervernetzung, Fällung der DNA, Detektion des präzipitierten DNA-Abschnitts mittels PCR.

Bei der Etablierung der ChIP für Nicotiana tabacum stellten sich mehrere Arbeitsschritte als kritisch heraus. Dazu gehörte zunächst die Behandlung des Blattmaterials mit Formaldehyd. Durch die Formaldehydbehandlung werden in der pflanzlichen Zelle die Proteine mit der DNA quervernetzt. Bei diesem Arbeitsschritt können zwei Probleme auftreten (s. Kapitel 5.3.1). Bei zu geringer Inkubationsdauer ist die Quervernetzung reduziert. Dieses wirkt sich negativ auf die DNA-Ausbeute beim Präzipitationsschritt aus. Auf der anderen Seite konnte bei einer Verlängerung der Formaldehyd-Behandlung eine Reduktion der DNA-Ausbeute beobachtet werden. Zusätzlich kann eine Denaturierung des Antigens durch das reaktive Formaldehyd oder die Quervernetzung des Antigens mit zufällig benachbarten Proteinen zu einem Verlust der antigenen Eigenschaften führen. Eine 20-minütige Inkubation erschien im Hintergrund der Experimente aus Kapitel 5.12 als 
geeignete Quervernetzungsdauer. Der zweite Punkt ist die Zusammensetzung des Chromatinextraktionspuffers. Die Wahl und Konzentration der verwendeten Detergenzien im Extraktionspuffer hat scheinbar Einfluss auf die Exposition der Epitope des Antigens während der Immunopräzipitation und somit auf die Antigen-Antikörper-Erkennung. Das Protokoll von WANG et al. (2002) verwendet als Detergenz Sarkosyl (0.5\%). Bei der Durchführung des Protokolls konnten in der abschließenden PCR zur Detektion des spezifischen DNA-Abschnitts nur Signale mit geringer Stärke nachgewiesen werden (s. Abb. 5.8). Die Extraktion in Anwesenheit von 0.5\% SDS wird im Protokoll nach TURCK et al. (2004) verwendet. ChIP-Experimente, bei denen diese SDS-Konzentration verwendet wurde, ergaben deutlich höhere Signalstärken im Vergleich zu Puffern mit Sarkosyl als Detergenz. Ein nachfolgender Verdünnungsschritt lässt die SDS-Konzentration auf $0.1 \%$ sinken. Diese Konzentration entspricht den Vorgaben der meisten Protokolle für eine Immunopräzipitation. Eine zu hohe SDS-Konzentration würde zu einer Denaturierung des Antikörpers führen. Ebenso zeigte sich, dass eine hohe Konzentration an reduzierenden Agenzien zu vermeiden ist. Die Isolation von Zellkernen aus Tabak erfolgte mit $8 \mathrm{mM}$ ß-Mercaptoethanol (ß-ME), da sich die von KEGLER (2001) vorgegebene Menge von $80 \mathrm{mM}$ als zu hoch erwies. Durch die Extraktion des Chromatins ist der Anteil an verbleibenden ß-ME im Extrakt relativ hoch. Die Auflösung der Disulfibrücken und somit die Denaturierung des Antikörpers bei der Immunopräzipitation könnten der Grund für ausbleibende PCR-Signale sein.

In den ersten ChIP-Experimenten erfolgte die Abschätzung des DNA-Gehalts im Chromatinextrakt noch über die Auftrennung eines Aliquots im Agarosegel. Ein Beispiel wird in Abb. 5.8 A gezeigt. Diese Methode ermöglichte jedoch nur eine grobe Abschätzung der DNA-Konzentration und ist für die genaue Quantifizierung ungeeignet. Die in den beschriebenen Experimenten verwendete Methode zur Bestimmung der DNA-Konzentration ist bei TURCK et al(2004) und in Kapitel ?? beschrieben. Sie umfasst die Aufreinigung eines Aliquots Chromatinextrakt über einen Proteinverdau mit Proteinase K, die Reversion der Quervernetzung sowie eine anschließende Phenol/Chloroform-Reinigung mitsamt Ethanolfällung. Der DNA-Gehalt der Probe kann nun ohne störende Proteinkontaminationen über die optische Dichte bei $260 \mathrm{~nm}$ gemessen werden. Für die ChIP bedeutet dies, dass für jede Probe die Menge an eingesetztem Chromatin bzw. DNA genau berechnet werden kann. Bei der Aufreinigung kann es jedoch zu Schwankungen durch Aufreinigungsverluste kommen. Da die Messung jedoch die Grundlage zur Bestimmung der 
DNA-Menge für die Chromatin-Immunopräzipitation darstellt, können sich Schwankungen auf die späteren PCR-Reaktionen auswirken. Dieses wurde bei den durchgeführten Experimenten zum Teil beobachtet (siehe „Input“-Kontrollen Abb. 5.25). Als weitere Methode zur Quantifizierung der Rohextrakte bietet sich an über die Messung der optischen Dichte bei einer Wellenlänge von $260 \mathrm{~nm}$ (SPENCER et al.2003) an. Diese Methode misst alle UV-absorbierenden Bestandteile, also auch quervernetzte Proteine und RNA. Eine direkte Messung des Extraktes ist anzustreben, da Aufreinigungen immer mit Verlusten und Fehlern verbunden sind.

Bei Verwendung der PCR als Nachweis präzipitierter DNA kann bei zu hohen Zyklenzahlen die Sättigungsphase der PCR eintreten. Eine Auflösung der zu detektierenden Bindungs-Unterschiede kann somit nicht erfolgen. Aufschluss über diese wichtige Fragestellung konnte die in Abb. 5.18 gezeigte Kontrolle geben. Hierbei wurden je drei Zeitwerte (0, 3 und $12 \mathrm{~h}$ nach SA-Behandlung) sowie die korrespondierenden Input-Kontrollen in einer PCR bei verschiedenen Zyklen verwendet. Das Ergebnis zeigt deutlich, daß mit den im Hauptteil der Experimente verwendeten Zyklenzahl nicht die Phase der Sättigung erreicht wurde. Eine weitaus genauere Methode stellt die Realtime-PCR dar. Sie wäre für weiterführende Experimente zu empfehlen.

\subsection{TGA-Faktoren der Klasse 2 binden konstitutiv und SA-un- abhängig am as-1-Element sowie am as-1-ähnlichen Element des frühen Gens parA}

In der vorliegenden Arbeit wurde zunächst die Besetzung des as-1-Elements und des as1-ähnlichen Elements im Promotor des frühen Gens GNT35 mit Klasse-2-TGA-Faktoren (TGA-K2) untersucht. Beide Gene waren Bestandteil früherer Untersuchungen zum Einfluss der TGA-Faktoren zur Genexpression (KEGLER et al., 2004; NIGGEWEG et al. 2000b; THUROW et al., 2005). Die ChIP-Experimente zur Analyse des frühen Gens GNT35 führten jedoch nicht zu verwertbaren Ergebnissen. Es ist anzunehmen, dass die Besetzung des GNT35-Promotors mit Klasse-2-TGA-Faktoren (TGA-K2) unterhalb der Nachweisgrenze lag. 
Als Alternative wurde das gut charakterisierte frühe Gen parA (str246) untersucht. TAKAHASI et al. (1995a) identifizierten ein durch Auxin induzierbares as-1-ähnliches cis-Element im Promotor dieses Gens. SAKAI et al. (1998) wiesen daraufhin die Bindung des ASF-1 an das as-1-ähnliche Element des Promotors in vitro mithilfe von EMSAExperimenten nach. Die Vermutung, dass die Expression des parA-Gens ebenfalls durch Salizylsäure induzierbar ist, wurde von NIGGEWEG et al. (2000b) bestätigt. Experimente mit TGA2.2-Überexpressionspflanzen zeigten eine 1,5 fach höhere Expression des Gens nach Salizylsäurestimulus. Wird eine dominant-negative Variante von TGA2.2, die nicht mehr an die DNA binden kann, in den pflanzlichen Zellen exprimiert, so wird die salicylsäureabhängige Expression von parA reduziert (NIGGEWEG et al., 2000b; PONTIER et al., 2001). In transgenen Pflanzen, in denen die Transkriptionsfaktoren TGA2.1 und TGA2.2 mittels Western-Blot-Analyse nicht mehr detektierbar sind (THUROW et al., 2005) können parA-Transkripte nach Salizylsäurebehandlung nur in reduzierter Menge nachgewiesen werden (C. Thurow, persönliche Mitteilung). Mithilfe der ChIP war es möglich, direkt in vivo die Bindung der TGA-Faktoren TGA2.1 und TGA2.2 am as-1-Element als auch am as-1-ähnlichen cis-Element des parA-Promotors nach Salizylsäurestimulus zu untersuchen.

Die Anwendung der ChIP konnte eine salizylsäureunabhängige, konstitutive Bindung der TGA-K2 am as-1-Element und am as-1-ähnlichen Element im Promotor des frühen Gens parA nachweisen. Dieses Ergebnis konnte sowohl mit Antiserum $\alpha$ TGA2-C in den Pflanzen SNN as-1::GUS und W38 $\triangle 35$ S::GUS (s. Abb. 5.16), als auch bei Verwendung des affinitätsaufgereinigten $\alpha$ TGA2.2C in Extrakten aus W38 $\Delta 35 \mathrm{~S}:$ :GUS (s. Abb. 5.14) erzielt werden. Über die Verwendung von zwei transgenen Linien mit verschiedenen Reportergenkonstrukten konnten somit insertionsbedingte Regulationsvorgänge ausgeschlossen werden. Das Konstrukt as-1::GUS wurde in den Vektor pIB1641 (Droge-Laser et al., 1994), $\triangle 35 S:: G U S$ in den BIN19 (BEVAN, 1984) kloniert.

Die konstitutive Bindung des Fusionsproteins TGA2.2-VP16 (LENK, 2001) konnte sowohl am as-1-Element als auch am as-1-ähnlichen Element von parA mit dem Antiserum $\alpha$ VP16 gezeigt werden (s. Abb. 5.6.5). Zusammengenommen zeigen die Ergebnisse somit eine konstitutive Bindung des endogenen TGA2.2 am as-1-Element sowie am Promotor parA. ChIP-Experimente mit Extrakten aus SNN TGA2.2/2.1-RNAi zeigten eine stark verminderte Besetzung des as-1-Elements (s. Abb. 5.21). Für parA konnte ebenso eine verminderte Bindung festgestellt werden. 
Die Summe der Ergebnisse der ChIP-Experimente widersprechen somit der von JUPIN und CHUA (1996) und STANGE et al. (1997) postulierten Bindungsverstärkung. JUPIN und CHUA (1996) konnten in Gesamtzellextrakten aus salizylsäurebehandelten Tabakblättern in vitro eine dreifach verstärkte Bindung des aus TGA2.2 und TGA2.1 bestehenden SARP-Komplexes an das as-1-Element nachweisen. Es wurde postuliert, dass die DNA-Bindeaktivität der TGA-Faktoren von einem Bindungsinhibitor (SAI) abhängig ist. Nach SA-Stimulus löst sich dieser Inhibitor von den TGA-Faktoren und die freigesetzten TGA-Faktoren binden an das as-1-Element. Experimente, bei denen durch Vorbehandlung der Extrakte mit Detergenzien die Proteininteraktionen aufgehoben wurden, führten ebenfalls zu einer Bindungsvestärkung und unterstützen somit diese Annahme. STANGE et al. (1997) konnten die Ergebnisse einer SA-induzierte Bindeverstärkung durch Experimente mit Zellkernextrakten bestätigen.

Unterstützt werden die Ergebnisse der ChIP-Experimente durch die Versuche, welche mit den von LENK (2001) beschriebenen Pflanzen SNN TGA2.2-VP16 durchgeführt wurden. Diese Pflanzen exprimieren ein Fusionsprotein, bestehend aus der kostitutiven Aktivierungsdomäne des viralen Proteins 16 aus Herpes simplex und TGA2.2. NorthernBlot-Analysen von LENK (2001) zeigten für SNN TGA2.2-VP16 im Gegensatz zu Wildtyppflanzen eine leichte Basalexpression der Gene GUS und GNT35. Diese wurde von LENK auf eine Restbindeaktivität des TGA2.2-VP16 zurückgeführt. Es konnte jedoch, trotz der Anwesenheit der starken Aktivierungsdomäne VP16, eine konstitutive Expression der genannten Gene nicht festgestellt werden. Die Schlußfolgerung, dass nur eine schwache in vivo-Bindung des TGA-Faktors an das as-1-ähnliche Element im uninduzierten Zustand stattfindet, werden durch die Ergebnisse der ChIP (s.Abb. 5.22) widerlegt. Somit scheint ASF-1/SARP nicht mit einem DNA-Bindungsinhibitor zu interagieren, sondern mit einem anderen inhibitorischen Protein, welches für die Repression der Transkription verantwortlich ist. Dieses Protein besitzt eine reprimierende Wirkung, da es in der Lage ist, die Wirkung der Aktivierungsdomäne VP16 fast vollständig zu unterdrücken (s. Abb. 6.1 B)

Daten von JUPIN und CHUA (1996), STANGE et al. (1997), HIDALOGO et al. (2001) und KANG und KLESSIG (2004) deuten auf Phosphyorylierungsereignisse im Zuge der SA-Antwort. Die Bindeaktivität von ASF-1 an das as-1-Element nimmt in vitro durch Phosphorylierung zu (JUPIN und CHUA, 1996; STANGE et al., 1997; HIDALGO et al., 2001). Inwieweit diese Modifikationen ASF-1/SARP oder den Transkriptionsrepressor (TKR) betreffen, kann nur vermutet werden. KANG und KLESSIG (2004) konnten zu- 
mindest für TGA2 aus Arabidopsis thaliana eine CK2-abhängige Phosphorylierung nach SA-Stimulus feststellen. Sie zeigten durch Sequenzvergleiche, dass der Bereich der Phosphorylierungen bei allen Mitgliedern der TGA-Familie hoch konserviert ist (KANG und KLESSIG, 2004).

Vorstellbar wäre, dass über den Anstieg der SA-Konzentration ein Mechanismus ausgelöst wird, der für die Ablösung des TKR vom ASF-1 durch Konformationsänderung oder Verdrängung verantwortlich ist. Allerdings muss eine Aktivierung über einen Ko-Aktivator erfolgen, da TGA2.2 selbst kein Aktvierungspotential besitzt und TGA2.1 allein für die Transkriptionsaktivierung nicht ausreicht. Dies wurde von THUROW et al. (2005) mit Pflanzen gezeigt, die ein TGA2.1-RNAi-Konstukt tragen. Hierbei wurde bei verringerten Mengen an TGA2.1 eine normale Expression des Reporters as-1::GUS, des frühen Gens GNT35 und des späten Gens PR-1a nach SA-Stimulus beobachtet. Eine Aktivierung der Expression könnte über die die Interaktion mit anderen Partnern ausgelöst werden (s.Modell Abb. 6.1 A). 

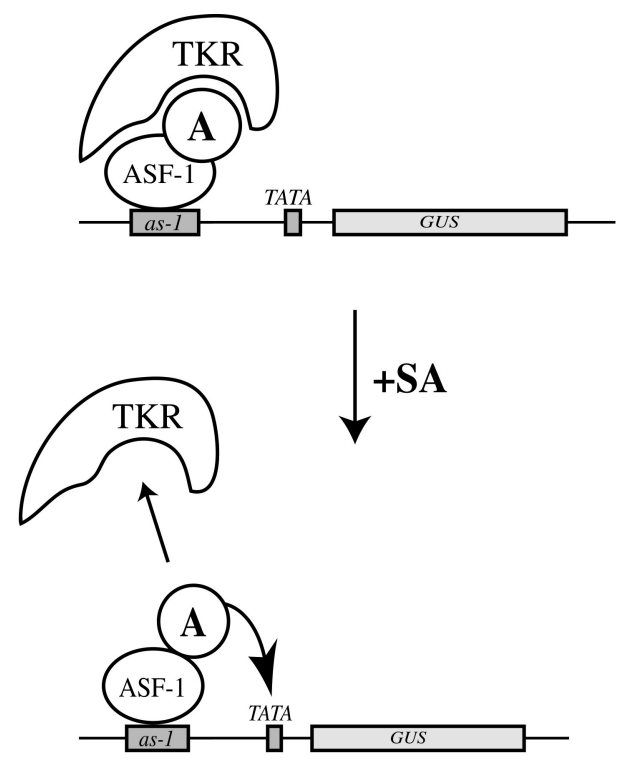

\section{Legende:}
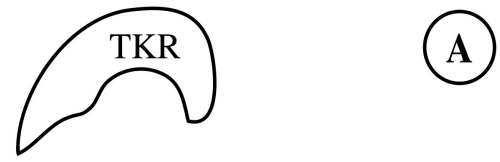

Transkriptionsrepressor

Aktivator

Abbildung 6.1: (A): Modell einer as-1-vermittelten Transkriptionsaktivierung. Legende: A ist ein nicht identifizierter Transkriptions-Aktivator, verbunden mit ASF-1 und dem TKR.

Die Expression der frühen Gene verläuft transient. Sehr schnell nach Salizylsäurestimulus ist mRNA nachweisbar. Nach einem Zeitraum von etwa 3-4 Stunden nimmt die Expression jedoch ab. Die Abnahme konnte in Zusammenhang mit einer de novoProteinsynthese gebracht werden (QIN et al. 1994). Nach Gabe von Cycloheximid, einem Inhibitor der Proteinbiosynthese, konnte LENK (2001) keine Signalabnahme der Expression des GUS-Reportergens beobachten. Dieses Ergebnis deutet darauf hin, dass der TKR im Zuge der Expression neu gebildet werden muss, um die Transkription durch eine Interaktion mit dem ASF-1/SARP abzuschalten. 


\subsection{Die Besetzung des as-1-ähnlichen Element im PR-1a-Promo- tor durch TGA-Faktoren der Klasse 2 ist durch Salizylsäure induzierbar}

Für TGA-K2 und TGA2.2-VP16 konnte im Zuge der SA-Antwort eine induzierte Bindung an das as-1-ähnliche Element im Pr-1a-Promotor nachgewiesen werden. Bei den untersuchten Zeitpunkten wurde das stärkste Signal $12 \mathrm{~h}$ nach SA-Stimulus detektiert (s. Abb. 5.20 und 5.22). Diese Daten aus Nicotiana tabacum entsprechen somit den von JOHNSON et al. (2003) für Arabidopsis thaliana gefundenen Ergebnissen. Die eng verwandten TGA-Faktoren TGA2 und TGA3 binden nach SA-Stimulus an das as-1-ähnliche Element $L S 7$ des PR-1-Promotors. JOHNSON konnte durch die Verwendung der sensitiven radioaktiven PCR eine Besetzung des LS7-Elements bereits nach $2 \mathrm{~h}$ zeigen. Ähnliches konnte durch die ChIP mit affinitätsaufgereinigtem Antikörper $\alpha$ TGA2.2C gezeigt werden (s. Abb. 5.14). Hierbei wurde eine Signalzunahme $3 \mathrm{~h}$ nach SA-Gabe detektiert.

Die ChIP-Experimente zeigen zudem eine unterschiedliche Affinität der TGA-K2 zu den untersuchten Promotoren im uninduzierten Zustand. Vergleicht man die PCR-Signale as-1 und parA mit Signalen von PR-1a, so werden die Unterschiede in der Besetzung deutlich. Während sich die Signale für die Promotoren der frühen Gene in ihrer Stärke kaum von der Input-DNA unterscheiden, erreichen die Signale des PR-1a-Promotors diese Stärke meist erst beim $12 \mathrm{~h}$-Wert. Dies lässt auf eine geringere Besetzung des $P R$ 1a-Promotors schließen. Hierbei könnten die Unterschiede zwischen den TGACG-Motiven des as-1-Elements entscheidend sein. Die Experimente von KRAWCZYK et al. (2002) zeigen den Einfluss des Abstands auf die Bindeaktivität von ASF-1 in vitro. Eine Deletion um zwei Basenpaare (bp) führt zu einer erhöhten in vitro-Bindung des ASF-1, während die Insertion von 2 bp eine Abnahme bewirkt. Diese Ergebnisse ließen sich ebenso für das rekombinante Protein TGA2.2 nachweisen. Im as-1-ähnlichen Element von PR-1a aus Nicotiana tabacum beträgt der Abstand zwischen den TGACG-Motiven 14 bp, bei $P R$ 1 aus sogar Arabidopsis thaliana 17 bp. Inwiefern der vergößerte Abstand zwischen den Palindromen für deren besondere regulatorische Eigenschaften verantwortlich ist, konnte noch nicht geklärt werden. Denkbar wäre, dass eine schwache DNA-Bindeaktivität durch Protein-Protein-Wechselwirkungen stabilisiert werden könnte. Als stabilisierendes Protein könnte NPR1 fungieren, da es bereits als interagierendes Protein für TGA2.1 und TGA2.2 aus Nicotiana tabacum (NIGGEWEG et al. 2000b) sowie TGA2, TGA5 und TGA6 aus Arabidopsis thaliana nachgewiesen wurde (ZHOU et al., 2000). Für npr1-Mutanten, die 
nicht mehr in der Lage sind, eine SAR ausbilden zu können, wurden keine Interaktionen mit TGA-Faktoren beobachtet (DESPRÉS et al., 2000; ZHOU et al., 2000). Experimente von DESPRÉS et al. (2000) zeigten eine Bindungsverstärkung sowohl des as-1-Elements als auch des $L S 7$-Elements von in vitro-translatiertem TGA2 in Gegenwart von NPR1. Allerdings basieren diese Ergebnisse auf Daten von EMSA-Analysen, entsprechen also bedingt dem in vivo-Zustand. JOHNSON et al. (2003) konnten zeigen, daß für die in vivoBindung des as-1-ähnlichen Elements LS7 durch TGA-Faktoren in Arabidopsis thaliana NPR1 notwendig ist. Eine weiterer Regulationsschritt könnte über Dof-Motiv bindenden (DNA binding with one finger; Dof-Motiv: A/TAAAG) Transkriptionsfaktoren der OBP-Familie erfolgen (CHEN et al., 1996). Mitglieder der OBP-Familie verstärken die Bindung von TGA-Faktoren am as-1-Element in vitro (ZHANG et al. 1995) Sie binden an die Konsensus-Sequenz A/TAAAG, die man z.B. auch im PR-1-Promotor von Arabidopsis thaliana gefunden hat (LEBEL et al. 1998) Für den PR-1a-Promotor aus Nicotiana tabacum können diese cis-regulatorischen Elemente angenommen werden. Denkbar wäre eine SA-induzierte Bindung und Interaktion von OBP1 mit ASF-1, verbunden mit einer Transkriptionsaktivierung.

\subsection{Einfluß von Strukturveränderungen des Chromatins}

Im Kapitel 5.7 wurde auf die Möglichkeit der Trankriptionsregulation über die Änderung der Chromatinstruktur hingewiesen. Die daraufhin durchgeführten Experimente, bei denen der Acetlyierungsgrad der H4-Histone im Zuge der SA-Induktion untersucht wurde, könnten somit Aufschluss über die Verfügbarkeit von Promotorbereichen für potenzielle Transaktivatoren, Repressoren und anderen regulatorischen Proteinen geben.

Die PCR-Reaktionen einer ChIP mit Antiserum gegen acetylierte Histone H4 in Abb. 5.24 zeigen über den gesamten SA-Induktionsverlauf ein Signal gleicher Stärke für das as-1-Element und den Promotor von parA. Die Signalstärke der einzelnen ChIP-PCRs reichen an die Stärke der Input-DNA heran (parA; Abb. 5.24) bzw. übersteigen diese sogar (as-1; s. Abb. 5.24). Ein weiteres unabhängiges Experiment konnte für das as-1-Element und parA eine Abnahme der Acetylierung durch SA feststellen. Jedoch wurden diese Pflanzen unter anderen Bedigungen angezogen als der Hauptteil des für die Experimente verwendeteten Materials. Um die Experimente aus Abb. 5.24 und 5.25 vergleichen zu können, ist es notwendig, das Experiment mit Pflanzen zu wiederholen, die unter gleichen Bedingungen angezogen wurden. 
Es kann für das as-1-Element und das frühe Gen parA nach Ergebnissen aus Abb. 5.24 eine basale Acetylierung angenommen werden. Das Ergebnis für parA steht jedoch im Widerspruch zu CHUA et al. (2004). Über eine ChIP, verbunden mit MicorarrayHybridisierungen, konnte eine sehr geringe Acetylierung für parA nachgewiesen werden. Erst nach Gabe von Trichostatin A, einem Inhibitor der für die Histon-Deactylierung wichtigen Deacetylase, konnte die Acetylierung mit einer verbundenen Expression des Gens detektiert werden. Für dies Ergebnis kann der physiologische Zustand des Ausgangsmaterials verantwortlich sein. Während CHUA et al. (2004) Keimlinge von Nicotiana tabacum verwendeteten, wurden die beschriebenen Versuche der vorliegenden Arbeit mit adulten Pflanzen durchgeführt, die zudem unter verschiedenen Bedingungen angezogen wurden.

Die Ergebisse der Experimente zeigen deutlich, dass die Promotoren der früh exprimierten Gene as-1 und parA nicht durch die Auflösung der Chromatinstruktur zugänglich gemacht werden. Sie sind bereits im uninduzierten Zustand frei zugänglich für Transkriptionsfaktoren oder andere regulatorische Proteine. Die Expression dieser Gene findet bereits in kurzer Zeit nach Gabe von SA statt (NIGGEWEG et al., 2000b), weshalb auch eine ständige Besetzung der Promotoren durch reprimierte Transkaktivatoren oder Vorläuferproteine als sinnvoll erscheint. Somit kann eine schnelle Reaktion durch kleinste Veränderungen erfolgen, z.B. durch Phorphorylierung von Interaktionspartnern (JUPIN und CHUA, 1996; KANG und KLESSIG, 2005; JOHNSON et al., 2001; STANGE et $a l ., 1998)$ Dies unterstützt die gefundenen Ergebnisse einer konstitutiven Besetzung des as-1-Elements sowie des parA-Promotors.

Somit deuten die Experimente auf eine untersch.voneinander ablaufende Transkriptionsaktivierung zwischen frühen und späten Genen, denn für den Promotor PR-1a wurden induzierbare Acetylierungen festgestellt (s. Abb. 5.24PR-1a). Hierbei bleiben die Signale der $0 \mathrm{~h}$ und $3 \mathrm{~h}$-Werte sogar noch unter den Signalstärken der Input-DNA, erreichen ihre höchste Signalstärke jedoch beim $12 \mathrm{~h}$-Wert. Der zeitliche Verlauf der PR-1a-Expression verläuft weitestgehend deckungsgleich mit der zunehmenden Acetylierung (NIGGEWEG et al., 2000b). Da der Abstand des Palindroms des as-1-Elements um 2 Basenpaare vergößert ist, wäre die Ausbildung eines Proteinkomlexes mit NPR1 aber auch Faktoren der OBP-Familie, als Stabilisator denkbar. Für Mitglieder der OBP-Familie konnte eine Induzierbarkeit durch SA sowie Transaktivierungspotential gezeigt werden. 
Möglich wäre die vorherige Assemblierung eines Proteinkomplexes mit Acetylase-Aktivität (HAT), welcher durch spezifisch gebundene Proteine rekrutiert wird. Durch fortschreitende Acetylierung der Histone können TGA-Faktoren, stabilisiert durch Protein-Interaktionen, am Promotor binden und zeitversetzt die Expression einleiten. Der höchste Acetylierungsgrad der Histone ließ sich bei den untersuchten Zeitpunkten für den $12 \mathrm{~h}$-Wert feststellen. Dass die TGA-Faktoren die Acetylierung nicht beeinflussen, konnte durch Experimente mit SNN TGA2.2/2.1-RNA gezeigt werden. Abb. 6.2 zeigt ein Schema der möglichen Regulation des PR-1a-Promotors. 

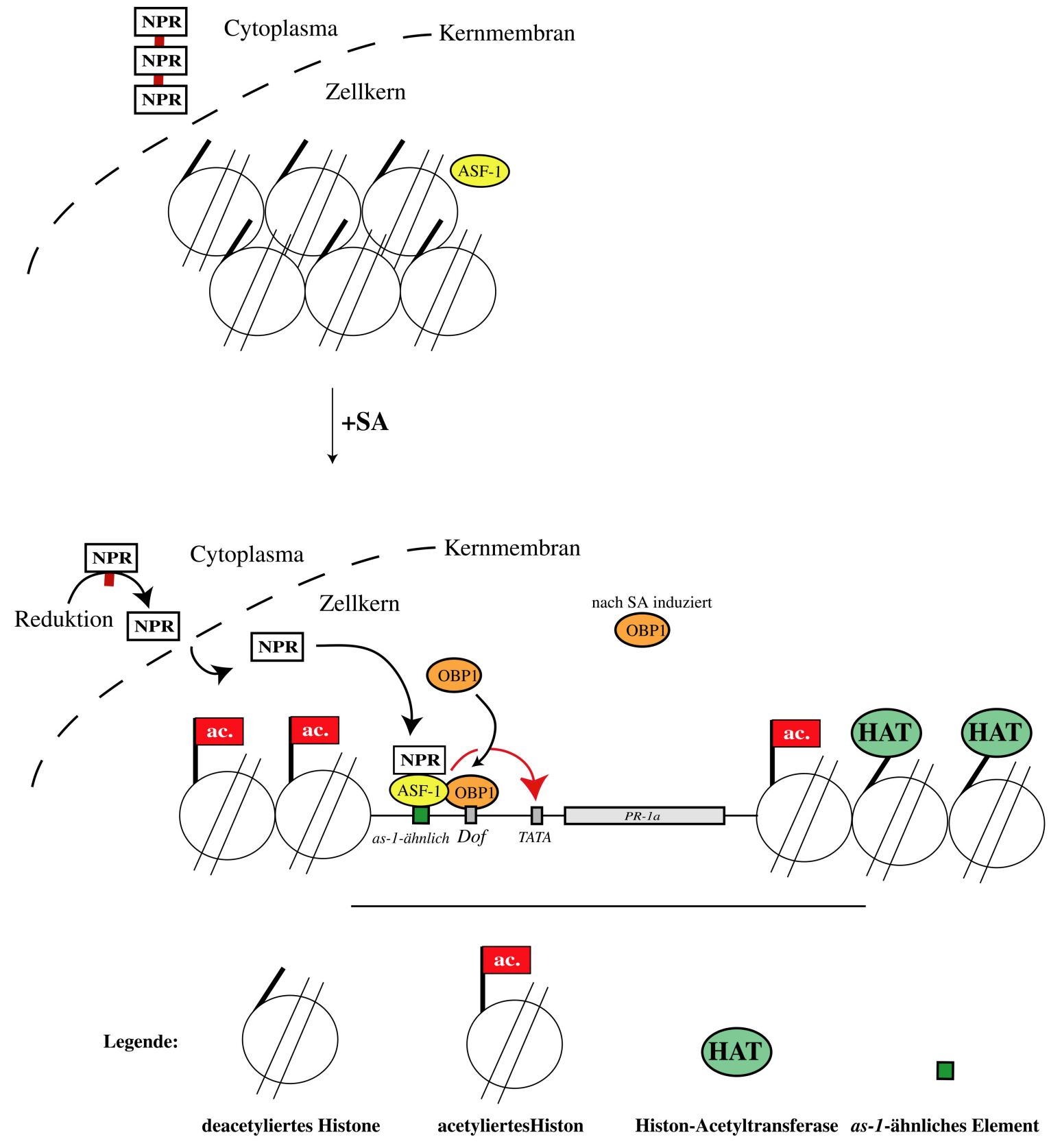

Abbildung 6.2: Modell einer Transkriptionsaktivierung des PR-1a-Promotors aus Nicotiana tabacum . NPR1 liegt als Oligomer im Cytoplasma vor. Nach SA-Stimulus wird NPR1 durch Reduktion monomerisiert und wandert in den Kern. Die Assemblierung eines Proteinkomplexes mit Histon-AcetyltransferaseAktivität (HAT) acetyliert die Histone und der Promotor wird freigesetzt. ASF-1 bindet exponierte as-1--ähnliche Elemente und die Transkription wird u.a. über die Interaktion mit NPR1 eingeleitet. 


\subsection{Anwendung proteinbiochmischer Methoden zur Analyse des TGA2.2}

Die Analyse von denturierten Zellkernextrakten aus SNN as-1::GUS durch Immunodetektion (s. Abb. 5.1) mit dem Antiserum TGA2-C zeigte auf der Höhe von 35-40kDA das Protein TGA2.2, welches in Extrakten der Pflanzen SNN TGA2.2RNAi nicht detektierbar war. Es kann nicht ausgeschlossen werden, dass es sich bei dem starken Signal um ein heterogenes Gemisch an TGA2.2 und homologen, unbekannten TGA-Faktoren handelt, da das Antiserum gegen die innerhalb der TGA-Familie hoch konservierten CTermini von TGA2.1 und TGA2.2 sowie die bZIP-Domäne gerichtet ist. Eine weitere Möglichkeit stellen Phosphorylierungen dar. KANG und KLESSIG (2004) fanden hoch konservierte Phosphorylierungsbereiche innerhalb der Klasse-2 der TGA-Faktoren. Über massenspektroskopische Analysen (MALDI-TOF) können sogenannte „fingerprints“ von Proteinen erstellt werden. Ebenso kann durch weitere Verfahren die Aminosäuresequenz abgeleitet werden, welches Aussagen über das mögliche Vorhandensein von Phosphorylierungsbereichen zulässt. Vor diesem Hintergrund erschien eine Charakterisierung des Proteins TGA2.2 als sinnvoll. Das Protein muss daher für weiterführende Experimente isoliert werden. Diese Anreicherung erfolgt über eine Immunopräzipitation. Die Immunopräzipitation wurde erfolgreich mit dem affinitätsaufgereinigten Antikörper TGA2.2C durchgeführt und die erhaltenen Eluate per Immunodetektion auf das Vorhandensein von TGA2.2 untersucht (Daten nicht gezeigt). Es zeigte sich jedoch im weiteren Verlauf des Experiments, dass die Anfärbung des Proteins nach Auftrennung in einem $10 \%$ SDSPAAG weder durch Coomassie noch durch die weitaus sensitivere Silberfärbung erfolgte. Diese Detektion ist jedoch essentieller Bestandteil der Analyse, da nur ein spezifischer, eingegrenzter Bereich zur Analyse herangezogen werden kann. Mehrere Experimente erwiesen sich nicht als erfolgversprechend.

Aus diesem Grund wurde die Anwendung einer weiteren Variante der biochemischen Auftrennung herangezogen. Die Verwendung der zweidimenionalen Gelelektrophorese (2DPAGE) ermöglicht die Aufreinigung einer Proteinmischung sowohl nach Ladung der einzelnen Proteine, als auch nach Molekulargewicht aufzutrennen. Es wurden daher Pflanzenextrakte aus SNN as-1::GUS und SNN TGA2.2/2.1RNAi im uninduzierten Zustand und aus SNN as-1::GUS jeweils $3 \mathrm{~h}$ und $12 \mathrm{~h}$ nach SA-Stimulus durch die 2D-PAGE aufgetrennt und per Western-Blot-Analyse untersucht. Das Ergebnis zeigt Abb. 5.26. Wie bereits in Kapitel 5.8 beschrieben wurde, zeigten sich spezifisch für TGA2.2 in allen Zeitwerten der 
SA-Induktion die gleichen Proteinmuster. Ein Gemisch aus homologen Proteinen würde allein schon durch kleinste Veränderungen der Aminosäuresequenz oder einer zusätzlichen Phosphatgruppe ein anderes Molekulargewicht aufweisen, was aus Abb. 5.26 nicht ersichtlich ist. Eine mögliche Phosphorylierung ist ebenso verbunden mit einer Veränderung des Laufverhaltens in der SDS-PAGE. Eine genauere Aussage lässt sich somit nicht aus den gefundenen Daten schließen. Die beschriebenen Proteinspots sprechen eher für ein experimentelles Artefakt. Für die 2D-PAGE mit Proteinextrakten aus Hefe wurde beobachtet, dass das Vorhandensein großer Mengen an Histonen das Laufverhalten von Proteinen in der isoelektrischen Fokussierung massiv beeinträchtigt (O. Valerius, persönliche Mitteilung). Da allein Zellkerne zur Extraktion benutzt wurden, sind Histone in hohem Maße vertreten, was zu der Ausbildung des an eine Perlenschnur erinnernden Proteins TGA2.2 führen kann. Eine verbesserte Auftrennung würde wahrscheinlich nur mit aufgereinigten Exktrakten möglich sein. Über die Ausfällung hochabundanter Proteine wie z.B. Histone kann wahrscheinlich eine wesentlich höhere Auflösung erzielt werden. Das Protein ließ sich in allen Proben aus SNN as-1::GUS gleichmäßig nachweisen. Auch eine Induktion mit SA bewirkte dabei keine Veränderung. Eine posttranslationale Modifikation konnte unter 


\subsection{Ausblick}

Im Rahmen der Arbeit wurde mithilfe der Chromatin-Immunopräziptation (ChIP) das Bindeverhalten der TGA-Transkriptionsfaktoren TGA2.1 und TGA2.2 aus Nicotiana tabacum an Promotoren der frühen und späten Genantwort sowie am as-1-Element nach Induktion mit Salizylsäure untersucht. Die Daten sprechen für eine konstitutive, salizylsäureunabhängige Bindung der Klasse 2-TGA-Faktoren am as-1-ähnlichen Element im Promotor des frühen Gens parA sowie am isolierten as-1-Element. Für PR-1a wurde hingegen eine induzierbare, salizylsäure-abhängige Besetzung festgestellt. Pflanzen, die das Fusionsprotein TGA2.2-VP16 exprimieren, zeigen ebenso eine konstante Besetzung der frühen Promotoren. Northern Analysen zeigten, dass die Fusionsproteine TGA2.2-VP16 nicht in der Lage ist, eine konstitutive Expression des nachgeschalteten Reportegens im uninduzierten Zustand zu vermitteln

Die Ergebnisse deuten auf die Anwesenheit eines Transkriptionsrepressors (TKR) hin, der im uninduzierten Zustand mit dem ASF-1/SARP verbunden an as-1-Elementen bindet und die Expression der frühen Gene unterdrückt. Für das weitere Verständnis der Regulation der as-1-vermittelten Genexpression ist die Identifikation des TKR erforderlich.

Die Hyperacetylierung des $P R$-1a-Promotors nach Salizylsäure wirft neue Fragen bezüglich der Regulation dieses Gens auf. TGA-Faktoren scheinen keinen Einfluss auf diesen Mechanismus zu haben, sind jedoch für die spätere Transkription wichtig. Der genaue Mechanismus ist noch unbekannt. Die Identifizierung von Regulatoren der AcetyltransferaseAktivität oder beteiligter Proteine wäre somit ein erster Schritt zur Aufklärung des Regulationsmechanismus. 


\section{Literaturverzeichnis}

Alexander, D., Goodman, R. M., Gut-Rella, M., Glascock, C., Weymann, K., Friedrich, L., Maddox, D., Ahl-Goy, P., Luntz, T., Ward, E. und Ryals, J. (1993): Increased tolerance to two oomycete pathogens in transgenic tobacco expressing pathogenesis-related protein 1a, Proc Natl Acad Sci U S A 90, 7327-7331.

Baker, C. J. und Orlandi, E. W. (1995). Active oxygen in plant pathogenesis, Ann Rev Phytopath 33, 299-321.

Benfey, P.N., and Chua, N.-H. (1990): The cauliflower mosaic virus 35S promoter: Combinatorial regulation of transcription in plants. Science 250, 959-966.

Benfey, P.N., Ren, L., and Chua, N.-H. (1989): The CaMV 35S enhancer contains at least two domains which can confer different developmental and tissue-specific expression patterns. EMBO J. 8, 2195-2202.

Blum, H., Beier, H. und Gross, H.J. (1987): Improved silver staining of plant proteins, RNA and DNA in polyacrylamide gels. Electrophoresis, vol. 8, 93-99.

Böhner. S., Lenk, I., Rieping, M., Herold, M. und Gatz, C. (1999): Transcritional activator TGV mediates dexamethasone-inducible and tetracyclin-inactivatable gene expression. Plant J., 19, 87-95

Bolton E., McCarthy B. (1962): A general method for the isolation of RNA complementary to DNA. Proc Natl Acad Sci U S A. 1962 48:1390-7

Bonas, U., and van den Ackerveken, G. (1999): Gene-for-gene interaction: bacterial avirulence proteins specify plant disease resistance. Curr. Opin. Microbiol. 2, 94-98

Boot, K.J.M., van der Zaal, B.J., Velterop, J., Quint, A., Mennes, A.M., Hooykaas, P.J.J., and Libbenga, K.R. (1993): Further characterization of expression of auxin-induced genes in tobacco (Nicotiana tabacum) cell-suspension cultures. Plant Physiol. 102, 513-520.

Bouchez, D., Tokuhisa, J.G., Llewellyn, D.J., Dennis, E.S., and Ellis, J.G. (1989): The ocs-element is a component of the promoters of several T-DNA and plant viral genes. EMBO J. 8, 4197-4204.

Bradford, M.M. (1979): A rapid and sensitive method for the quantification of microgram quantities of protein utilizing the principle of protein dye binding. Anal. Biochem. 72, 248-254.

Cao, H., Bowling, S.A., Gordon, A.S. und Dong, X. (1994): Characterization of an Arabidopsis mutant that is nonresponsive to inducers of systemic acquired resistance. Plant Cell, 6, 1583-1592 
Cao, H., Glazebrook, J., Clarke, J.D., Volko, S., and Dong, X. (1997): The Arabidopsis NPR1 gene that controls systemic acquired resistance encodes a novel protein containing ankyrin repeats. Cell 88, 57-63.

Cao, H., Li, X. und Dong, X. (1998): Generation of broad-spectrum disease resistance by overexpression of an essential regulatory genein systemic acquired resistance. Proc. Natl. Acad. Sci. USA, 95, 6531-6536

Chen, W., Provart, N.J., Glazebrook, J., Katagiri, F., Chang, H.-S., Eulgem, T., Mauch, F., Luan, S., Zou, G., Whitham, S.A., Budworth, P.R., Tao, Y., Xie, Z., Chen, X., Lam, S., Kreps, J.A., Harper, J.F., Si-Ammour, S., Mauch-Mani, B., Heinlein, M., Kobayashi, K., Hohn, T., Dangl, J-L., Wang, X., and Zhu, T. (2002): Expression profile matrix of Arabidopsis transcription factor genes suggests their putative functions in response to enviromental stresses. Plant Cell 14, 559- 574.

Chen, W. und Singh, K.B. (1999): The auxin, hydrogen peroxide and salicylic acid induced expression of the Arabidopsis GST6 promoter is mediated in part by ocs element. Plant J., 19, 667-677

Cheong, N.E., Kim, W.Y., Lee, H.S., Bahk, J.D., Cho, M.J. und Lee, S.Y. (1994): Molecular characterization of a cDNA encoding a small GTP-binding protein, SYPT, in soybean. Plant Physiol, 105(2), 765-6.

Chern, M.-S., Fitzgerald, H.A., Yadav, R.C., Canlas, P.E., Dong, X., and Ronald, P.C. (2001): Evidence for a disease-resistance pathway in rice similar to the NPR1-mediated signaling pathway in Arabidopsis. Plant J. 27, 101-113.

Chua, Y.L., Watson, L.A. und Gray, J.C. (2003): The transcriptional enhancer of the pea plastocyanin gene associates with the nuclear matrix and regulates gene expression through histone acetylation. Plant Cell., 15(6), 1468-79.

Chua, Y.L., Brown, A.P. und Gray, J.C. (2001): Targeted histone acetylation and altered nuclease accessibility over short regions of the pea plastocyanin gene. Plant Cell., 13(3), 599-612.

Chua, Y.L., Mott, E., Brown, A,P., MacLean, D. und Gray, J.C. (2004): Microarray analysis of chromatin-immunoprecipitated DNA identifies specific regions of tobacco genes associated with acetylated histones. Plant J., 37(6), 789-800.

Chuang, C.-F., and Meyerowitz, E.M. (2000): Specific and heritable genetic interference by double-stranded RNA in Arabidopsis thaliana. Proc. Natl. Acad. Sci. USA 97, 4985-4990.

Chuang, C.-F., Running, M.P., Williams, R.W., and Meyerowitz, E.M. (1999): The PERIANTHIA gene encodes a bZIP protein involved in the determination of floral organ number in Arabidopsis thaliana. Genes Dev. 13, 334-344. 
Cutt, J.R., Dixon, D.C., Carr, J.P., and Klessig, D.F. (1988): Isolation and nucleotide sequence of cDNA clones for the pathogenesis-related proteins PR1a, PR1b and PR1c of Nicotiana tabacum cv. Xanthi nc induced by TMV infection. Nucl. Acids Res. 16, 9861.

Daniel, V. (1993): Glutathion S-transferases: gene structure and regulation of expression. Crit. Rev. Biochem. Mol. Biol. 24, 337-384.

Delaney, T.P., Friedrich, L. und Ryals, J.A. (1995): Arabidopsis sognal transduction mutant defective in chemically and biologically induced disease resistance. Proc. Natl. Acad. Sci. USA, 92, 6602-6606

De Pater, S., Pham, K., Memelink, J., and Kijne, J. (1996): Binding specificity and tissue-specific expression pattern of the Arabidopsis bZIP transcription factor TGA2. Mol. Gen.Genet. 250, 237- 239.

Després, C., Chubak, C., Rochon, A., Clark, R., Bethune, T., Desveaux, D., and Fobert, P.R. (2003): The Arabidopsis NPR1 disease resistance protein is a novel cofactor that confers redox regulation of DNA binding activity to the basic domain/leucin zipper transcription factor TGA1. Plant Cell 15, 2181-2191.

Després, C., DeLong, C., Glaze, S., Liu, E., and Fobert, P.R. (2000): The Arabidopsis NPR1/NIM1 protein enhances the DNA binding activity of a subgroup of the TGA familiy of bZIP transcription factors. Plant Cell 12, 279-290.

Dinesh-Kumar, S.P. und Baker, B.J. (2000): Alternatively spliced N resistance gene transcripts:their possible role in tobacco mosaic virus resistance. Proc. Natl. Acad. Sci. USA, 97, 1908-1913.

Dong, X. (1998): SA, JA, ethylene, and disease resistance in plants. Curr. Opin. Plant Biol. 1, 316-323.

Droog, F., Spek, A., van der Kooy, A., de Ruyter, A., Hoge, H., Libbenga, K., Hooykaas, P., and van der Zaal B. (1995): Promoter analysis of the auxin-regulated tobacco glutathione S-transferase genes Nt103-1 and Nt103-35. Plant Mol. Biol. 29, 413-429.

Durner, J., Shah, J., and Klessig, D.F. (1997): Salicylic acid and disease resistance in plants. Trends Plant Sci. 2, 266-274.

Duroux, M., Houben, A., Ruzicka, K., Friml, J. und Grasser, K.D., (2004):The chromatin remodelling complex FACT associates with actively transcribed regions of the Arabidopsis genome. Plant J., 40(5), 660-71.

Ehrlich, M. und Ehrlich, K.C. (1993): Effect of DNA methylation on the binding of vertebrate and plant proteins to DNA. EXS., 64, 145-68. 
Ellis, J.G., Tokuhisa, J.G., Llewellyn, D.J., Bouchez, D., Singh, K., Dennis, E.S., and Peacock, W.J. (1993): Does the ocs-element occur as a functional component of the promoters of plant genes? Plant J. 4, 433-443.

Fan, W., and Dong, X. (2002): In vivo interaction between NPR1 and transcription factor TGA2 leads to salicylic acid-mediated gene activation in Arabidopsis. Plant Cell, 14, 1-13.

Feltkamp, D., Masterson, R., Starke, J., and Rosahl, S. (1994): Analysis of the involvement of ocs-like bZip-binding elements in the differential strenght of the bidirectional mas1'2'promoter. Plant Physiol. 105, 259-268.

Flor, H.H., (1955): Host-parasite interactions in flax rust, its genetic and other implications. Phytopathology, 45, 680-685.

Foley, R.C., Grossmann, C., Ellis, J.G., Llewellyn, D.J., Dennis, E.S., Peacock, W.J., and Singh,K.B. (1993): Isolation of a maize bZIP protein subfamily: Candidates for the ocs-element transcription factor. Plant J. 3, 669-679.

Fromm, H., Katagiri, F., and Chua, N.-H. (1989): An octopine synthase enhancer element directs tissue-specific expression and binds ASF-1, a factor from tobacco nuclear extracts. Plant Cell 1, 977-984.

Fromm, H., Katagiri, F., and Chua, N.-H. (1991): The tobacco transcription activator TGA1a binds to a sequence in the $5^{\prime}$-upstream region of a gene encoding a TGA1a related protein. Mol. Gen. Genet. 229, 181-188.

Fromm, H., Taylor, L.P., and Walbot, V. (1985): Expression of genes transferred into monocot and dicot plant cells by electroporation. Proc. Natl. Acad. Sci. USA 82 (9), $5824-5828$.

Fusco, C., Guidotti, E., and Zervos, A.S. (1999): In vivo construction of cDNA libraries for use in the yeas two-hybrid system. Yeast 15, 715-720.

Gaffney, T., Friedrich, L., Vernooij, B., Negrotto, D., Nye, G., Uknes, S., Ward, E., Kessmann, H. und Ryals, J. (1993): Requirement of salicylic acid for the induction of systemic acquired resistance. Science, 261, 754.

Gatz, C., Kaiser, A., and Wendenburg, R. (1992): Regulation of a modified CaMV 35S promoter by the Tn10-encoded Tet repressor in transgenic tobacco. Mol. Gen. Genet. 227, 229-237.

Glazebrook, J., Rogers, E., and Ausubel, F.(1996): Isolation of Arabidopsis mutants with enhanced disease susceptibility by direct screening. Genetics 179, 89-95. 
Görg, A. (1998): Two-Dimensional Electrophoresis of Proteins using Immobilized pH Gradients-A LABORATORY MANUAL, beziehbar unter http://www.weihenstephan.de/blm/deg Gough, C., Hemon, P., Tronchet, M., Lacomme, C., Marco, Y. und Roby, D. (1995): Developmental and pathogen-induced activation of an msr gene, str 246C, from tobacco involves multiple regulatory elements. Mol Gen Genet., 247(3), 323-37.

Hammond-Kosack, K.E. und Jones, J.D.G. (1996): Resistance gene-dependent plant defense responses. Plant Cell, 8, 1773-1791

Harlow, E., und Lane, D., eds (1999). Antibodies: A Laboratory Manual. (Cold Spring Harbor, NY: Cold Spring Harbor Laboratory Press).

Herbert, B., Galvani, M., Hamdan, M., Olivieri, E., MacCarthy, J., Pedersen, S. und Righetti, P.G. (2001): Reduction and alkylation of proteins in preparation of two-dimensional map analysis: why, when, and how? Electrophoresis., 22(10), 2046-57.

Hidalgo, P., Garreton, V., Berrios, C.G., Ojeda, H., Jordana, X. und Holuigue L. (2002): A nuclear casein kinase 2 activity is involved in early events of transcriptional activation induced by salicylic acid in tobacco. Plant Physiol., 125(1), 396-405.

Horvath, D.M., and Chua, N.-H. (1996): Identification of an immediate-early salicylic acid-inducible tobacco gene and characterization of induction by other compounds. Plant Mol. Biol. 31, 1061-1072.

Horvath, D. M., Huang, D. J. und Chua, N. H. (1998): Four classes of salicylate-induced tobacco genes, Mol Plant Microbe Interact 11, 895-905.

Jakoby, M., Weisshaar, B., Dröge-Laser, W., Tiedemann, J., Kroij, T. and Parcy, F. (2002): The family of bZIP transcription factors in Arabidopsis thaliana. Trends Plant Sci. 7, 106-111.

Jefferson, R. A., Kavanagh, T. A. und Bevan, M. W. (1987): GUS fusions: ß-glucoronidase as a sensitive and versatile gene fusion marker in higher plants, Embo J 6, 3901-3907.

Jenuwein, T. und Allis, C.D. (2001): Translating the histone code. Science., 293(5532), 1074-80.

Johnson, C., Glover, G. und Arias, J. (2001a): Regulation of DNA binding and transactivation by a xenobiotic stress-activated plant transcription factor. J. Biol. Chem., 276, 172-178.

Johnson, C., Boden, E., and Arias, J. (2003): Salicylic acid and NPR1 induce the recruitment of trans-activating TGA factors to a defense gene promoter in Arabidopsis. Plant Cell. 15, 1846- 1858. 
Johnson, C., Boden, E., Desai, M., Pascuzzi, P., and Arias, J. (2001b): In vivo target promoter binding activities of a xenobiotic stress-activated TGA factor. Plant J.,28, 237243.

Johnson, C., Glover, G., and Arias, J. (2001a): Regulation of DNA binding and transactivation by a xenobiotic stress-activated plant transcription factor. J. Biol. Chem. 276, 172-178.

Jupin, I. und Chua, N. H. (1996): Activation of the CaMV as-1 cis-element by salicylic acid: differential DNA-binding of a factor related to TGA1a, Embo J 15, 5679-5689.

Kang, H.G. und Klessig, D.F.,(2005): Salicylic acid-inducible Arabidopsis CK2-like activity phosphorylates TGA2. Plant Mol Biol., 57(4), 541-57.

Katagiri, F., Lam, E., and Chua, N.-H. (1989): Two tobacco DNA-binding proteins with homology to nuclear factor CREB. Nature 340, 727-730.

Kawata, T., Imada, T., Shiraishi, H., Okada, K., Shimura, Y., and Ivabuchi, M. (1992): A cDNA clone encoding a HBP-1b homologue in Arabidopsis thaliana. Nucl. Acids Res. $20,1141-1147$.

Keen, N.T. (1992): Gene-for-Gene complementarity in plant-pathogen interactions. Annu. Rev. Genet., 24, 447-463.

Kegler, C. (2001): Analyse des Transkriptionsfaktors TGA2.1 aus Nicotiana tabacum. Dissertation, Georg-August-Universität Göttingen, Göttingen.

Kegler, C., Lenk, I., Krawczyk, S., Scholz, R. und Gatz, C. (2004): Functional characterization of tobacco transcription factor TGA2.1. Plant Mol Biol., 55(2), 153-64.

Kim, H.S., and Delaney, T.P. (2002): Over-expression of TGA5, which encodes a bZIP transcription factor that interacts with NIM/NPR1, confers SAR-independent resistance in Arabidopsis thaliana to Peronospora parasitica. Plant J. 32, 151-163.

Kim, T.S., and Delaney, T.P. (2002): Arabidopsis SON1 is an F-box protein that regulates a novel induced defense response independent of both salicylic acid and systemic acquired resistance. Plant Cell 14, 1469-1482.

Kinkema, M., Fan, W., and Dong, X. (2000): Nuclear localisation of NPR1 is required for activation of PR gene expression. Plant Cell 12, 2339-2350.

Kinzler, K.W. und Vogelstein, B. (1989): Whole genome PCR: application to the identification of sequences bound by gene regulatory proteins. Nuc. Acids Res. 17, 3645-3653. 
Klessig, D.F., and Malamy, J. (1994): The salicylic acid signal in plants. Plant Mol. Biol. $26,1439-1458$.

Klinedinst, S., Pascuzzi, P., Redman, J., Desai, M., and Arias, J. (2000): A xenobioticstress-activated transcription factor and its cognate target genes are preferentially expressed in root tip meristems. Plant Mol. Biol. 42, 679-688.

Kombrink, E., and Somssich, I.E. (1997): Pathogenesis-related proteins and plant defense. In: The Mycota (Part A, Plant Relationships, Carroll, G., and Tudzynski, P., eds), pp. 107-128, Springer-Verlag, Berlin.

Koyama T., Okada, T., Kitajima, S., Ohme-Takagi, M., Shinshi, H., and Sato, F. (2003): Isolation of tobacco ubiquitin-conjugating enzyme cDNA in a yeast two-hybrid system with tobacco ERF3 as bait and its characterization of specific interaction. J. Exp. Bot. $54,1175-1181$.

Krawczyk, S., Thurow, C., Niggeweg, R., and Gatz, C. (2002): Analysis of the spacing between the two palindromes of activation sequence- 1 with respect to binding to different TGA factors and transcriptional activation. Nucl. Acids Res. 30, 775-781.

Kuc, J. (1982): Induced immunity to plant disease resistance. BioScience, 32, 854-860.

Kyhse-Andersen, J. (1984): Electroblotting of multiple gels: a simple apparatus without tank for rapid transfer of proteins from polyacrylamide to nitrocellulose, J Biochem Biophys Methods 10, 203-209.

Laemmli, U.K. (1970): Cleavage of structural proteins during the assembly of the head of bacteriophage T4. Nature 227, 680-685.

Lam, E., Katagiri, F. und Chua, N. H. (1990): Plant nuclear factor ASF-1 binds to an essential region of the nopaline synthase promoter, J Biol Chem 265, 9909-13.

Lam, E., and Lam, Y.K.-P. (1995): Binding site requirements and differential representation of TGA factors in nuclear ASF-1 activity. Nucl. Acids Res. 23, 3778-3785.

Lam, E., Benfey, P.N., Gilmartin, P.M., Fang, R.-X., and Chua, N.-H. (1989): Site specific mutations alter in vitro factor binding and change promoter expression pattern in transgenic plants. Proc. Natl. Acad. Sci. USA 86, 7890-7894.

Lamb, C. und Dixon, R.A.(1997): The oxidative burst inb plant disease resistance. Annu Rev Plant Physiol Plant Mol Biol., 48, 251-275.

Lamb, C.J., Lawton, M.A., Dron, M. und Dixon, R.A. (1989): Signals and transduction mechanisms for activation of plant defenses against microbial attack. Cell, 56, 215-224. 
Lebel, E., Heifetz, P., Thorne, L., Uknes, S., Ryals, J., and Ward, E. (1998): Functional analysis of regulatory sequences controlling PR-1 gene expression in Arabidopsis. Plant J. 16, 223-233.

Lenk, I. (2001): Analyse der in-vivo Funktion der Transkriptionsfaktoren TGA2.1 und TGA2.2 aus Tabak nach Fusion mit einer konstitutiven Aktivierungsdomäne. Dissertation, Georg-August-Universität Göttingen, Göttingen.

Li, X., Zhang, Y., Clarke, J.D., Li, Y., and Dong, X. (1999): Identification and cloning of a negative regulator of systemic acquired resistance, SNI1, through a screen for suppressors of npr1-1. Cell 98, 329-339.

Liu, X., and Lam, E. (1994): Two binding sites for the plant transcription factor ASF-1 can respond to auxin treatments in transgenic tobacco. J. Biol. Chem. 269, 668-675.

Malamy, J., Carr, J.P., Klessig, D.F., and Raskin, I. (1990): Salicylic acid: a likely endogenous signal in the resistance response of tobacco to viral infection. Science 250, 1002-1004. Maleck, K., Levine, A., Eulgem, T., Morgan, A., Schmid, J., Lawton, K.A., Dangl, J.L., and Dietrich,R.A. (2000): The transcriptome of Arabidopsis thaliana during systemic acquired resistance. Nat. Genet. 25, 403-410.

Maleck, K., Levine, A., Eulgem, T., Morgan, A., Schmid, J., Lawton, K. A., Dangl, J. L. und Dietrich, R. A. (2000): The transcriptome of Arabidopsis thaliana during systemic acquired resistance, Nat Genet 26, 403-10.

Mauch, F., Mauch-Mani, B., Gaille, C., Kull, B., Haas, D., and Reimmann, C. (2001): Manipulation of salicylate content in Arabidopsis thaliana by the expression of an engineered bacterial salicylate synthase. Plant J. 25, 67-77.

McGhee, J.D. und von Hippel, P.H. (1975a): Formaldehyde as a probe of DNA structure. I. Reaction with exocyclic amino groups of DNA bases. Biochemistry., 14(6], 1281-96.

McGhee, J.D. und von Hippel, P.H. (1975b): Formaldehyde as a probe of DNA structure. II. Reaction with endocyclic imino groups of DNA bases. Biochemistry., 14(6), 1297-303.

Métraux, J.-P., Signer, H., Ryals, J., Ward, E., Wyss-Benz, M., Gaudin, J., Raschdorf, K., Schmid, E., Blum, W. und Inverardi, B. (1990): Increase in salicylic acid at the onset of systemic acquired resistance in cucumber. Science, 250, 1004.

Miao, Z.-H., and Lam, E. (1995): Construction of a trans-dominant inhibitor for members of the TGA family of transcription factors conserved in higher plants. Plant J. 7, 887-896.

Miao, Z.-H., Liu, X., and Lam, E. (1994): TGA3 is a distinct member of the TGA family of bZIP transcription factors in Arabidopsis thaliana. Plant Mol. Biol. 25, 1-11. 
Mou, Z., Fan, W., and Dong, X. (2003): Inducers of plant systemic acquired resistance regulate NPR1 function through redox changes. Cell 113, 935-944.

Mullis, K.B., and Faloona, F.A. (1987): Specific synthesis of DNA in vitro via a polymerasecatalyzed chain reaction. Methods Enzymol. 155, 335-350.

Murashige, T., and Skoog, F. (1962): A revised medium for rapid growth and bioassays with tobacco tissue culture. Plant Physiol. 15, 473-497.

Neuhaus, G., Neuhaus-Url, G., Katagiri, F., Seipel, K., and Chua, N.-H. (1994): Tissuespecific expression of as-1 in transgenic tobacco. Plant Cell 6, 827-834.

Nickolov, K. (2002): Subcellular Localization of Nicotiana tabacum TGA transcription factors. Dissertation, Georg-August-Universität Göttingen, Göttingen.

Niggeweg, R. (1999): Salizylsäure- und Auxin-induzierte Genexpression in Nicotiana tabacum: Funktionelle Bedeutung der TGA-Faktoren der Subklasse II. Dissertation, Universität Bielefeld.

Niggeweg, R., and Gatz, C. (1997): Isolation of TGA2.1 (Accession No U90214), a member of a new subclass of the TGA-family of bZIP-transcription-factors in Nicotiana tabacum. Plant Physiol. 113, 1464.

Niggeweg, R., Thurow, C., Kegler, C., and Gatz, C. (2000b): Tobacco transcription factor TGA2.2 is the main component of as-1-binding factor ASF-1 and is involved in salicylic acid- and auxin-inducible expression of as-1-containing target promoters. J. Biol. Chem. 275, 19897- 19905.

Niggeweg, R., Thurow, C., Weigel, R., Pfitzner, U., and Gatz, C. (2000a): Tobacco TGA factors differ with respect to interaction with NPR1, activation potential and DNAbinding properties. Plant Mol. Biol. 42, 775-788.

Odell, G.T., Nagy, F., and Chua, N.-H. (1985): Identification of DNA sequences required for activity of the cauliflower mosaic virus 35S promoter. Nature 313, 810-812.

Orlando, V. (2000): Mapping chromosomal proteins in vivo by formaldehyde crosslinked chromatin immunoprecipitation. Trends Biochem. Sci. 25, 99-104.

Ow, D.W., Jacobs, J.D., and Howell, S.H. (1987): Funtional regions of the cauliflower mosaic virus 35S truncated promotor. Mol. Gen.Genet. 217, 209-214.

Pascuzzi, P., Hamilton, D., Bodily, K., and Arias, J. (1998): Auxin-induced stress potentiates trans-activation by a conserved plant basic/leucine-zipper factor. J. Biol. Chem. 273, 26631- 26637. 
Perlman, D., Chikarmane, H. und Halvorson, H. (1987): Improved resolution of DNA fragments in polysaccharide-supplemented agarose gels, Anal Biochem 163, 247-54

Pontier, D., Miao, Z.-H., and Lam, E. (2001): Trans-dominant suppression of plant TGA factors reveals their negative and positive roles in plant defense responses. Plant J. 27, 529-538.

Pontier, D., Privat, I., Trifa, Y., Zhou, J.-M., Klessig, D.F., Lam, E. (2002): Differential regulation of TGA transcription factors by post-transcriptional control. Plant J. 32, 641653.

Prat, S., Willmitzer, L., and Sanchez-Serrano, J.J. (1989): Nuclear proteins binding to a cauliflower mosaic virus 35S truncated promotor. Mol. Gen. Genet. 217, 209-214.

Qin, X.-F., Holuigue, L., Horvath, D.M., and Chua, N.-H. (1994): Immediate early transcription activation by salicylic acid via the cauliflower mosaic virus as-1 element. Plant Cell 6, 863-874.

Rauscher, M., Adam, A.L., Wirtz, S., Guggenheim, R., Mendgen, K. und Deising, H.B. (1999): PR-1 protein inhibits the differentiation of rust infection hyphae in leaves of acquired resistant broad bean. Plant J., 19, 625-633.

Rieping, M., Fritz, M., Prat, S., and Gatz, C. (1994): A dominant negative mutant of PG13 suppresses transcription from a cauliflower mosaic virus $35 \mathrm{~S}$ truncated promoter in transgenic tobacco plants. Plant Cell 6, 1087-1098.

Ross, A.F. (1961): Systemic acquired resistance induced by localized virus infections in plants. Virology, 14, 340-358.

Ross, A.F. und Bozarth, R.F. (1960): Resistance induced in one plant as a result of virus infection in another part. (Abstract). Phytopathology, 50, 652.

Rossetti, S. und Bonatti, P.M. (2001): In situ histochemical monitoring of ozone- and TMVinduced reactive oxygen species in tobacco leaves. Plant Physiol. Biochem., 39, 433442.

Roux, C., and Perrot-Rechenmann, C. (1997): Isolation by differential display and characterization of a tobacco auxin-responsive cDNA Nt-gh3, related to GH3. FEBS Lett. 419, 131-136.

Rushton, P.J. und Somssich, I.E. (1998): Transcriptional control of plant genes responsive to pathogens. Curr. Opin. Plant Biol., 1, 311-315.

Ryals, J.A., Weymann, K., Lawton, K., Friedrich, L., Ellis, D., Steiner, H.-Y., Johnson, J., Delaney, T.P., Jesse, T., Vos, P., and Uknes, S. (1997): The Arabidopsis NIM1 protein 
shows homology to the mammalian transcription factor inhibitor I B. Plant Cell 9, 425439.

Sakai, T., Takahashi, Y. und Nagata, T. (1998): The identification of DNA binding factors specific for as-1-like sequences in auxin-responsive regions of parA, parB and parC, Plant Cell Physiol 39, 731-9.

Sambrook, J., Fritsch, E.F., and Maniatis, T. (1989): Molecular cloning: A Labatory Manual 2 nd edition. Cold Spring Harbour Laboratory Press.

Schenk, P.M., Kazan, K., Wilson, I., Anderson, J.P., Richmond, T., Somerville, S.C., and Manners, J.M. (2000): Coordinated plant defense response in Arabidopsis revealed by microarray analysis. Proc. Natl. Acad. Sci. USA 97, 11655-11660.

Schiermeyer, A. (2001): Klonierung und Charakterisierung eines neuartigen Transkriptionsfaktore der TGA-Familie aus Nicotiana tabacum. Dissertation, Georg-August- Universität Göttingen, Göttingen

Schiermeyer, A., Thurow, C., and Gatz, C. (2003): Tobacco bZIP factor TGA10 is a novel member of the TGA family of transcription factors. Plant Mol. Biol. 51, 817-829.

Schindler, U., Beckmann, H., and Cashmore, A.R. (1992): TGA1 and G-box binding factors: Two distinct classes of Arabidopsis leucine zipper proteins compete for the Gbox-like element TGACGTGG. Plant Cell 4, 1309-1319.

Shah, J., Kachroo, P., and Klessig, D.F (1999): The Arabidopsis ssi mutation restores pathogenesis-related gene expression in npr1 plants and renders defensin gene expression salicylic acid dependent. Plant Cell 11, 191-206.

Singh, K., Dennis, E.S., Ellis, J.G., Llewellyn, D.J., Tokuhisa, J.G., Wahleithner, J.A., and Peacock, W.J. (1990): OCSBF-1, a maize Ocs enhancer binding factor: Isolation and expression during development. Plant Cell 2, 891-903.

Singh, K., Tokuhisa, J.G., Dennis, E.S., and Peacock, W.J. (1989): Saturation mutagenesis of the octopine synthase enhancer: Correlation of mutant phenotypes with binding of a nuclear protein factor. Proc. Natl. Acad. Sci. USA 86, 3733-3737.143

Stange, C., Ramirez, I., Gómez, I., Jordana, X., and Holuigue, L. (1997): Phosphorylation of nuclear proteins directs binding to salicylic acid-responsive elements. Plant J. 11, 13151324.

Strahl, B.D. und Allis, C.D. (2000): The language of covalent histone modifications. Nature., 403(6765), 41-5. 
Staskawicz, B.J., Ausubel, F.M., Baker, B.J., Ellis, J.G. und Jones, J.D. (1995): Molecular genetics of plant disease resistance. Science, 268, 661-667.

Strompen, G., Grüner, R., and Pfitzner, M. (1998): An as-1-like motif controls the level of expression of the gene for the pathogenesis-related protein 1a from tobacco. Plant Mol. Biol. 37, 871-883.

Subramaniam, R., Desveaux, D., Spickler, C., Michnick, S.W., and Brisson, N. (2001): Direct visualization of protein interactions in plant cells. Nat. Biotechnol. 19, 769-772.

Sutherland, M. W. (1991): The generation of oxygen radicals during host plant responses to infection, Physiol Mol Plant Pathol 39, 79-93.

Tabata, T., Nakayama, T., Mikami, K. und Iwabuchi, M. HBP-1a and HBP-1b: leucine zipper-type transcription factors of wheat. EMBO J., 10(6), 1459-67.

Takahashi, Y., Kuroda, H., Tanaka, R., Machida, T., and Nagata, T. (1989): Isolation of an auxin-regulated gene cDNA expressed during the transition from G 0 to $\mathrm{S}$ phase in tobacco mesophyll protoplasts. Proc. Natl. Acad. Sci. USA 86, 9279-9283.

Takahashi, Y., Hasezawa, S., Kusaba, M. und Nagata, T. (1995): Expression of the auxinregulated parA gene in transgenic tobacco and nuclear localization of its gene products, Planta 196, 111-7.

Thurow, C. (2001): Biochemische Aufreinigung, funktionelle Analyse und Identifikation eines Interaktionspartners des an der Salicysäure-induzierbaren Genexpression beteiligten SARP-Komplexes aus Tabak. Dissertation, Georg-August-Universität Göttingen, Göttingen.

THUROW, C., Schiermeyer, A., Krawczyk, S., Butterbrodt, T., Nickolov, K., and Gatz, C. (2005: Tobacco bZIP transcription factor TGA2.2 and related factor TGA2.1 have distinct roles in plant defense responses and plant development. Plant J

Turck F., Zhou A., Somssich, IE.,Plant Cell, 16(10), 2573-85

Turner, B.M. (2000): Histone acetylation and an epigenetic code. Bioessays., 22(9), 836-45.

Turner, J.G., Ellis, D., and Devoto, A. (2002): the jasmonate signal pathway. Plant Cell 14, S153- S164.

Uknes, S., Dincher, S., Friedrich, L., Negrotto, D., Williams, S., Thompson-Taylor, H., Potter, S., Ward, E., and Ryals, J. (1993b): Regulation of pathogenesis-related protein-1a gene expression in tobacco. Plant Cell 5, 159-169. 
Uknes, S., Winter, A.M., Delaney, T., Vernooij, B., Morse, A., Friedrich, L., Nye, G., Potter, S., Ward, E., and Ryals, J. (1993a): Biological induction of systemic acquired resistance in Arabidopsis. Mol. Plant Microbe Interact. 6, 692-698.

Ulmasov, R., Hagen, G., and Guilfoyle, T. (1994): The ocs element in the soybean GH2/4 promoter is activated by both active and inactive auxin and salicylic acid analogues. Plant Mol. Biol. 26, 1055-1064.

Utley, R.T., Ikeda, K., Grant, P.A., Cote, J., Steger, D.J., Eberharter, A., John, S. und Workman, J.L. (1998): Transcriptional activators direct histone acetyltransferase complexes to nucleosomes. Nature, 394(6692),498-502.

Turck F, Zhou A, Somssich IE (2004): Stimulus-dependent, promoter-specific binding of transcription factor WRKY1 to its native promoter and the defense-related gene PcPR1-1 in Parsley. Plant Cell, 16, 2573-2585.

Vanacker, H., Lu, H., Rate, D.N. und Greenberg, J.T. (2002): A role for salicylic acid and NPR1 in regulating cell growth in Arabidopsis. Plant J., 28(2), 209-16.

van der Biezen, E.A. und Jones, J.D. (1998): Plant disease-resistance proteins and the gene-for-gene concept. Trends. Biochem. Sci., 23, 454-456.

van der Zaal, E.J., Droog, F.N.J., Boot, C.J.M., Hensgens, L.A.M., Hoge, J.H.C., Schilperoort, R.A., and Libbenga,K.R. (1991): Promoters of auxin-induced genes from tobacco can lead to auxin-inducible and root tip-specific expression. Plant Mol. Biol. 10, 145-157.

van der Zaal, B. J., Droog, F. N., Pieterse, F. J. und Hooykaas, P. J. (1996): Auxinsensitive elements from promoters of tobacco GST genes and a consensus as-1-like element differ only in relative strength, Plant Physiol 110, 79-88.

van Loon, L.C., and Antoniw, J.F. (1982): Comparison of the effects of salicylic acid and etephon with virus-induced hypersensitivity and aquired resistance in tobacco. Neth. J. Plant Pathol. 88, 237-256.

Van Loon, L.C. und Van Strien, E.A., (1999): The families of pathogenesis-related proteins, their activities, and comparative analysis of PR-1 type proteins. Physiol. Mol. Plant Pathol., 55, 85-97.

Varshavsky, A. (1997): The N-end rule pathway of protein degradation. Genes to Cell 2, $13-28$.

Verberne, M.C., Verpoorte, R., Bol, J.F., Mercado-Blanco, J., and Linthorst, H.J. (2000): Overproduction of salicylic acid in plants by bacterial transgenes enhances pathogen resistance. Nat. Biotechnol. 18, 779-783. 
Walsh, J., Waters, C.A., and Freeling, M. (1997): The maize gene liguleless2 encodes a basic leucine zipper protein involved in the establishment of the leaf blade-sheath boundary. Genes Dev. 11, 208-218.

Wang, H., Tang, W., Zhu, C. and Perry, S.E. (2002): A chromatin immunoprecipitation (ChIP) approach to isolate genes regulated by AGL15, a MADS domain protein that preferentially accumulates in embryos. Plant J. 32, 831-843.

Ward, E.R., Uknes, S.J., Williams, S.C., Dincher, S.S., Wiederhold, D.L., Alexander, D.C., Ahl-Goy,P., Métraux,J.-P., and Ryals,J.A. (1991): Coordinate gene activity in response to agents that induce systemic acquired resistance. Plant Cell 3, 1085-1094.

Weinmann, A.S. und Farnham, P.J. (2002): Identification of unknown target genes of human transcription factors using chromatin immunoprecipitation. Methods, 26(1), 3747.

Wells, J. und Farnham P.J. (2002): Characterizing transcription factor binding sites using formaldehyde crosslinking and immunoprecipitation. Methods, 26(1), 48-56.

White, R.F. (1979): Acetylsalicylic acid (aspirin) induces resistance to tobacco mosaic virus in tobacco. Virology, 99, 410-412.

Xiang, C., Miao, Z., and Lam E. (1997): DNA-binding properties, genomic organization and expression pattern of TGA6, a new member of the TGA familiy of bZIP transcription factors in Arabidopsis thaliana. Plant Mol. Biol. 34, 403-415.

Xiang, C., Miao, Z. und Lam, E. (1995): Isolation of TGA6 (Accession No. L42327), a new member of the TGA family of bZIP transcription factors in Arabidopsis thaliana, Plant Physiol 109, 721.

Xiang, C., Miao, Z.-H., and Lam, E. (1996): Coordinated activation of as-1-type elements and a tobacco glutathione S-transferase gene by auxins, salicylic acid, methyl-jasmonate and hydrogen peroxide. Plant Mol. Biol. 32, 415-426.

Yang, Y.O. und Klessig, D.F. (1996): Isolation and characterization of a tobacco mosaic virus-inducible myb oncogene homolog from tobacco. Proc. Natl. Acad. Sci. USA, 93, 14972-14977.

Zhang, B., and Singh, K.B. (1994): Ocs element promoter sequences are activated by auxin and salicylic acid in Arabidopsis. Proc. Natl. Acad. Sci. USA 91, 2507-2511.

Zhang, B., Foley, R.C., and Singh, K.B. (1993): Isolation and characterization of two related Arabidopsis ocs-element bZIP binding proteins. Plant J. 4, 711-716. 
Zhang, Y., Fan, W., Kinkema, M., Li, X., and Dong, X. (1999): Interaction of NPR1 with basic leucine zipper protein transcription factors that bind sequences required for salicylic acid induction of the PR-1 gene. Proc. Natl. Acad. Sci. USA 96, 6523-6528.

Zhou, J.-M., Trifa, Y., Silva, H., Pontier, D., Lam, E., Shah, J., and Klessig, D.F. (2000): NPR1 differentially interacts with members of the TGA/OBF familiy of transcription factors that bind an element of the PR-1 gene required for induction by salicylic acid. Mol. Plant Microbe Interact. 13 (2), 191-202. 


\section{Anhang}

\subsection{Abkürzungen}

\begin{tabular}{|c|c|}
\hline $\mathrm{AD}$ & Aktivierungsdomäne \\
\hline APS & Ammoniumpersulfat \\
\hline$a s-1$ & activating sequence-1 \\
\hline ASF-1 & activating sequence factor-1 \\
\hline A.t & Arabidopsis thaliana \\
\hline ATP & Adenosin-5'-Triphosphat \\
\hline bidest & bidestilliertes Wasser \\
\hline bp & Basenpaar \\
\hline $\mathrm{BSA}$ & Rinderserumalbumin \\
\hline $\mathrm{BTB} / \mathrm{POZ}$ & broad-complex, tramtrack, bric-à-brac/poxvirus \\
\hline BY-2 & Bright Yellow-2 \\
\hline & Nicotiana tabacum-Suspensionskultur \\
\hline bZIP & basische Region / Leucin-Zipper-Domäne \\
\hline${ }^{\circ} \mathrm{C}$ & Grad Celsius \\
\hline ca. & cirka \\
\hline$C a M V$ & Blumenkohlmosaikvirus Cauliflower Mosaic Viru \\
\hline ChIP & Chromatin-Immunopräzipitation \\
\hline $\mathrm{Ci}$ & Curie \\
\hline $\mathrm{cm}^{r}$ & Chloramphenicol-Resistenzgen \\
\hline DNA & Desoxyribonukleinsäure \\
\hline dNTP & Desoxynukleosidtriphosphat \\
\hline dsDNA & doppelsträngige DNA \\
\hline DTT & Dithiothreitol \\
\hline ECL & Enhanced Chemiluminescence \\
\hline EDTA & Ethylendiamintetraessigsäure \\
\hline et al. & und andere \\
\hline $\mathrm{EtBr}$ & Ethidiumbromid \\
\hline $\mathrm{EtOH}$ & Ethanol \\
\hline GFP & green flourescent protein \\
\hline & (-Grün-floureszierendes Protein) \\
\hline $\mathrm{Gm}^{r}$ & Gentamycin-Resistenzgen \\
\hline GNT1 & Glutathion-N-Transferase 1 \\
\hline GNT35 & Glutathion-N-Transferase \\
\hline Gus & ß -Glucoronidase \\
\hline $\mathrm{h}$ & Stunde $(n)$ \\
\hline HEPES & N-[2-Hydroxyethyl]-piperazin-N' \\
\hline & -[2-Ethansulfonsäure \\
\hline
\end{tabular}




\begin{tabular}{|c|c|}
\hline HIS & Histidin \\
\hline $\mathrm{HR}$ & hypersensitive Reaktion \\
\hline $\operatorname{hyg}^{r}$ & Hygromycin-Resistenzgen \\
\hline IPTG & Isopropyl-1-thio-ß $-\mathrm{D}$-galactosid \\
\hline $\mathrm{k}$ & kilo (x 103 ) \\
\hline $\operatorname{kan}^{r}$ & Kanamycin-Resistenzgen \\
\hline $\mathrm{kb}$ & Kilobasen \\
\hline $\mathrm{kDa}$ & Kilo-Dalton \\
\hline 1 & Liter \\
\hline LB & Luria/Bertani-Medium \\
\hline $\mathrm{m}$ & milli $(\mathrm{x} 10-3)$ \\
\hline M & molar \\
\hline $\min$ & Minute(n) \\
\hline $\mathrm{mm}$ & Millimeter \\
\hline MOPS & 3-(N-Morpholino)-propansulfonsäure \\
\hline mRNA & messenger RNA \\
\hline MS & Murashige und Skoog Medium \\
\hline MW & Molekulargewicht \\
\hline $\mathrm{n}$ & nano $(x-10-9)$ \\
\hline N.t & Nicotiana tabacum \\
\hline nim1, NIM1 & noninducible immunity \\
\hline npr1, NPR1 & nonexpresser of PR genes 1 \\
\hline ocs & Octopin-Synthase \\
\hline OD & optische Dichte \\
\hline OD260 & optische Dichte bei $260 \mathrm{~nm}$ \\
\hline OD280 & optische Dichte bei $280 \mathrm{~nm}$ \\
\hline${ }^{32} \mathrm{P}$ & Phosphorisotop der Masse $32 \mathrm{P}$. \\
\hline PAA & Polyacrylamid \\
\hline $\operatorname{par} A$ & protoplast auxin related $A$ \\
\hline PCR & Polymerasekettenreaktion \\
\hline $\mathrm{pH}$ & $\begin{array}{l}\text { negativ dekadischer Logarithmus } \\
\text { der Wasserstoff-ionenkonzentration }\end{array}$ \\
\hline PMSF & Phenylmethylsulfonylfluorid \\
\hline $\mathrm{PPT}^{r}$ & Phosphinotricin-Resistenzgen \\
\hline $\mathrm{PR}$ & $\begin{array}{l}\text { pathogenesis-related } \\
\text { (= mit der Pathogenese zusammen-hängend) }\end{array}$ \\
\hline PVDF & Polyvinylendifluorid \\
\hline RNA & Ribonukleinsäure \\
\hline RNAi & RNA-Interferenz \\
\hline RNAse A & Ribonuklease A \\
\hline ROS & reaktive Sauerstoff-Spezies \\
\hline
\end{tabular}




\begin{tabular}{|c|c|}
\hline rpm & Umdrehungen pro Minute \\
\hline RT & Raumtemperatur \\
\hline $35 S$ & 35S-Promotor des $C a M V$ \\
\hline S & $\operatorname{Sekunde}(\mathrm{n})$ \\
\hline SA & Salicylsäure \\
\hline SAI & SA-inhibitor sai1, SAI1 salicylic acid-insensitiv \\
\hline SAR & systemic acquired resistance \\
\hline SARP & salicylic acid response protein \\
\hline SDS & Natriumdodecylsulfat \\
\hline SDS-PAGE & diskontinuierliche \\
\hline & SDS-Polyacrylamid-Gelelektrophorese \\
\hline sni1, SNI1 & suppressor of npr1-1 \\
\hline SNN & Tabakkultivar Samsun NN \\
\hline TEMED & $\mathrm{N}, \mathrm{N}, \mathrm{N}^{\prime}, \mathrm{N}^{\prime}-$ Tetramethylethylendiamin \\
\hline $\mathrm{TF}$ & Transkriptionsfaktor \\
\hline TKR & Transkriptionsrepressor \\
\hline TMV & Tabakmosaikvirus \\
\hline Tris & Tris(hydroxymethyl)aminomethan \\
\hline $\mathrm{Tx}$ & Tetracyclin-induzierbarer Promotor \\
\hline $\mathrm{U}$ & Unit (=Einheit) der Enzymaktivität \\
\hline u.a. & unter anderem \\
\hline UE & Überexpression \\
\hline ü.N. & über Nacht \\
\hline UV & Ultraviolettes Licht \\
\hline $\mathrm{V}$ & Volt \\
\hline Vol. & Volumen \\
\hline$(\mathrm{v} / \mathrm{v})$ & Volumenprozent \\
\hline WT & Wildtyp \\
\hline$(\mathrm{w} / \mathrm{v})$ & Gewichtsprozent \\
\hline X-Gal & 5-Chlor-4-Brom-3-Indolyl- $§$-D-Galactopyranosid \\
\hline z.B. & zum Beispiel \\
\hline ZIP & Leucin-Zipper-Domäne \\
\hline$\mu$ & micro $(\mathrm{x} 10-6)$ \\
\hline$\Omega$ & Ohm \\
\hline
\end{tabular}




\section{Lebenslauf}

\section{Persönliche Daten}

Thomas Butterbrodt

Diplom-Biologe

geboren am 16.11.1970 in Itzehoe

deutsche Staatsangehörigkeit

\section{Schulbildung}

08/1993-07/1996 Fachgymnasium für Ernährung und Hauswirtschaft Einbeck, Abschluss: Allgemeine Hochschulreife

\section{Studium}

10/1996-09/2001 Studium der Biologie, Georg-August-Universität Göttingen, Anfertigung der Diplomarbeit am Albrecht-von-Haller-Institut für Pflanzenphysiologe der Georg-August-Universität Göttingen, Abteilung Allgemeine und Entwicklungsphysiologie der Pflanze (Prof. Dr. C. Gatz) mit dem Thema „Identifikation von Zielgenen der TGA-Familie aus Tabak"

10/2001-11/2005 Anfertigung der vorliegenden Dissertation am Albrecht-von-HallerInstitut für Pflanzenphysiologe der Georg-August-Universität Göttingen, Abteilung Allgemeine und Entwicklungsphysiologie der Pflanze (Prof. Dr. C. Gatz)

18. November 2005 